SOLAR PHOTOCHEMICAL PROCESS ENGINEERING FOR PRODUCTION OF FUELS AND CHEMICALS

By

J. R. Biddle

D. B. Peterson

T. Fujita
May 1, 1984

LANGLEY RESEARCH C:

LIBRARY, NASA

HAMPTON, VIRGINIA

Work Performed Under Contract No. AM04-80AL13137

Jet Propulsion Laboratory

Pasadena, California

Technical Information Center

Office of Scientific and Technical Information

United States Department of Energy 


\title{
DISCLAIMER
}

\begin{abstract}
This report was prepared as an account of work sponsored by an agency of the United States Government. Neither the United States Government nor any agency thereof, nor any of their employees, makes any warranty, express or implied, or assumes any legal liability or responsibility for the accuracy, completeness, or usefulness of any information, apparatus, product, or process disclosed, or represents that its use would not infringe privately owned rights. Reference herein to any specific commercial product, process, or service by trade name, trademark, manufacturer, or otherwise does not necessarily constitute or imply its endorsement, recommendation, or favoring by the United States Government or any agency thereof. The views and opinions of authors expressed herein do not necessarily state or reflect those of the United States Government or any agency thereof.
\end{abstract}

This report has been reproduced directly from the best available copy.

Available from the National Technical Information Service, U. S. Department of Commerce, Springfield, Virginia 22161.

Price: Printed Copy A05

Microfiche A01

Codes are used for pricing all publications. The code is determined by the number of pages in the publication. Information pertaining to the pricing codes can be found in the current issues of the following publications, which are generally available in most libraries: Energy Research Abstracts (ERA); Government Reports Announcements and Index (GRA and I); Scientific and Technical Abstract Reports (STAR); and publication NTIS-PR-360 available from NTIS at the above address. 
ENTER:

58

DISTAU

2 UTP/CNGIHEERING *+1 FIFLO *+1 TEST * $* 3$ SOLAR

ITEM DISPLAY OWPLETED OR NO ITESE IN THE SET

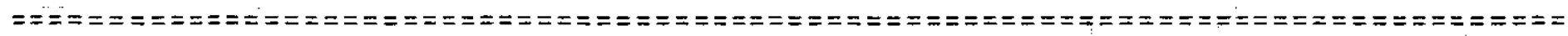

59

1 OISPAY $59 / 2 / 1$

1 UTP/SOLAR +1 PHOTOCHEMICAL +1 PROCESS $* 1 \mathrm{E}$

Q4PO917\% ISSUE 2 PAGE 3617 CATECON 44 RPT: NASA-CR-173916

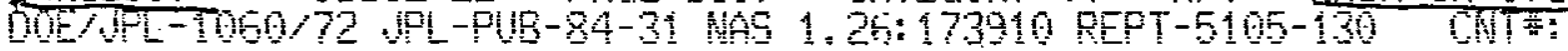

HA57-918 DE-AM04-80AL-13137 84/05/01 93 PAGES UNCLASSIFIED DOCUAENT

UTI: Solar photochemical process engineering for production of fuels and chemicals

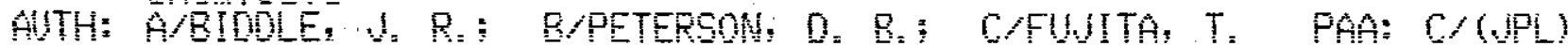

Con: Callomia State Polytechic Univ: Pomona : Jet propulsion lob.,

Calliforna Inst of Tech: Pasadena AMIL. NTIS SAP: HC AOS/VP AOl

CI: UITED STATFS Prepored for JPI

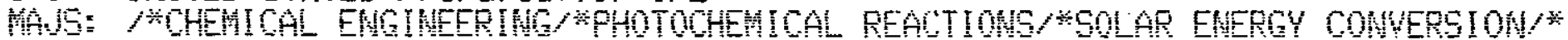
SUSTEM EFFETIVENESS

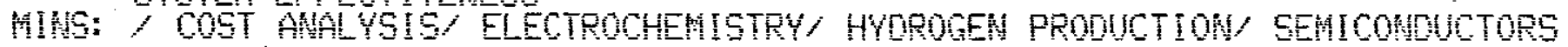
MATERIALS) SOLAP COLLCTOPS

ABA: Guthor

Ass: The engineering costs and perfommen of a nominal 25,000 sond $(883,000$ sctol photochemical plant to produce dihodrogen from water were studied. Two systems were considered one based on flat-plate collector/reactors and the other on linear parabolic troughs. Fngineering subsystems were specified including the collectoryeactop, support hardmare, field transport piping, aas compression equipment, and balance-of-plant ub) items. 0verall plant efficlencies of 19.3 and $11.6 \%$ are estimated for the ENTER: flat-plate and trough systems, respetively, based on assumed solar 


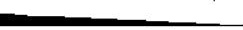




\section{Solar Photochemical Process Engineering For Production of Fuels and Chemicals}

J.R. Biddle (Consultant, California State Polytechnic University, Pomona) D.B. Peterson (Consultant, University of San Diego)

T. Fujita

May 1, 1984

Prepared for

U.S. Department of Energy

Through an Agreement with

National Aeronautics and Space Administration

by

Jet Propulsion Laboratory

California Institute of Technology

Pasadena, California

JPL Publication 84-31 

The engineering costs and performance of a nominal 25,000 scmd $(883,000$ scfd) photochemical plant to produce dihydrogen from water have been studied. Two systems were considered, one based on flat-plate collector/reactors and the other on linear parabolic troughs. Englneering subsystems were specified including the collector/reactor, support hardware, fleld transport piping, gas compression equipment, and balance-of-plant (BOP) items. Overall plant eff1clencies of 10.3 and $11.6 \%$ are estimated for the flat-plate and trough systems, respectively, based on assumed solar photochemical effictencies of 12.9 and $14.6 \%$. Because of the opposing effects of concentration ratio and operating temperature on efficiency, it was concluded that reactor cooling would be necessary with the trough system. Both active and passive cooling methods were considered. Capital costs and energy costs, for both concentrating and non-concentrating systems, were determined and their sensitivity to efficiency and economic parameters were analyzed. Results predict energy costs in the range of $\$ 34$ to $\$ 55 / 10^{6} \mathrm{~kJ}\left(\$ 36\right.$ to $\left.\$ 59 / 10^{6} \mathrm{Btu}\right)$ for the flat-plate system and $\$ 94$ to $\$ 141 / 10^{6} \mathrm{~kJ}$ ( $\$ 99$ to $\$ 149 / 10^{6} \mathrm{Btu}$ ) for the trough system. The overall plant efficiency is the single most important factor in determining the cost of the fuel. Therefore, solar quantum conversion processes were reviewed for the purpose of 1dentifying processes which promise better performance and lower costs. Operating and systems options, including operation at elevated temperatures and hybrid and coupled quantum-thermal conversion processes, were also brief ly examined. 
FOREWORD

This report covers a part of a study of solar photochemical quantum conversion processes for producing fuels and chemicals that addressed engineering feasibility issues and reviewed the status of solar quantum conversion processes. Results of the study are summarized in the following two complementary reports (which include the present report):

(1) Solar Photochemical Process Engineering for Production of Fuels and Chemicals.

(2) Review of Solar Fue1-Producing Quantum Conversion Processes.

The first report investigates engineering feasibility by analyzing processes with characteristics determined by a review of solar quantum conversion processes. The second report documents the review of quantum processes and delves into specific aspects of the chemistry associated with these processes. The engineering and economic feasibility issues from the first report provide a framework within which specific processes are reviewed in the second report. The first report is intended for those primarily concerned with engineering issues and their implications with regard to research directions for solar photochemical processes. The second report is directed toward those whose primary interest is the chemistry of quantum conversion processes.

\section{ACKNOWLEDGMENTS}

The authors acknowledge the supportive management direction and encouragement for the study provided by Marvin R. Christensen, the Program Manager for Fuels and Chemicals at the Jet Propulsion Laboratory (JPL), and Gerald Katz, the Program Coordinator for Solar Fuels and Chemicals at the U.S. Department of Energy/San Francisco Operations Office (DOE/SAN). The technical inputs of Chris England of the Engineering Research Group, who collaborated with the authors during all phases of the study, is especially appreciated. The study also benefited from technical reviews provided by Gerry Nix and Dave Johnson of the Solar Energy Research Institute (SERI).

The efforts of Joyce Murry, who provided editorial assistance and expedited publication of the report, and Hope Hill, Gina Guzman, and Maxine Koop, who typed the report, are gratefully acknowledged. 
AM Air Mass. AM is followed by a number that indicates the relative air mass through which solar radiation has passed (e.g., AM 0 is the solar insolation just outside the Earth's atmosphere)

CR Concentration ratio

E Energy

$\mathrm{E}_{\mathrm{g}}$ Band-gap energy. Only photons with $\mathrm{E} \geq \mathrm{E}_{\mathrm{g}}$ can initiate the quantum conversion process

h Plank's constant

M Molar concentration. Moles of solute per liter of solution

mol Mole. One gram-molecular mass

$\mathrm{T}_{0} \quad$ Ambient temperature

$\mathrm{T}_{\mathrm{Q}} \quad$ Photochemical reaction temperature

$\mathrm{V} \quad$ Average coolant velocity

$\eta_{c} \quad$ Efficiency of compression of gaseous product to pipeline pressure

$\eta_{\text {co }} \quad$ Efficiency of the concentrating collector, including optics

$\eta_{\mathrm{E}} \quad$ Fraction of incident solar energy that can initiate the quantum conversion process

$\eta_{0} \quad$ Overall system efficiency. Ratio of energy content of product gas to incident solar flux

$\eta_{\mathrm{pu}} \quad$ Efficiency of pumping reagents from a central location to the collector/reactor

$\eta_{\mathrm{Q}} \quad$ Estimated overall efficiency of the solar quantum converter (includes absorption and product collection efficiencies)

$\eta_{\mathrm{QT}} \quad$ Limiting thermodynanic efficiency of a solar quantum conversion process

$\eta_{\mathrm{s}} \quad$ Efficiency of separation of the product gases, dihydrogen and dioxygen

$\lambda \quad$ Wavelength

$\lambda_{\mathrm{g}} \quad$ Band-gap wavelength. Only radiation with $\lambda \leq \lambda_{\mathrm{g}}$ can initiate the quantum conversion process

y $\quad$ Frequency

$\phi \quad$ Quantum yield. The number of molecules of product per photon absorbed 

CONTENTS

PART ONE. EXECUTIVE SUMMARY

INTRODUCTION •

SOLAR PHOTOCHEMISTRY . . . . . . . . . . . . . . . . . . . . . . 1

ENGINEERING ASSESSMENT OF SOLAR PHOTOCHEMICAL

DIHYDROGEN PRODUCTION . . . . . . . . . . . . . . . . . . . 6

STATE OF THE ART • . . . . . . . . . . . . . . . . . 15

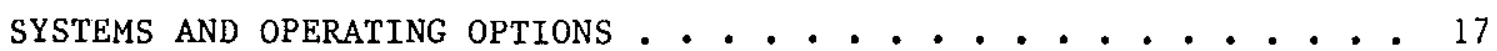

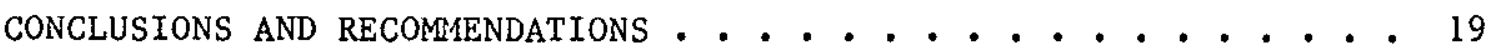

PART TWO. SOLAR PHOTOCHEMICAL PROCESS ENGINEERING

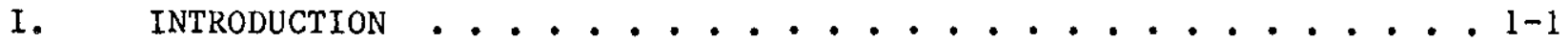

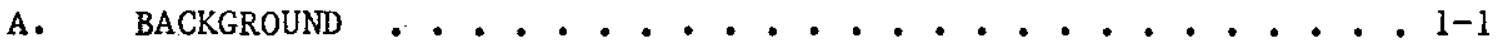

B. OBJECTIVES AND SCOPE ............... 1-1

II. SOLAR PHOTOCHEMISTRY ............... 2-1

A. INTRODUCTION ..................... 2-1

B. HOMOGENEOUS PHOTOCHEMICAI, WATER SPLITTING ........ 2-2

C. PHOTOELECTROCHEMICAL PROCESSES .......... . 2-4

D. EFFICIENCY ................... 2-7

1. Limiting Thermodynamic Efficlency ........ 2-7

2. Efficiencies of Real Systems ......... 2-12

III. ENGINEERING ASSESSMENT OF SOLAR PHOTOCHEMICAL

DIHYUROGEN PRODUCTION ................... . . . .

A. APPROACH AND METHODOLOGY ................ 3-1

B. NON-CONCENTRATING SYSTEM ................. 
c. CONCENTRATING SYSTEM ................ 3-9

D. SYSTEMS COMPARISONS .............. 3-23

IV. STATE OF THE ART ....................... 4-1

A. INTRODUCTION .................... 4-1

B. HOMOGENEOUS PHOTOCHEMICAL WATER SPLITTING ......... . 4-1

1. Cyclic Photoredox Processes .......... 4-1

2. Sacrificial Reagents .......... 4-2

3. Organized Assemblies ........... 4-3

C. PHOTOELECTROCHEMICAL WATER SPLITTING ......... . 4-3

1. Voltage-Assisted Photoelectrolysis ...... 4-4

2. Unbiased Cells with a Single Photoelectrode ... 4-4

3. Unbiased Cells with Two Photoelectrodes ..... 4-5

4. Colloidal Semiconductor Systems ....... 4-5

5. Problem Areas ............. 4-6

D. CONCLUSIONS ..................... 4-7

v. SYSTEMS AND OPERATING OPTIONS ............... . . 5-1

A. INTRODUCTION .................... 5-1

B. PHOTOCHEMISTRY AT ELEVATED TEMPERATURES ......... . 5-1

C. THERMOCHEMICAL-PHOTOCHEMICAL HYBRIDS .......... 5-3

D. COUPLED SYSTEMS .................. 5-4

vi. conClustons ......................... 6-1

VII. RECOMMENDATIONS ....................... 7-1

VIII. REFERENCES ...................... . . . . . . 
1. Schematic Diagram for Cyclic Photochemical

Water Splitting ..................... 3

2. Photoelectrolysis Cell with a Single Semiconductor

Electrode... . . . . . . . . . . . . 4

3. Efficiency Contours for a Quantum Converter Using

Two Photosystems and Unfocused AM 1.2 Solar Energy . . . . 5

4. Baseline Flat-Plate Collector/Reactor Configuration . . . 7

5. Artist's Conception of Flat-Plate Photochemical Plant . . 8

6. Cost of Dihydrogen from the Baseline Flat-Plate System . . 9

7. Parabolic Trough Collector/Reactor . . . . . . . . 11

8. Effect of Concentration on Efficiency, Case 2....... 11

9. Artist's Conception of Parabolic Trough Photochemical

Plant...................... 13

10. Cost of Dihydrogen from the Baseline Concentrating System . - 14

11. Conversion Efficiency Versus Temperature for a Single

Collector Coupled Quantum/Therma1 System . . . . . . 19

2-1. Schematic Diagram for Cyclic Photochemical Water

Splitting ....................... 2-3

2-2. Photoelectrolysis Cell with a Single Semiconductor

Electrode . . . . . . . . . . . . . . . 2-5

2-3. Voltage-Assisted Photoelectrolysis . . . . . . . . 2-5

2-4. Colloidal Systems $\left(\mathrm{n}-\mathrm{TiO}_{2}\right.$ Loaded with $\mathrm{P}_{\mathrm{t}}$ and $\left.\mathrm{RuO}_{2}\right)$. . . . 2-6

2-5. A Generalized Quantum Converter . . . . . . . . 2-8

2-6. Limiting Thermodynamic Efficiency for an Ideal Quantum Converter as a Function of Band-Gap Wavelength . . . . . . 2-9

2-7. Efficiency Contours for a Quantum Converter Using Two Photosystems and Unfocused AM 1.2 Solar Energy . . . . . 2-11

2-8. A Photochemical Scheme for Splitting Water Using Two Photosystems ...................... 2-11

3-1. Baseline Flat-Plate Collector/Reactor Configuration . . . 3-3 


\section{Figures (Cont'd)}

3-2. Side View of Collector/Reactor Assembly . . . . . . . 3-4

3-3. Detail of Flat-Plate System Layout . . . . . . . . . 3-5

3-4. Flat-Plate Field Layout Showing Piping Connections . . . 3-5

3-5. Plant Layout for Baseline Flat-Plate System . . . . . 3-6

3-6. Capital Cost Breakdown for Baseline Flat-Plate System . . . 3-7

3-7. Cost of Dihydrogen from the Baseline Flat-Plate System . . 3-9

3-8. Concentration Effect on Limiting Thermodynamic

Efficiency .................... 3-10

3-9. Parabolic Trough Collector/Reactor . . . . . . . 3-11

3-10. Bare Glass Receiver Solar Energy Distribution . . . . . 3-12

3-11. Gold Filter Recelver Solar Energy Distribution . . . . . 3-13

3-12. Front Side Cooled Receiver Solar Energy Distribution . . . 3-14

3-13. Core Cooled Receiver Solar Energy Distribution . . . . 3-14

3-14. Concentrator/Receiver Geometries . . . . . . . . 3-15

3-15. Effect of Coolant Flow Rate on Efficlency . . . . . . 3-16

3-16. Effect of Concentration on Efficiency (Case 1) . . . . 3-17

3-17. Effect of Concentration on Efficiency (Case 2) . . . . 3-17

3-18. Detail of Concentrating System Layout . . . . . . . 3-20

3-19. Concentrating Field Layout Showing Piping Connections . * 3-20

3-20. Capital Cost Breakdown for Concentrating System . . . . 3-22

3-21. Cost of Dihydrogen from the Baseline Concentrating

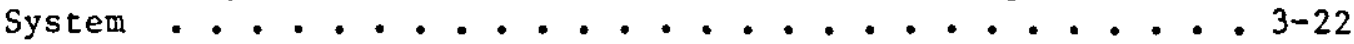

4-1. Photochemical Diode .............. 4-5

5-1. Coupled Quantum/Thermal Converter ........... 5-5

5-2. Conversion Efficiency Versus Temperature for a Single

Collector Coupled Quantum/Thermal System . . . . . . . 5-5

5-3. IR-81-E Conductive Infrared Reflection Coating . . . . 5-6 
1. Characteristics of the Baseline Non-Concentrating System . . 6

2. Capital Cost Breakdown for Baseline Flat-Plate System . . . 9

3. Characteristics of the Baseline Concentrating System . . . 10

4. Capital Cost Breakdown for Concentrating System . . . . 14

2-1. Limiting Thermodynamic Efficiencies for AM 1.2 Solar Radiation at Various Intensities and Absorber Temperatures . . . . . . . . . 2-10

3-1. Characteristics of the Baseline Non-Concentrating System . . . . . . . . . . . . . . . . . 3-2

3-2. Capital Cost Breakdown for Baseline Flat-Plate System . . . 3-7

3-3. Balance-of-Plant Cost Summary for Flat-Plate System . . . 3-8

3-4. Comparison of the Baseline Non-Concentrating and Concentrating Systems . . . . . . . . . . 3-10

3-5. Subsystem Costs . . . . . . . . . . . . 3-19

3-6. Balance-of-Plant Cost Summary for Concentrating System . . 3-21

3-7. Capital Cost Breakdown for Concentrating System . . . . 3-21

4-1. Fractions of Solar Energy as a Function of the Band-Gap Energy of the Semiconductor Electrode . . . . . . . 4-7 


\section{$\cdot$}




\section{INTRODUCTION}

Photochemical processes seem to be a promising method for conversion of solar energy to fuels and chemicals because of the possibility of direct conversion of the photon energy to chemical energy. These processes involve the production of electronically excited species as a result of the absorption of photons of appropriate energy from the incident solar flux. The energy of these excited species is directed into chemical energy stored in a high energy product, the fuel. Because the overall efficiency is expected to be relatively low, there is concern that photochemical processes may suffer from high costs associated with the distribution of reactors over large areas and, concurrently, costs associated with transporting the reagents and product gases to and from the reactors.

Higher efficiency systems hold promise of reducing energy costs by yielding smaller field sizes for the same plant output. Concentrated solar radiation focused on the reactor will increase the efficiency as long as temperature increases are held in check by reactor cooling. These concentrating systems provide better performance but are more technically sophisticated and costly. By scoping the engineering cost and performance of commercial-size baseline non-concentrating and concentrating photochemical plants for fuel production, guidelines can be established for selection of the most promising and appropriate photon-driven technologies.

A brief, general description of currently avallable processes for direct conversion of solar energy into storable chemical energy is given in the Solar Photochemistry section. This information provides the photochemical basis for defining the baseline systems used in the engineering feasibility study that. follows in the Engineering Assessment of Solar Photochemical Dihydrogen Production section. Current research pertinent to fuel producing quantum conversion processes is reviewed in the State of the Art section. Systems and operating options, such as coupled and hybrid systems and elevated temperature photochemistry, are discussed in the Systems and Operating Options section. Finally, the conclusions from this study are summarized together with recommendations for further work.

\section{SOLAR PHOTOCHEMISTRY}

Photochemical processes convert solar energy directly into chemical energy. Devices based on such processes are classifled as quantum converters because they are initiated by the electronic excitation of an absorber by photons of appropriate energy, a quantized event. The required photon energy is called the threshold or band-gap energy $\left(E_{g}\right)$, and it is usually large enough that less than half of the solar spectrum can initiate photochemistry.

Photochemical processes differ from thermal processes in a number of important aspects. In photochemistry, absorber molecules, of ten present at low 
concentration, are selectively excited. In thermal processes, excitation is essentially non-specific. Thermal systems also differ in that the molecules involved in reaction almost invariably remain in their ground elect ronic states. Because of these differences, the reaction products may differ markedly when the same system is exc1ted photochemically rather than thermally.

The following are some general requirements for solar photochemical systems that produce fuels or chemicals:

(1) The process should constitute a closed cycle with respect to all species except the feedstock and its decomposition products (e.g., $\mathrm{H}_{2} \mathrm{O}, \mathrm{H}_{2}$, and $\mathrm{O}_{2}$ in the photochemical splitting of water).

(2) They should operate over a wide band of the solar spectrum.

(3) The quantum yield should be high. 1

(4) The product(s) should be easily separated, stored and transported.

(5) The materials of construction and the reagents involved must be inexpenstve and relatively abundant.

Considering such factors as process chemistry and the cost and avallability of feedstock, it seems unlikely that fuels will be produced on a large scale from feedstocks other than water, carbon dioxide, and dinitrogen $\left(\mathrm{N}_{2}\right)$.

Most of the research related to development of solar photochemical processes for the production of fuels has focused on splitting water to produce dihydrogen.

Homogeneous Photochemical Water Splitting

Direct solar photolysis of water to produce dihydrogen is not practical because of the large band-gap energy 1nvolved. However, Indirect photolysis is posstble in the presence of an appropriate sensitizer. The sensitizer absorbs energy over a wide band in the solar spectrum and uses the energy to drive a cyclic process, the net result of which is decomposition of water into dihydrogen and dioxygen.

A typlcal process is represented schematically in Figure 1. The sensitizer, $S$, absorbs photons to produce the electronically excited state, $S *$, which transfers an electron to the quencher, $Q$, resulting in formation of $Q^{-}$ and $\mathrm{S}^{+}$. The latter species undergo catalyzed redox reactions with water to produce $\mathrm{H}_{2}$ and $\mathrm{O}_{2}$.

1The quantum yield is the number of molecules of product divided by the rumber of photons absorbed. 


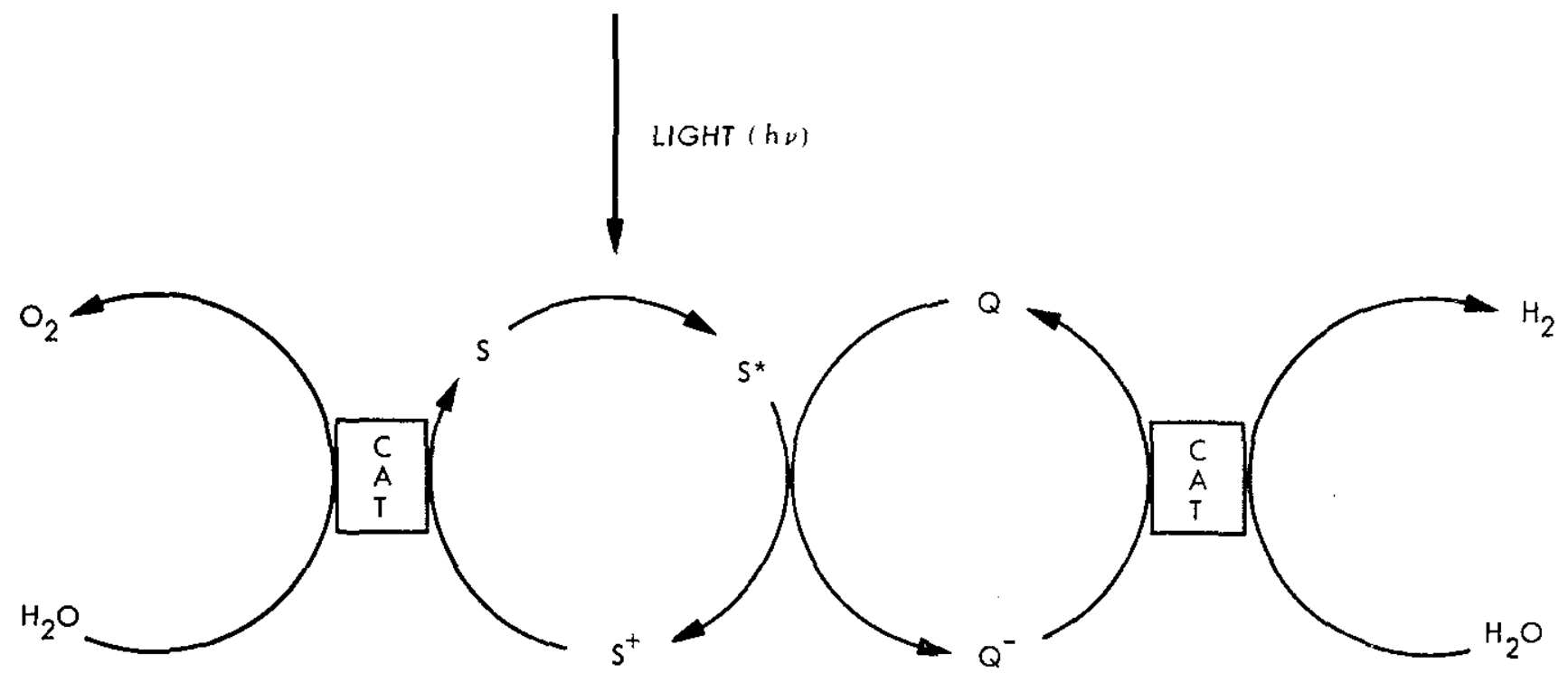

Figure 1. Schematic Diagram for Cyclic Photochemical Water Splitting

\section{Photoelectrochemical Processes}

The distinguishing feature of photoelectrochemical processes is that the fuel-producing chemical reactions ${ }^{2}$ occur at electrodes, one or both of which is an illuminated semiconductor. Illumination of the semiconductor results in excitation of electrons from the valence to the conduction band.

The resulting electron-hole pairs migrate to the electrodes where the chemical reactions occur. Various cell configurations are possible. A schematic diagram of a photoelectrochemical cell with a single semiconductor electrode is shown in Figure 2. In such cells, the counter electrode is an iner conductor such as platinum or carbon. Photons absorbed at the photoelectrode provide the only energy input.

Other configurations include those in which both electrodes are illuminated semiconductors and cells in which the photoelectrochemical cell is reduced to colloidal dimensions. In the latter case, platinized colloidal particles of the semiconductor are dispersed in the electrolyte to produce what are, in effect, wireless photoelectrochemical celis.

Voltage-assisted photoelectrolysis is another option. In this configuration, an external power source is used to bias the electrodes, and the energy input includes both radiant energy and electrical energy.

${ }^{2}$ Photoelect rochemical devices may also be designed to convert solar photons directly to electricity. Such devices, usually referred to as photogalvanic cells, are not considered in this report. 


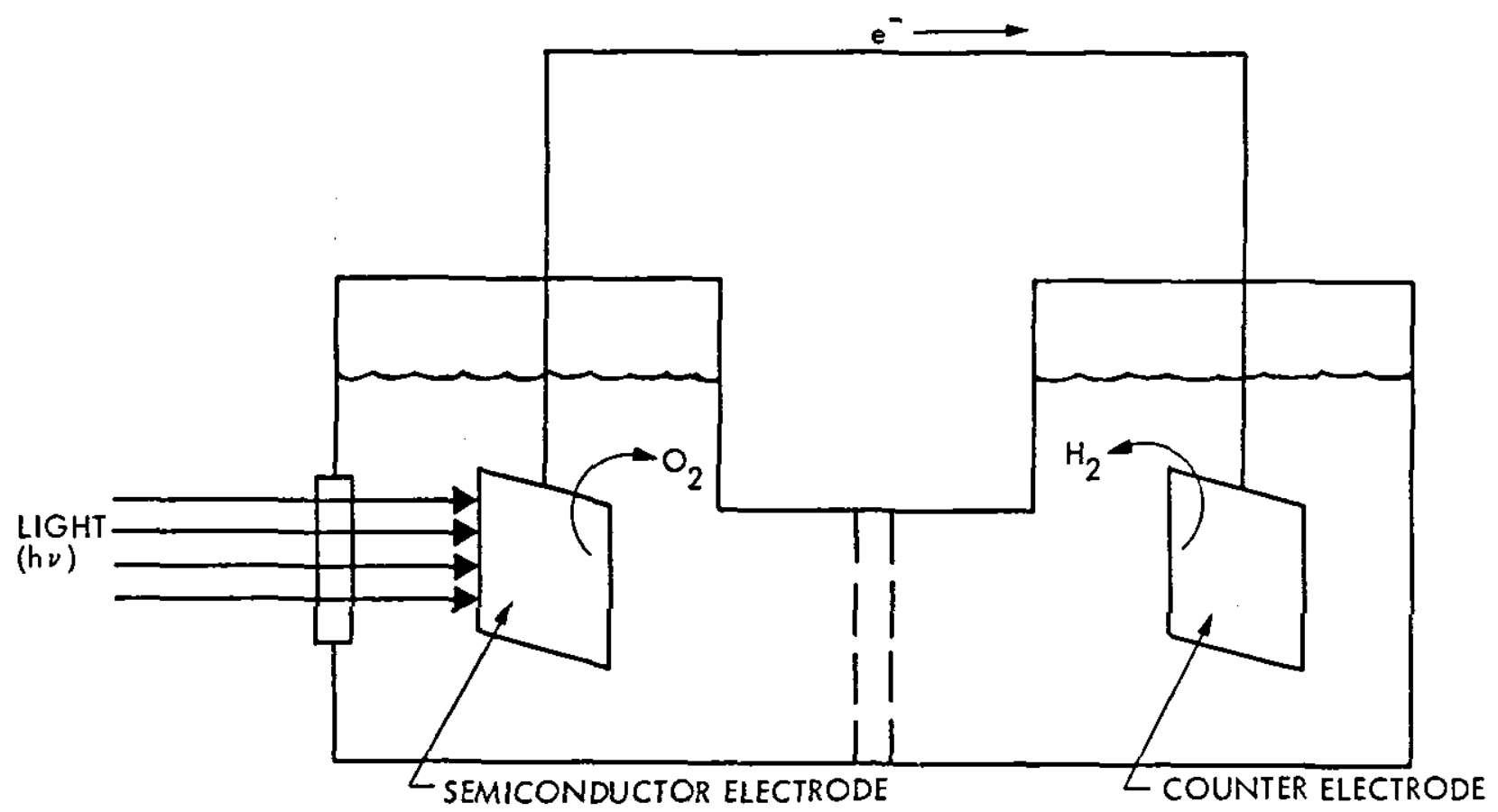

Figure 2. Photoelectrolysis Cell with a Single Semiconductor Electrode

\section{Efficlency}

Limiting Thermodynamlc Efflciency. Both thermodynamic and kinetic factors Iimit the efficlency with which solar energy can be converted directly to work and/or storable chemical energy. The limiting thermodynamic efficiency, $\eta_{\mathrm{QT}}$, has been examined by several investigators.

There is general agreement that for quantum converters with a single photosystem and unfocused sunlight, $\eta_{\mathrm{QT}}$ has a maximum of about $31 \%$ for AM 0 and $300 \mathrm{~K}$. The relatively low value is inherent in the quantum nature of the converston process and the consequences of the second law and, as such, 1 s independent of the mechanfstic detalls of the process.

Haught and Bllchak, et al, have shown that the limiting thermodynamic efficlency increases approximately two percentage points for each tenfold increase in solar intensity and decreases by about that same amount for each $50 \mathrm{~K}$ increase in temperature. Thus, if solar concentration is to be employed for the purpose of Increasing efficiency, it will probably be necessary to cool the reactor.

The efficlency, $\eta_{\mathrm{QT}}$, can be increased by using two or more separate photosystems involving different absorbers with different band-gap or threshold energies. Figure 3 shows contours of $\eta_{Q T}$ (as a percentage) as a function of $\lambda_{1}$ and $\lambda_{2}$ for a system with two photosystems subjected to AM 1.2 solar energy. One absorber absorbs all light with $\lambda \leq \lambda_{1}$; the other absorbs all light with $\lambda_{1} \leq \lambda \leq \lambda_{2}$. A maximum $\eta_{\mathrm{QT}}$ of $44 \%$ is predicted for $\lambda_{1}=830 \mathrm{~nm}$ and $\lambda_{2}=1320 \mathrm{~nm}$. 


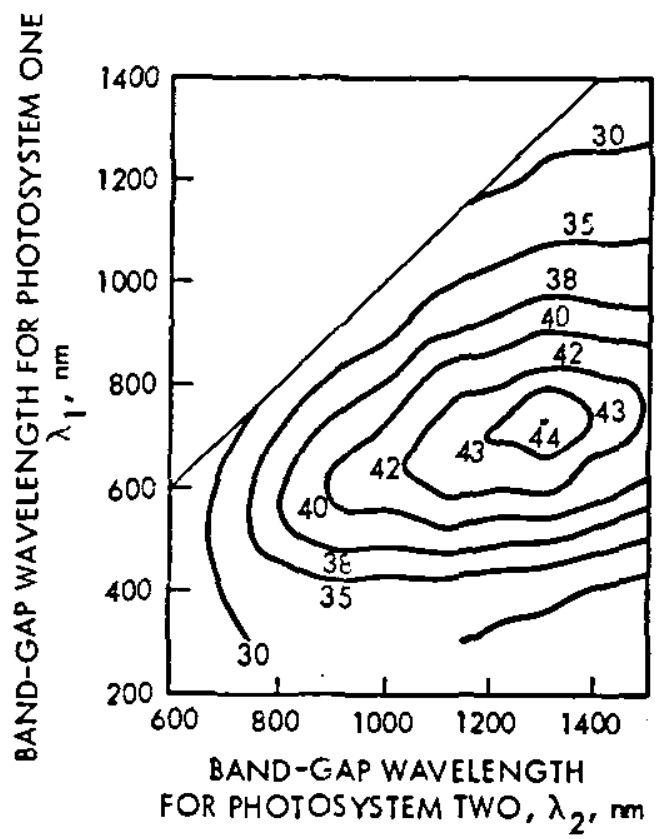

NOTE:

AM 1.2 (AIR MASS 1.2) CORRESPONDS TO THE INSOLATION AT THE EARTH'S SURFACE WHERE THE SUN PASSES THROUGH $20 \%$ MORE AIR MASS THAN AT ITS ZENITH ON A CLEAR DAY

Figure 3. Efficiency Contours for a Quantum Converter Using Two Photosystems and Unfocused AM 1.2 Solar Energy

Efficiencies of Real Systems. Real systems, producing chemically stored energy, will have efficiencies that are significantly lower than $\eta_{\mathrm{OT}}$, the IImiting thermodynamic efficiency. For example, the values of $\eta_{\mathrm{OT}}$ are calculated assuming that the absorber is ideal, i.e., all photons with $\lambda \leq \lambda \mathrm{g}$ are absorbed. In real photochemical systems, the absorption characteristics of the photosensitizer are such that not more than 70 to $80 \%$ of these photons are $11 \mathrm{kely}$ to be absorbed. Also, not all of the photochemical product wfll be collected from the system. Collection efficlency is unlikely to be greater than $90 \%$, especlally when a gas is generated in a liquid system. There are also kinetic limitations that reduce the efficiency of processes that store energy chemically. If the product is to be kinetically stable, there must be an energy barrier to prevent its back reaction. It is estimated that this kinetic effect will reduce the limiting efficiency for a quantum converter using a single photosystem from about $31 \%$ to about $21 \%$. When all of these factors are considered, it seems unlikely that the overall efficiency of a real quantum converter of this type will exceed 12 to $15 \%$. 
ENGINEERING ASSESSMENT OF SOLAR PHOTOCHEMICAL DIHYDROGEN PRODUCTION

The object of this phase of the study is to identify engineering requirements associated with solar photochemical systems and scope the costs of a commercial scale plant for producing fuels. The nominal plant size chosen produces 25,000 scrod $(850,000$ scfd) dihydrogen gas at 50 atm. Production of dihydrogen from water was selected because it has received the most attention.

\section{Non-Concentrating Systen}

The initial system investigated is based on a non-concentrating, flatplate design. Characteristics of this design are given in Table 1. The collector/reactor for this system is shown in detall in Figure 4 . It is, essentlally, two $1.22 \times 3.66 \mathrm{~m}(4 \times 12 \mathrm{ft})$ glass sheets, $2.54 \mathrm{~cm}$ (1 In.) apart, surrounded by an extruded, aluminum frame. Water is pumped to the unit (inclined at $35 \mathrm{deg}$ ) where solar energy is collected and the photochemical reaction occurs. The product gases (dihydrogen and dioxygen) are assumed to be separated. Twelve of these individual units are field assembled into a gang which are laid out in a field such as that shown in Figure 5. Dihydrogen gas is piped to a central site where it is compressed to 50 atm (typlcal gas pipeline transmission pressure). All field piping is uninsulated carbon steel and almost $90 \%$ is $0.95 \mathrm{~cm}(3 / 8 \mathrm{in.})$ size.

Table 1. Characteristic's of the Baseline Non-Concentrating System

Characteristics

Feedstock

Product

Operating Pressure

Operating Temperature

Nominal plant Size

Overa11 System Efflciency

Nominal Collector Area

Annual Solar Flux
Selected Conditions

Water

Dihydrogen gas

1 atm

$54^{\circ} \mathrm{C}\left(130^{\circ} \mathrm{F}\right)$

25,000 scmd

$10.3 \%$

$120,000 \mathrm{~m}^{2}$

$2430 \mathrm{kWh} / \mathrm{m}^{2} / \mathrm{yr}$ 


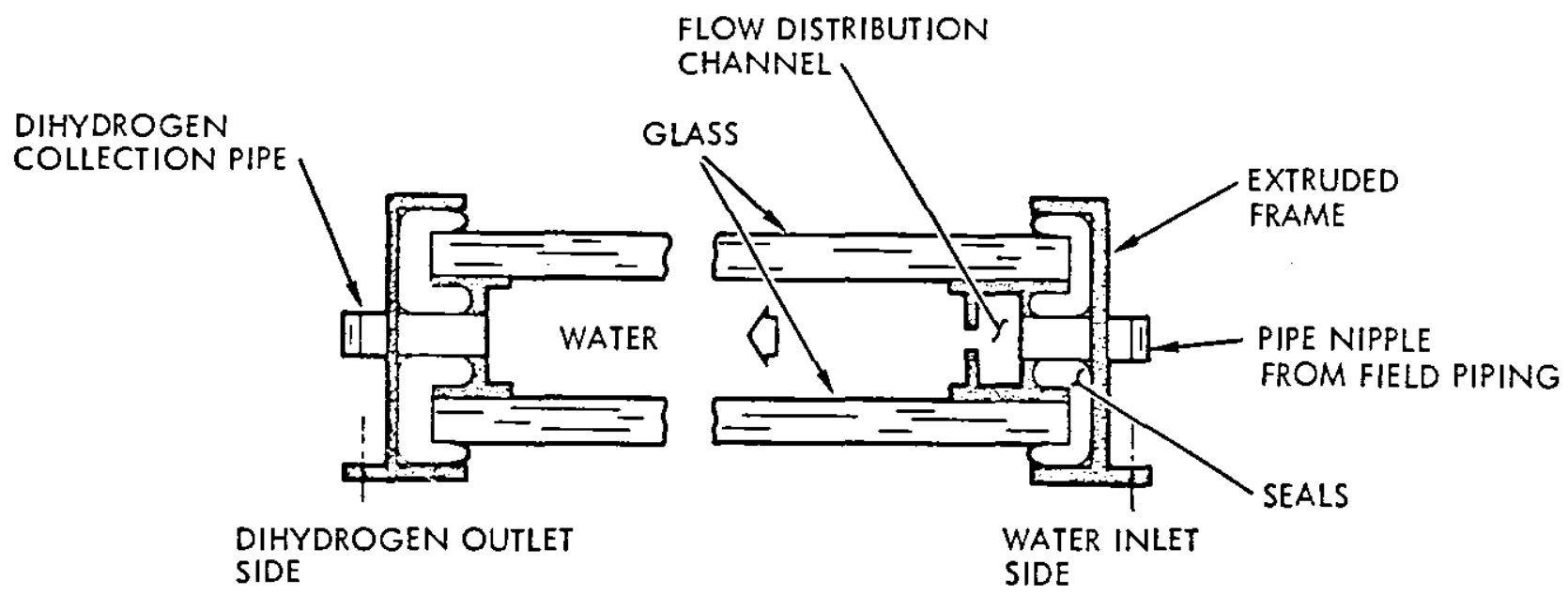

Figure 4. Baseline Flat-Plate Collector/Reactor Configuration

The capital cost breakdown for this non-concentrating baseline flat-plate system is shown in Table 2. The balance of plant (BOP) includes site preparation, construction, plant facilities, and plant equipment. All costs are based on 1983 dollars. These capital costs are translated into energy costs by an economics model widely used in solar energy studies. The results, as a function of overall plant system efficiency, is shown in Figure 6 . Fixed charge rates of 0.20 (typical of utility industry economics) and 0.30 (typical of chemical industry economics) are used. Operating and maintenance are assumed to be $2 \%$ of the plant capital cost. The overall system efficiency includes photochemical, separation, and compression efficiencies. For the baseline system efficiency of $10.3 \%$, the energy cost ranges from $\$ 34$ to $\$ 56 / 10^{6} \mathrm{~kJ}$ ( $\$ 36$ to $\left.\$ 59 / 10^{6} \mathrm{Btu}\right)$. 


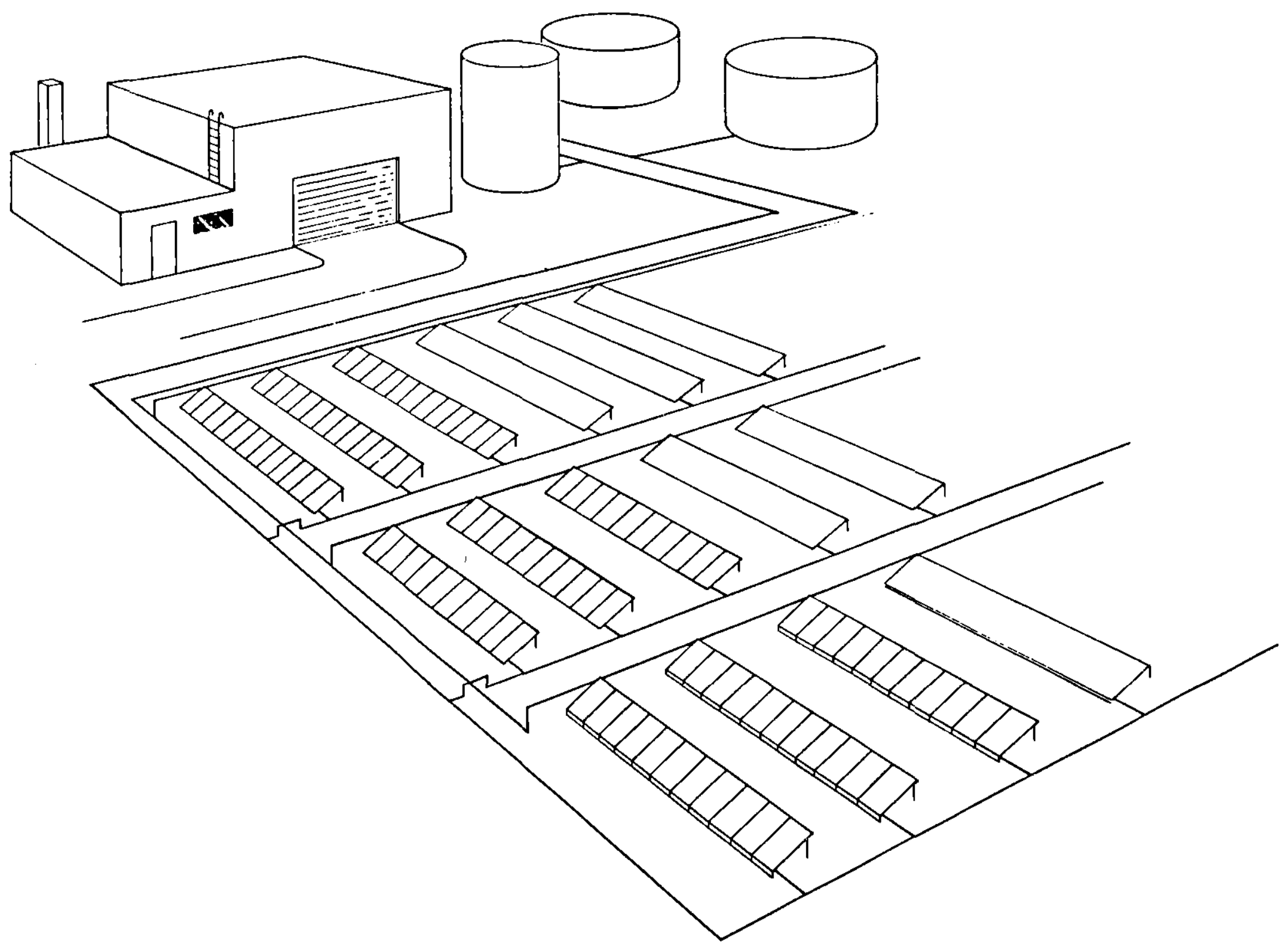

Figure 5. Artist's Conception of Flat-Plate Photochemical Plant 
Table 2. Capital Cost Breakdown for Baseline Flat-Plate System

\begin{tabular}{lc} 
Subsystem & Cost, $\$ \times 10^{3}$ \\
Collector/Reactor & 7,096 \\
Piping and Reactor Support & 1,305 \\
Field Piping & 1,483 \\
Gas Compression & 1,160 \\
Balance of Plant & $\underline{8,410}$ \\
Total & 19,454 \\
\hline
\end{tabular}

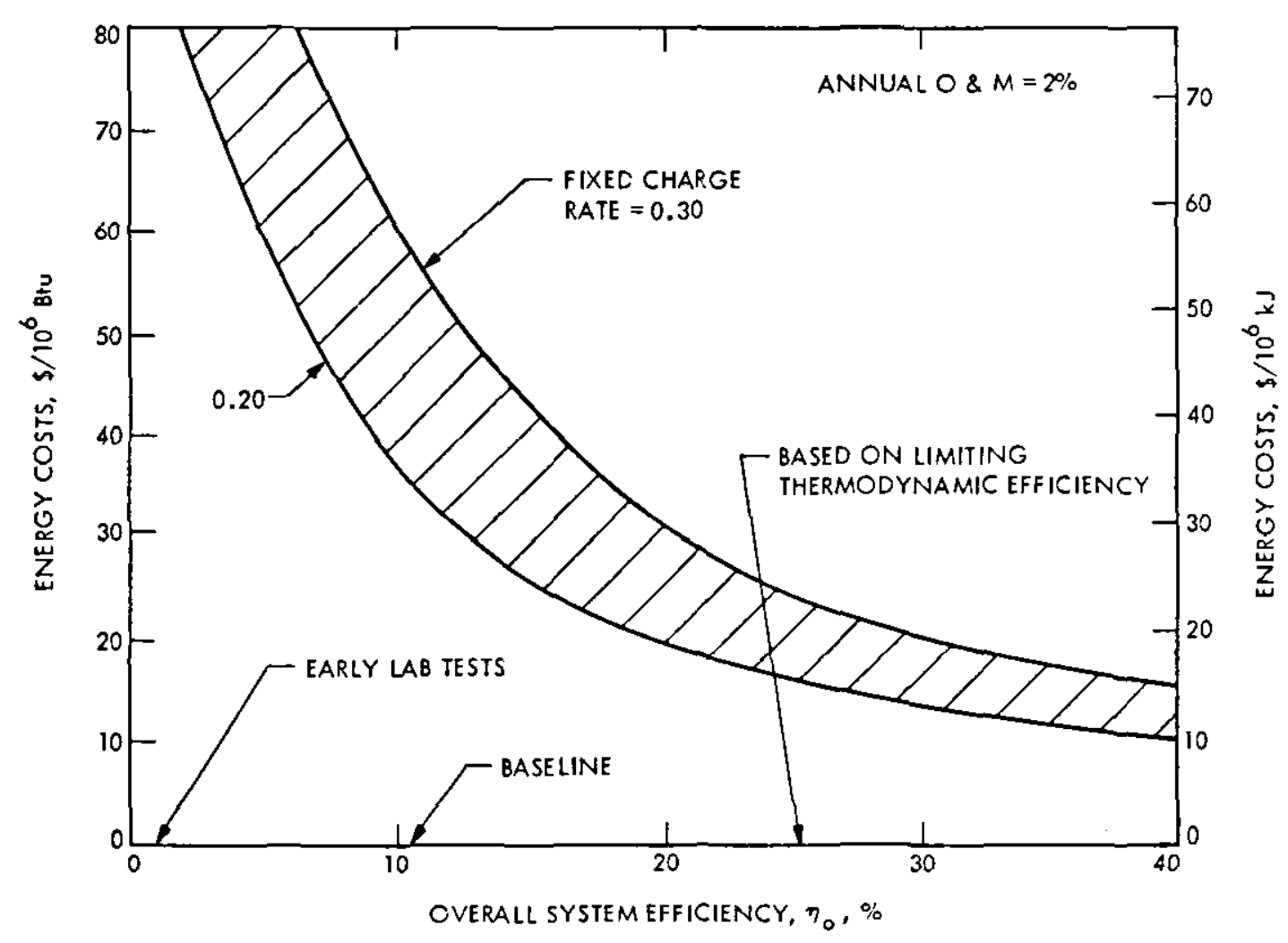

Figure 6. Cost of Dihydrogen from the Baseline Flat-Plate System 
Because energy costs are dominated by the efficiency, it was decided to investigate the use of concentrated solar radiation. This might increase the system efficiency and decrease energy costs by reducing the field size and associated piping and BOP costs.

Characteristics of the baseline concentrating system chosen are given in Table 3. A parabolic trough collector (Figure 7) was selected for the baseline because it has a moderate concentration range and is commercially availabie. The major modffication required is the redesign of the receiver tube to serve as a reactor for the photochemical process. It was determined that, if left uncooled, the reaction temperature could approach $250^{\circ} \mathrm{C}$. To provide for reactor cooling, a concentric glass tube arrangement was proposed. A core-cooled arrangement was one in which the photochemical solution was carried in the anmular region and the coolant water in the core region. In front-side cooling, the photochenical solution is in the core and the cooling water is in the annular region. For both of these geometries, the concentration ratio was varied and the efficlency (photochemical and pumping) was calculated. Increasing the concentration ratio produces higher photochemical efficiencies, but the pumping required to cool the reactor increases. There is a specific temperature which yields optimum efficiency. The results illustrated in Figure 8 (typical of both geometrles) reveal a very weak dependence on concentration ratio.

Table 3. Characteristics of the Baseline Concentrating System

Characteristics

Feedstock

Product

Operating Pressure

Operating Temperature

Nominal Plant Size

Overal1 System Efficiency

Nominal Collector Area

Annual Solar Flux

Concentration Ratio
Selected Conditions

\section{Water}

Dihydrogen gas

1 atm

$29^{\circ} \mathrm{C}\left(85^{\circ} \mathrm{F}\right)$

$25,000 \mathrm{scmd}$

$11.6 \%$

$125,000 \mathrm{~m}^{2}$

$2150 \mathrm{kWh} / \mathrm{m}^{2} / \mathrm{yr}$ 


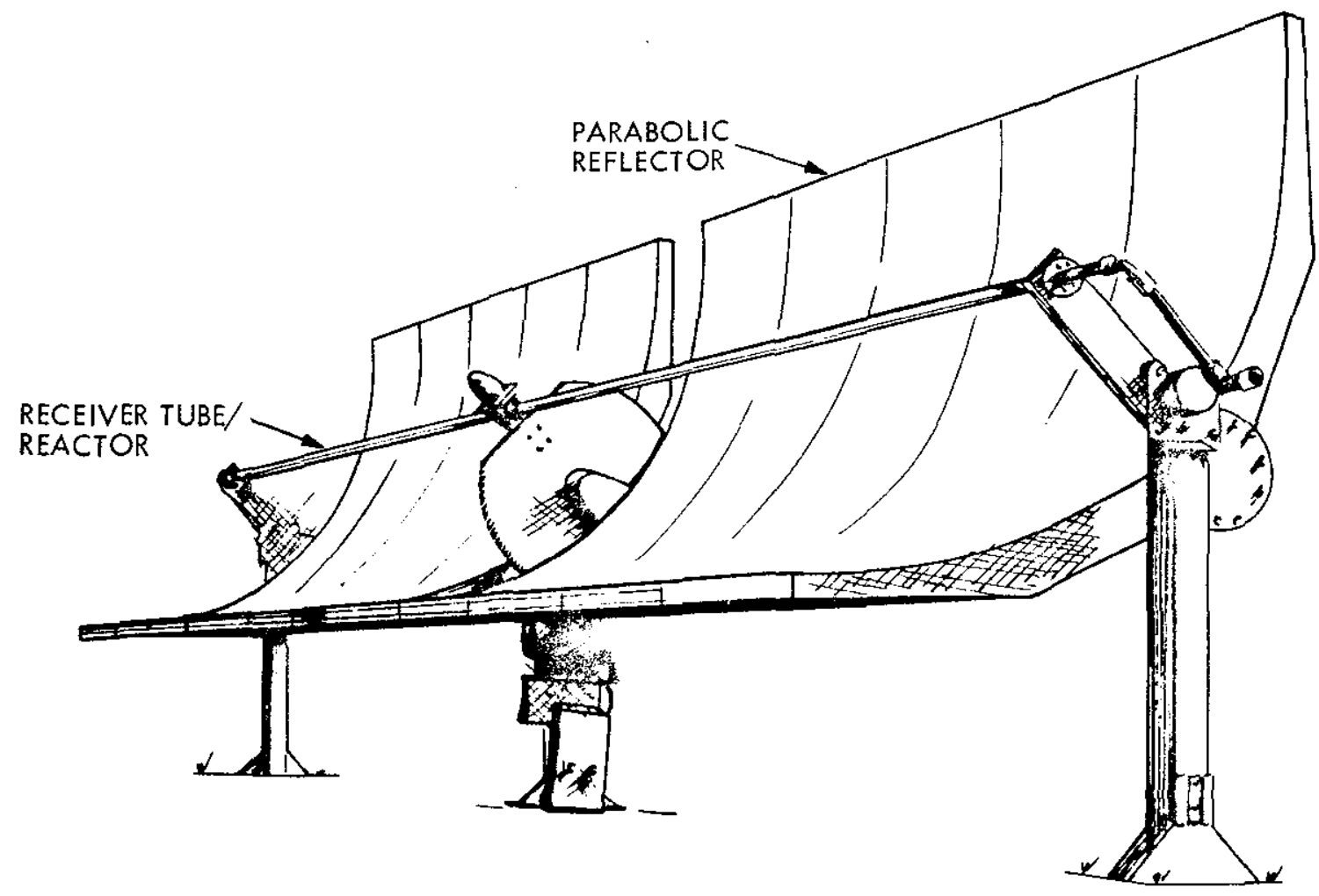

Figure 7. Parabolic Trough Collector/Reactor

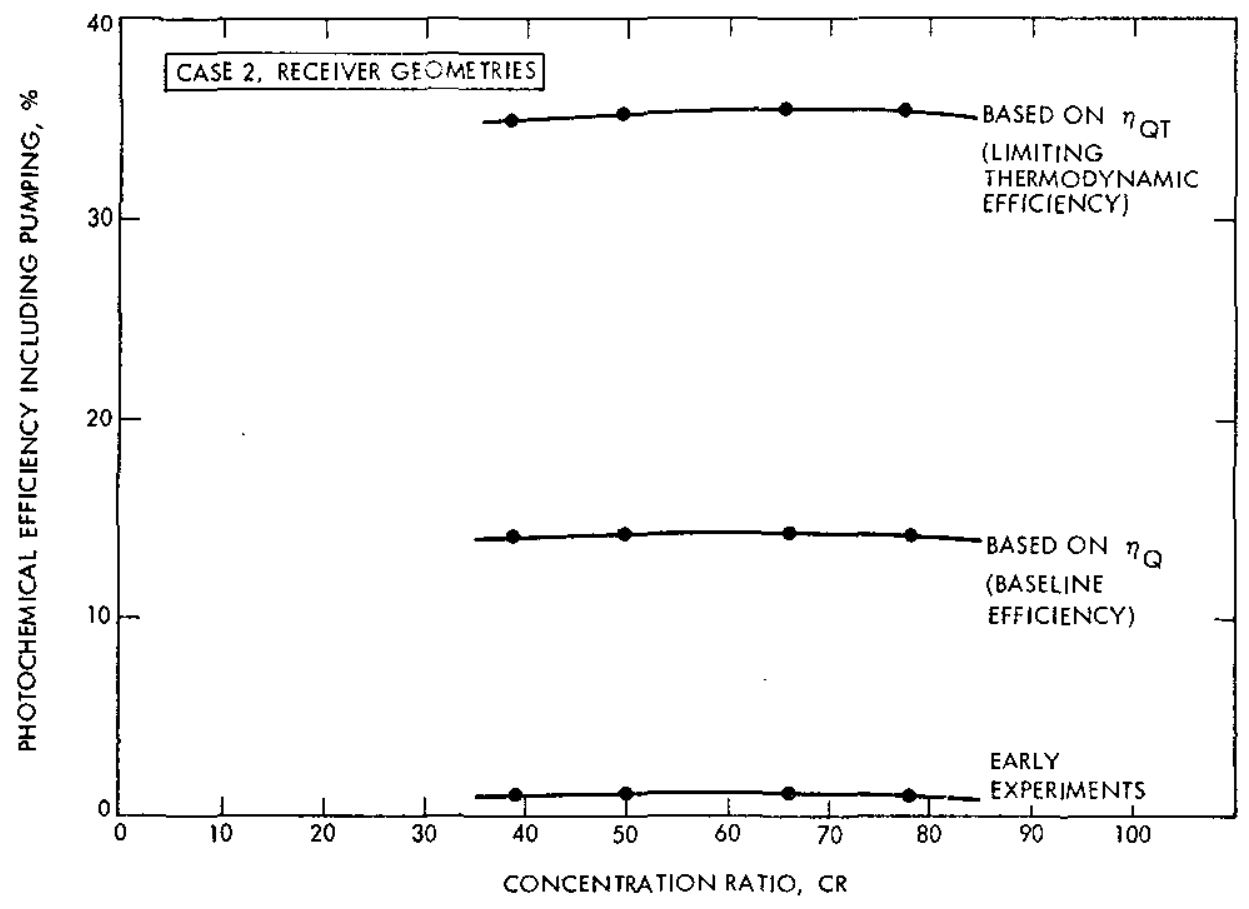

Figure 8. Effect of Concentration on Efficiency, Case 2 
Based on these results, a receiver/reactor was chosen which consisted of concentric glass tubes with diameters of $5.1 \mathrm{~cm}(2 \mathrm{in.})$ and $2.5 \mathrm{~cm}$ (1 in.) in a parabolic trough with a $2.1 \mathrm{~m}(7 \mathrm{ft})$ aperture, giving a concentration ratio of 42.8. The trough length was $6.1 \mathrm{~m}(20 \mathrm{ft})$. Front-side cooling was employed with heat rejection via a plping loop on the backside of the trough with a forced air/water heat exchanger. Four of these troughs are assumed to be coupled in series to form an 80-ft-long string. Strings were laid out in an east-west field orientation shown in Figure 9 . About $64 \%$ of the field piping for gas and Ilquid transport is $0.95 \mathrm{~cm}$ ( $3 / 8$ in.).

The capital cost breakdown for the baseline concentrating system is given in Table 4. Energy costs are presented in Figure 10 as a function of the overall system efficiency. Comparison with the flat-plate system reveals that, for the baseline concentrating system shown, energy costs are two-to-three times greater than those for the non-concentrating system, depending on the fixed charge rate used. For the baseline system (overall efficiency of $11.6 \%$ ), the energy cost would be from $\$ 94$ to $\$ 141 / 10^{6} \mathrm{~kJ}$ ( $\$ 99$ to $\left.\$ 149 / 10^{6} \mathrm{Btu}\right)$. This dramatic difference in energy costs can be attributed to the higher cost for the collection system (the tracking parabolic trough collectors). Any small advantage gained in the photochemical efficiency due to increased concentration is lost because of the much higher costs for collection and lower annual energy collection efficiency that results because the concentrating system does not use the diffuse component of solar radiation. 


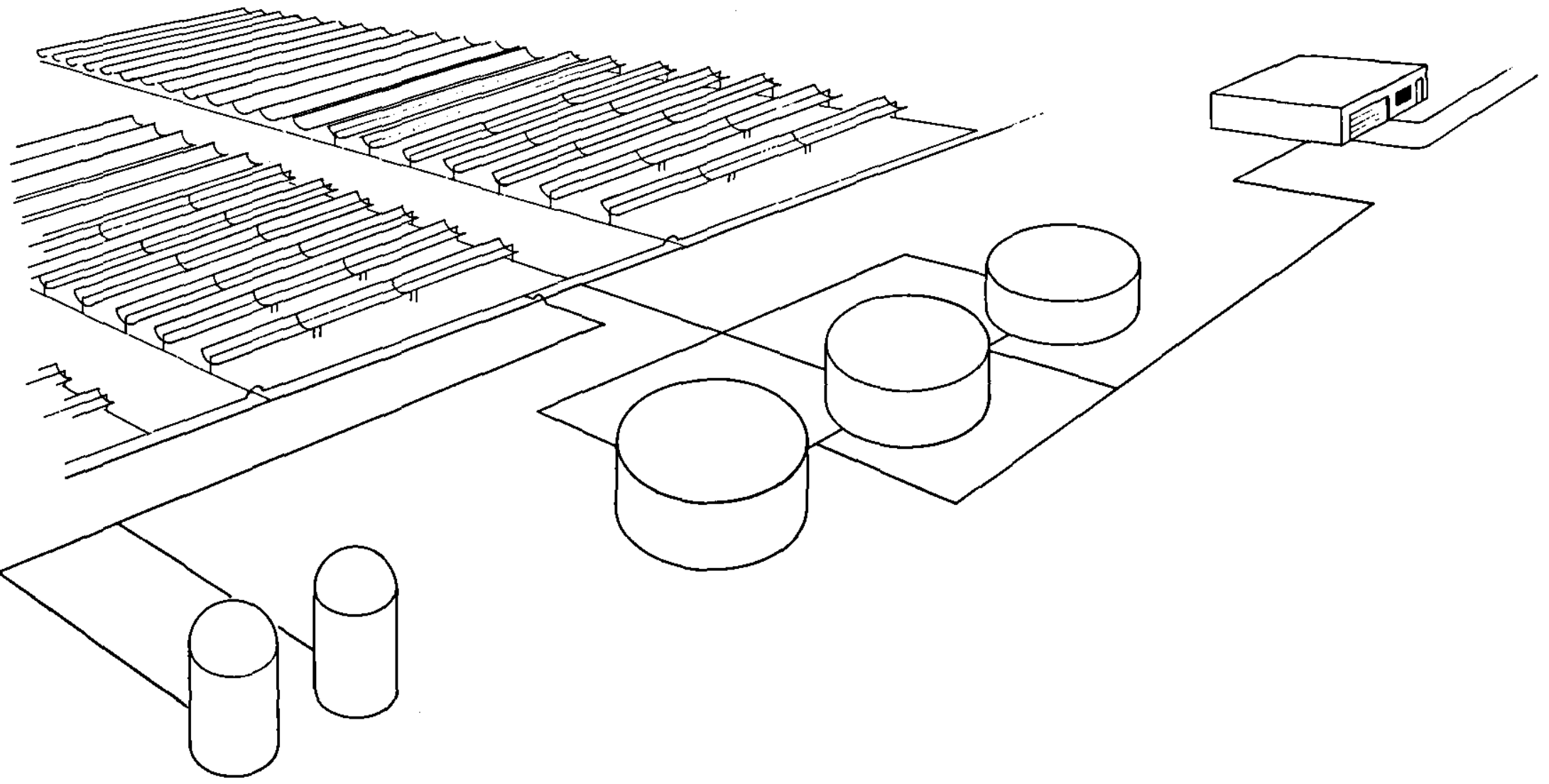

Figure 9. Art1st's Conception of Parabolic Trough Photochemical Plant 
Table 4. Capital Cost Breakdown for Concentrating System

\begin{tabular}{lc} 
Item & Cost, $\$ \times 10^{3}$ \\
\hline Collector/Reactor & 30,658 \\
Conlant Equipment & 2,170 \\
Field Piping & 553 \\
Gas Compression & 1,160 \\
Balance of Plant & 13,646 \\
Total & 48,187 \\
\hline
\end{tabular}

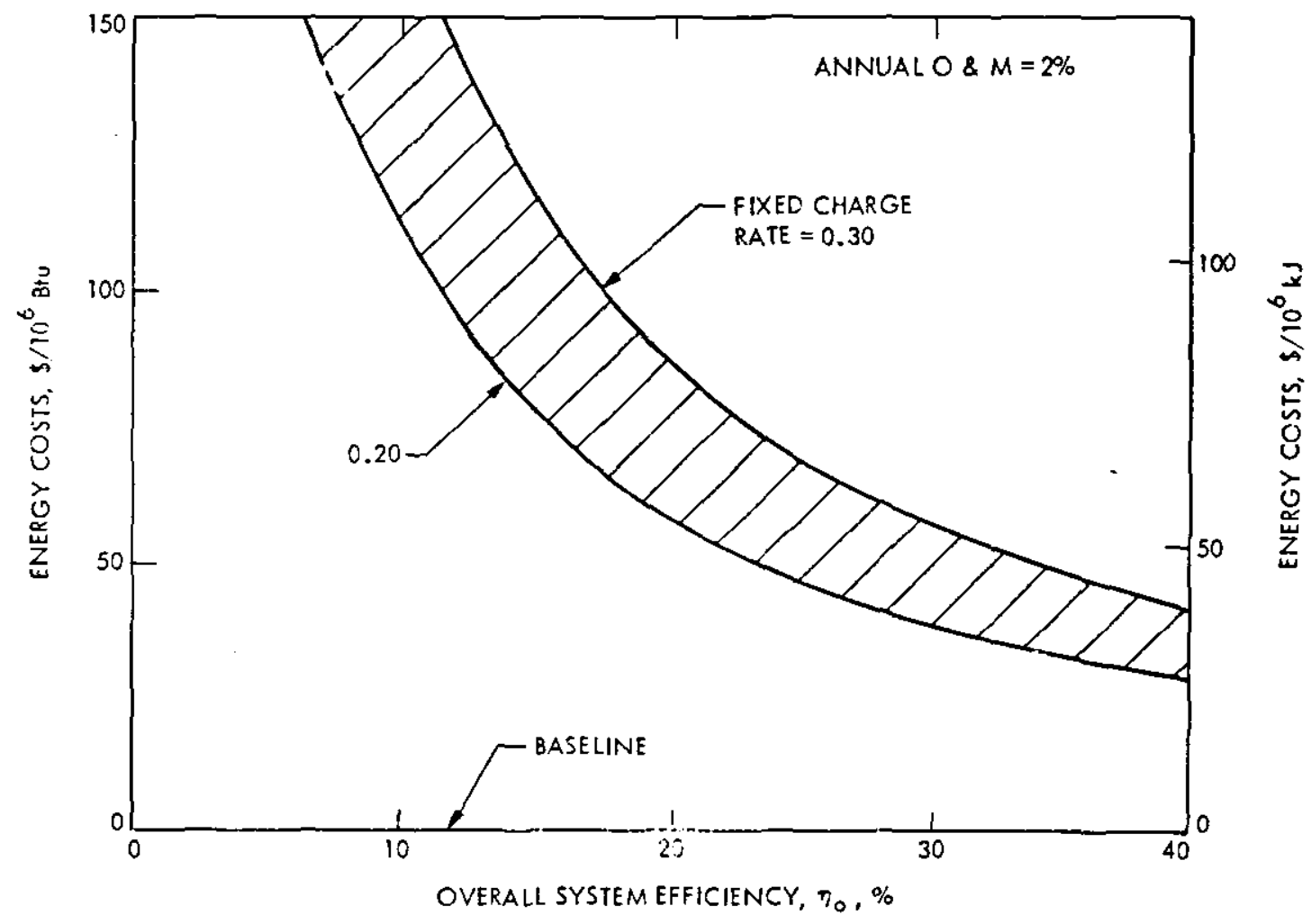

Figure 10. Cost of Dihydrogen from the Baseline Concentrating System 


\section{Systems Comparisons}

Comparison of the two baseline systems (non-concentrating flat-plate and concentrating parabolic troughs) leads to the following conclusions:

(1) The low, overall efficiencies of both systems, coupled with the costly baseline collector/reactor designs, leads to high energy costs.

(2) Energy costs presented are optimistic as gas separation, reactor gas seals, and freeze protection have not been addressed.

(3) For the baseline systems studied, energy costs are higher for concentrating than for non-concentrating systems.

(4) For the baseline concentrating system, cooling is necessary to optimize the overall efficiency.

(5) Balance-of-plant items amount to a substantial fraction of the overall system costs for both baseline systems ( 28 to $44 \%$ ).

(6) Field piping for gas and liquid transport are not a critical cost item; therefore, refined optimization methods applied to this subsystem will not result in substantially lower energy costs.

\section{STATE OF THE ART}

The current status of fuel-producing photochemical and photoelectrochemical processes is briefly reviewed to provide background and perspective for the study of engineering feasibility that is the focus of this report. As of this date, such research has concentrated aimost exclusively on splitting water to produce dihydrogen.

\section{Cyclic Photoredox Processes}

These processes are cyclic in the sense that all species are regenerated except water and its decomposition products, $\mathrm{H}_{2}$ and $\mathrm{O}_{2}$. Because only a very small fraction $(<<1 \%)$ of solar radiation is at wavelengths short enough to initiate direct photodecomposition of water, a sensitizer is required. The sensitizer is electronically excited by the absorption of solar photons of appropriate energy $\left(E \geq E_{g}\right)$, and uses its excitation energy to drive a sequence of reactions that result in the decomposition of water to $\mathrm{H}_{2}$ and $\mathrm{O}_{2}$ (Figure 1 ).

Complexes of transition metals with appropriate organic ligands that absorb strongly in the vistble are among the more widely used sensitizers and the viologens, particularly methyl viologen, are the most widely used quenchers.

Cyclic processes of this general type have efficiencies of less than one percent. The major reason for the low efficiencies observed in such systems seems to be the very rapid non-productive back reaction between the charge pairs. 
Significantly higher yields of $\mathrm{H}_{2}$ can be obtained by introducing a sacrificlal reagent, however, such systems are no longer cyclic. The sacriffcial reagent may inhlbit charge recombination by scavenging one of the ions via an irreversible redox reaction in which the sacrificial reagent is consumed. The unscavenged ion is then able to produce $\mathrm{H}_{2}$ or $\mathrm{O}_{2}$.

Mild reducing agents are effective sacrifical reagents if dihydrogen is the desired product, and the highest efficiency observed is about $13 \%$.

Systems requiring a sacrificial reagent might be practical for commercial sale production of $\mathrm{H}_{2}$ if an inexpensive reagent were available. At the present stage of development, studies with sacrificial reagents are used primarily to obtain kinetic data and to evaluate various components of photoredox/systems.

Photoelectrochemical Water Splitting

These processes involve production of the fuel via chemical reactions at the surface of electrodes, one or both of which is a semiconductor. Varfous cell configurations are possible.

Voltage-Assisted Photoelectroylsis. In 1972, Honda and Fujishima reported that water could be decomposed to $\mathrm{H}_{2}$ and $\mathrm{O}_{2}$ at voltages well below the theoretical decomposition potential in a cell with a $\mathrm{n}-\mathrm{TiO}_{2}$ photoanode and a platinum cathode.

Since then, a number of semiconductors have been used in voltage-assisted photoelectrolysis but, in general, conversion efficiencies with solar radiation have been relatively low, $3 \%$ or less. A conversion efficlency of $12 \%$ has been reported for photoelectrolysis of aqueous $1 \mathrm{M} \mathrm{HCl}-2 \mathrm{M} \mathrm{KCl}$ to produce $\mathrm{H}_{2}$ and $\mathrm{Cl}_{2}$. The cell employed a platinized $\mathrm{p}$-In photocathode and a platinum anode. This is the highest efficiency that has been reported for any fuel-producing solar quantum converter.

Unbiased Cells with a Single Photoelectrode. In these devices, one electrode is an illuminated semiconductor and the counter electrode is an inert conductor, such as platinum or carbon (see Figure 2). Light absorbed at the photoelectrode is the only energy input. Sustained photoelectrolysis of water without application of an external voltage was first achieved using a UV-illuminated, n-SrTiO3 photoanode, and a platinum cathode. However, the band-gap energy in this case is so large $(3.2 \mathrm{eV})$ that the efficiency would be unacceptably low with solar radiation.

Major problems are the poor match of semiconductor band-gap with the solar spectrum and photo corrosion. The spectral response can be improved by sensitization of the semiconductor electrode with dyes or molecular substrates attached to the surface. A number of semiconductor-sensitizer combinations have been investigated, but efficiencies remain low. 
Unbiased Cells with Two Photoelectrodes. In this case, two photons are absorbed (one at each photoelectrode) to generate one net electron-hole pair for the fuel-producing reaction. Such devices may be able to use lower band-gap semiconductors that better utilize the solar spectrum. A variety of such cells have been investigated but, thus far, efficiencles have been less than $1 \%$.

Colloidal Semiconductor systems. Cells have been designed in which colloidal n-TiO 2 particles loaded with ultrafine deposits of RuO 2 and platinum act as wireless cells with an $\mathrm{n}-\mathrm{TiO} 2$ photoanode short-circuited to a platinum cathode. However, the efficiency is extremely low with solar radiation because of the large band-gap energy of $\mathrm{T}_{10}$. Grätzel and his coworkers are attempting to extend the spectral response into the visible by surface-doping the colloidal $\mathrm{TiO}_{2}$ particles with transition metals. Sustained water cleavage with visible light has been observed with aqueous suspensions of $\mathrm{TiO}_{2}$ particles doped with $\mathrm{Cr}^{3+}$. The observed quantum efficiency for production of $\mathrm{H}_{2}$ is approximately $1 \%$.

Particle systems are attractive hecause their relative simplicity could result in lower construction and maintenance costs. However, unlike cells with well separated electrodes, particle systems produce a mixture of gases which must be separated.

SYSTEMS AND OPERATING OPTIONS

Photochemistry at Elevated Temperatures

Because of the significant difference in the specificity of the excitation process, and the fact that electronically excited molecules may react quite differently than ground-state molecules, the reaction products may differ when the same system is excited photochemically rather than thermally. Since increased temperature will reduce this specificity, there is usually no incentive to operate photochemical systems at elevated temperatures. There are also other factors that mitigate against using high temperatures. For example, absorbers well matched to the solar spectrum are usually rather complex molecules that may be expected to undergo increased degradation when the temperature is increased. In most fuel-producing photochemical systems, the absorber must survive repeated cycling if the process is to be cost effective.

Another factor that must be considered is the decrease in the limiting thermodynamic efficiency of all quantum converters with increasing temperatures. The limiting efficiency decreases approximately two percentage points per $50 \mathrm{~K}$ increase in temperature. Nonetheless, experimental results have been reported that show significant increases in yield with temperature for chemical systems operating far below the thermodynamic limit. In such cases, favorable kinetic effects are responsible for the observed increases in yield. Because real systems will almost certainly operate below the limiting efficiency, there may be advantages to operating water-splitting systems at temperatures above ambient. 
Pure solar thermochemical processes for water splitting receive the necessary driving energy as heat. Such processes are expected to have greater eficiencies because they use the solar spectrum more efficiently and are not subject to some of the losses inherent in quantum conversion (e.g., internal conversion).

Thermochemical water splitting can be carried out indirectly by a series of chemical reactions that constitute a closed cycle with respect to all species except water and its decomposition products, dihydrogen and dioxygen. Preliminary analyses indicate that some of the cycles have efficiencis as high as 40 to $45 \%$.

In some cycles, at least one step is driven primarily by the input of electrical work. These so-called thermochemical-electrochemical hybrids are designed to eliminate a difficult processing step(s) or to close a cycle that includes a step that is thermally unworkable.

By analogy, it might be expected that a hybrid cycle could incorporate a photochemical step. However, hybrids of this type do not appear to be viable because of the low efficiency of solar photochemical processes.

Coupled Systems

Haught has examined the efficiency of a system consisting of a quantum converter coupled to a thermal converter at a common temperature. Figure 11 shows the efficiency of such a system as a function of temperature. The efficiency of the quantum converter decreases with increasing temperature while that of the thermal converter increases. It is clear that there is little incentive to couple the two converters in this fashion unless the quantum converter is significantly cheaper than the thermal device. In that case, a coupled system might be useful up to about $600 \mathrm{~K}$.

As an alternative, the quantum converter could be operated at near ambient temperatures and the thermal converter at high temperatures. The shorter wavelengths of the solar spectrum would be used to drive a photochemical process in the quantum converter and the long wavelengths would be collected by the thermal converter. In this case, the quantum converter would produce chemically stored energy and the thermal converter would probably produce electricity. For example, the heliostats of a central receiver solar-thermal power plant might be made with a mirror coating that is highly reflective in the infrared, but highly transparent in the visible and near-ultraviolet. The quantum converter would be located beneath the mirrored surface. 


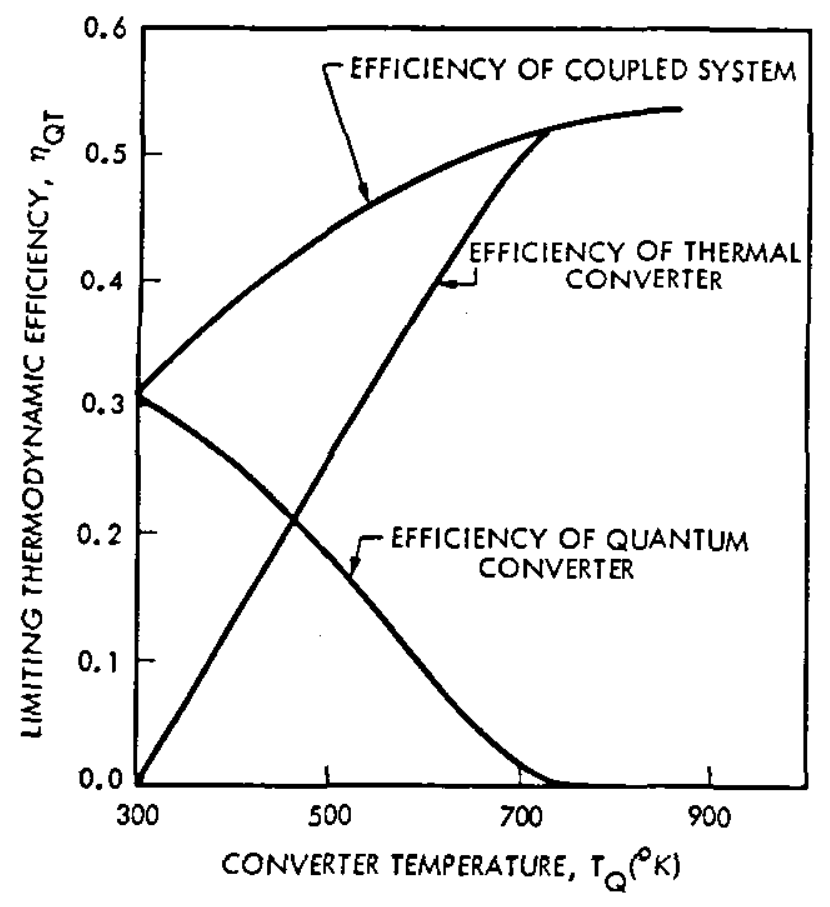

Figure 11. Conversion Efficiency Versus Temperature for a Single Collector Coupled Quantum/Thermal System

\section{CONCLUSIONS AND RECOMIENDATIONS}

The study effort was focused on: (1) the assessment of selected baseline systems for hydrogen production, and (2) the identification of the potential for improvement via options that differ from the baseline systems. Major conclusions pertaining to these two efforts are sumarized below.

Baseline Systems for Hydrogen Production

(1) Major improvements in photochemical conversion efficiencies in excess of the baseline values are required for economic viability.

(2) Potential for plant cost reduction is limited and depends on finding low-cost substitutes for glass and reflectlve surfaces of collectors.

Potential and Options for Improvement

(1) Multiple photon systems can potentially provide the required efficiencies in excess of target baseline values $(-40 \%$ greater $)$.

(2) Novel solar collection concepts, such as a shallow solar pond with a thin photochemical reaction layer, can avoid the high cost of materials associated with the baseline systems and warrant further study. 
(3) Coupled systems, wherein the portion of the solar spectrum applicable to photochemical conversion 1s allowed to enter the reactor while the remainder is used to generate thermal energy, can potentlally utilize hardware in a synergistic manner and warrant further study.

The pursuit of the above 1 dentified options having potential for improvement form the basis for the recommendations resulting from this effort. Key recommendations are to:

(1) Pursue photochemical research leading toward identification of practical concepts utilizing efficient multiple photon conversion processes.

(2) Investigate novel solar collection concepts such as a shallow solar pond that has potential for avoiding the high cost of materials associated with the baseline systems.

(3) Investigate systems that can potentially ut1lize hardware in a synergistic manner, e.g., hellostats with surfaces that transmit a selected portion of the solar spectrum to drive a photochemical process in a reactor located beneath the surface while reflecting the remainder of the flux to the tower of a central receiver solar thermal power plant. 


\section{SECTION I}

\section{INTRODUCTION}

\section{A. BACKGROUND}

Solar photochemical processes may be an attractlve method for conversion of solar energy to fuels and chemicals because of the possibility of direct conversion of photon energy to chemlcal energy. Water splitting processes to produce dihydrogen (gaseous $\mathrm{H}_{2}$ ), such as those using essentially homogeneous photochemícal reactions in solution and photoelectrolysis, have recelved the most attention. There is concern, however, that because of low efficiencies these processes may suffer from high costs associated with the distribution of collector/reactors over large areas.

One method of reducing such costs is to use concentrated solar radiation. Although this may reduce the combined reactor and piping system costs, it will change the thermal and flux characteristics of the reactor. Because the limiting thermodynamic efficiency of photochemical processes increases with intensity but decreases with temperature, reactor cooling may be required.

To guide research in the areas of fuel-producing solar photochemistry and photoelectrochemistry, it would be helpful to develop estimates of the engineering performance and costs even before the chemical details have been characterized. If, for example, the costs of distribution of feedstock and recovery of products strongly dominate the process, the chemical process detalls could be frrelevant to potential practicality.

\section{B. OBJECTIVES AND SCOPE}

This study is divided into two separate, but complementary, areas: (1) the identification of potentially useful fuel-producing photochemical processes, and (2) the engineering performance and costs of a commercial-scale dihydrogenproducing solar quantum conversion plant. Although these were generally separate and parallel tasks, there were interactions throughout the study. On the one hand, these interactions provided the necessary scientific background for the engineering analyses. On the other hand, potentlal engineering constraints gave practical perspective to the review of photochemical processes.

A brief, general description of currently avallable processes for direct conversion of solar energy into storable chemlcal energy is given in Section II together with a discussion of both limiting efficiencies of ideal solar photochemical processes and probable efficiencies for real systems. This information provides the photochemical basis for defining the baseline system used in the engineering feasibility study that follows in Section III.

The engineering analysis begins with a broad scoping of performance and costs of a non-concentrating solar photochemical system that produced dihydrogen by splitting water. Components include: (1) the collector/reactor equipment, 
(2) piping to circulate the photochemical solution and collect and compress the product gas, and (3) balance-of-plant items.

The applicability of concentrating systems to solar photochemical processes is also considered. Because theoretical studies of efficiency indicate that cooling is likely to be necessary in concentrated systems, various cooling designs are analyzed. Fuel costs and systems performance characteristics are projected for these design options.

Although the solar photochemical reactor costs can only be estimated at the present stage of development, the results obtained in this study should help guide reactor design and photochemical process selection by imposing cost constraints. Major cost-influencling factors, including process efficiency, solar concentration ratio, and operating temperature and pressure, are analyzed parametrically.

Current research pertinent to fuel-producing solar quantum conversion processes is reviewed in Section IV. This review identifles candidate processes and compares such processes with the baseline system used in the engineering feasibility study in terms of solar conversion efficiency.

Various operating and systems options are considered in Section $V$. These include: (I) operation at elevated temperatures, (2) the incorporation of photochemical step(s) into fuel-producing thermochemical cycles, 1.e., thermochemical-photochemical hybrids, and (3) the coupling of quantum converters with thermal converters.

Finally, the conclusions from this study are summarized in Section VI together with recommendations for further work. 
SECTION II

SOLAR PHOTOCHEMISTRY

\section{A. INTRODUCTION}

Photochemical processes are among the options available for the production of fuels and chemicals from solar energy. They convert solar energy directly into chemical energy and can be classified as quantum converters in contrast to thermal converters which are essentially solar heat engines.1 They are quantum converters because the conversion process is initiated by the electronic excitation of an absorber by photons of appropriate energy. The excitation process is a quantized event that requires photons with energies equal to, or in excess of, the threshold or band-gap energy $\left(E_{g}\right)$. In general, the band-gap energy is the minimum energy required to excite the absorber from its ground electronic state to the lowest allowed excited electronic state. It is usually large enough that less than half of the solar spectrum is capable of initiating photochemistry.

Photochemical processes differ from thermal processes in a number of important aspects. In photochemistry, absorber molecules are selectively excited resulting either in their dissociation or their conversion to an electronically exclted state. If the electronically excited state is sufficiently long-lived, it may react with suitable substrates or transfer energy to appropriate acceptor molecules with resultant chemical changes. In thermal processes, excitation is essentially non-specific; thus, the average energies of all molecules present in the system are increased. Chemical reaction occurs if a large enough fraction of reactant molecules acquires the necessary energy of activation. Thermal systems also differ in that the molecules involved in reaction almost invariably remain in their ground electronic states. Heating the system results in shifts in the translational, rotational and vibrational energy distributions, but the energy available is usually not sufficient for electronic excitation. Because of the significant difference in the specificity of excitation, and the fact that electronically excited molecules may react differently than ground-state molecules, the reaction products may differ markedly when the same system is excited photochemically, rather than thermally.

The following are some general requirements for solar photochemical systems that produce fuels or chemicals:

(1) The process should constitute a closed cycle with respect to all species except the feedstock and its decomposition products (e.g., $\mathrm{H}_{2} \mathrm{O}, \mathrm{H}_{2}$, and $\mathrm{O}_{2}$ in the photochemical splitting of water).

(2) They should use a wide band of the solar spectrum.

IThis includes thermochemical cycles which produce storable chemical energy. 
(3) The quantum yield should be high.2

(4) The product(s) should be easily separated, stored and transported.

(5) The materials of construction and the reagents involved must be inexpensive and relatively abundant.

Considering such factors as process chemistry and the cost and availability of feedstock, it seems unlikely that fuels will be produced on a large scale from feedstocks other than water, carbon dioxide, and dinitrogen $\left(\mathrm{N}_{2}\right)$.

Most of the research related to development of solar photochemical processes for the production of fuels has focused on splitting water to produce dihydrogen. The general nature of homogeneous photochemical processes for splitting water is briefly described in Section II-B and the closely related process of photoelectrochemical water splitting is described in Section II-C. Section II concludes with a discussion of the limiting thermodynamic efficiency of quantum conversion processes including some remarks on the probable conversion efficiencies of real systems. The current status of these water-spiitting processes is reviewed in Section IV.

\section{B. HOMOGENEOUS PHOTOCHEMICAL WATER SPLITTING}

Uirect solar photolysis of water to produce dihydrogen is not practical because of the large band-gap energy involved. 3 However, indirect photolysis is possible in the presence of an appropriate sensitizer. The sensitizer absorbs energy over a wide band in the solar spectrum ${ }^{4}$ and uses that energy to drive a cyclic process, the net result of which is decomposition of water into dihydrogen and dioxygen. Absorption of photons by the sensitizer, typically present at low concentrations $\left(10^{-4}\right.$ to $\left.10^{-5} \mathrm{M}\right)$, results in its electronic excitation. The excited sensitizer ( $S^{*}$ ) then transfers an electron with an appropriate quencher or relay, also present at relatively low concentrations. Depending upon the nature of the quencher, electron transfer may be either from or to $S^{*}$, 1.e., via Equation $(2-1)$ or $(2-2)$.

ZThe quantum yield is the number of molecules of product dividid by the number of photons absorbed.

${ }^{3}$ Direct photolysis of water requires wavelengths less than $190 \mathrm{~nm}$, and much less than $1 \%$ of the solar spectrum falls in that range.

${ }^{4}$ Ideally, the sensitizer should absorb strongly between 400 and $900 \mathrm{~nm}$. Below $400 \mathrm{~nm}$, the solar intensity is very low. Above $900 \mathrm{~nm}$, the excitation energy is likely to be too low to drive the process. 


$$
\begin{aligned}
& S+h \nu \rightarrow S^{*} \\
& S^{*}+Q^{+} S^{+}+Q^{-}
\end{aligned}
$$

or

$$
S^{*}+Q_{-}^{-}+Q^{+}
$$

Ideally, the products of the quenching reaction then produce dihydrogen and dioxygen by redox reactions with water, such as Equation (2-3) and Equation (.2-4), to complete the cycle. Because of the nature of its role in this process, the quencher is of ten referred to as an electron relay.

$$
\begin{aligned}
& 2 \mathrm{Q}^{-}+2 \mathrm{H}_{2} \mathrm{O} \stackrel{\text { cat. }}{\longrightarrow} 2 \mathrm{Q}+\mathrm{H}_{2}+2 \mathrm{H}^{-} \\
& 2 \mathrm{~S}^{+}+\mathrm{H}_{2} \mathrm{O} \stackrel{\text { cat. }}{\longrightarrow} 2 \mathrm{~S}+1 / 2 \mathrm{O}_{2}+2 \mathrm{H}^{+}
\end{aligned}
$$

The process is 1llustrated schematically in Figure 2-1. Ideally, the photosensitizer and any other species required are completely recycled so that

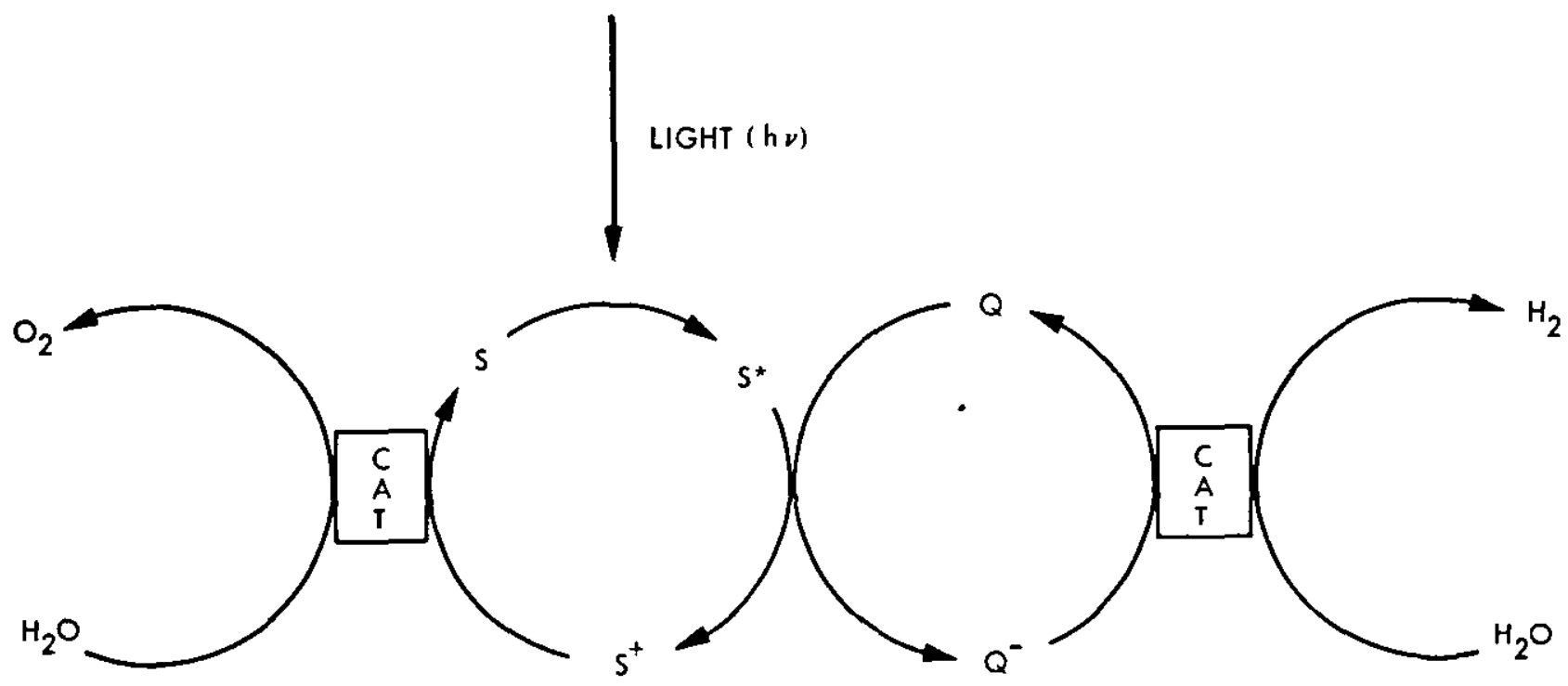

Figure 2-1. Schematic Diagram for Cyclic Photochemfcal Water Splitting 
the only net chemistry is the decomposition of $\mathrm{H}_{2} \mathrm{O}$ to $\mathrm{H}_{2}$ and $\mathrm{O}_{2}$. Real systems are not likely to be completely closed. Side reactions will result in some loss of reagents; a maior problem will be to hold such losses to an acceptable level.

The process described above involves a single photosystem. Processes with two or more photosystems are also of interest because of their higher limiting thermodynamic efficienctes (see Section II-D); however, no process using more than one photosystem has yet been developed.

The state of the art of homogeneous water splitting is reviewed in Section IV.

\section{PHOTOELECTROCHEMICAL PROCESSES}

The distinguishing feature of photoelectrochemical processes is that the fuel-producing chemical reactions ${ }^{5}$ occur at electrodes, one or both of which is an Illuminated semiconductor. Illumination of the semiconductor results in excitation of electrons from the valence to the conduction band. The resulting electron-hole pairs separate in the electric field that is produced spontaneously at the semiconductor-electrolyte interface, and migrate to the electrodes where the chemical reactions occur. A schematic diagram of a photoelectrochemical cell with a single semiconductor electrode is shown in Figure 2-2. In such cells, the counter electrode is an inert conductor such as platinum or carbon. Photons absorbed at the photoelectrode provide the only energy input.

Another configuration is one in which the energy input includes both electrical energy and photon energy. This process, usually referred to as photoassisted electrolysis, was pioneered by Honda and Fujishima. In 1972, they reported the electrolysis of water at voltages well below the theoretical decomposition potential in a cell with an illuminated $\mathrm{n}-\mathrm{TiO}_{2}$ anode and a platinum cathode (Figure 2-3).

Another interesting configuration is one in which the photoelectrochemical cell is reduced to colloidal dimensions. Platinized colloidal particles of semiconductor, dispersed in the electrolyte, act as wireless cells of the type 1llustrated in Figure 2-4. The semiconductor and platinum electrodes are simply short -circuited. This configuration is attractive because its simplicity could result in relatively low construction and maintenance costs.

The current state of the art of photoelectrochemical processes is reviewed in Section IV.

5 Photoelectrochemical devices may also be designed to convert the energy of solar photons directly to electricity. Such devices, usually referred to as photogalvanic cells, are not considered in this report. 


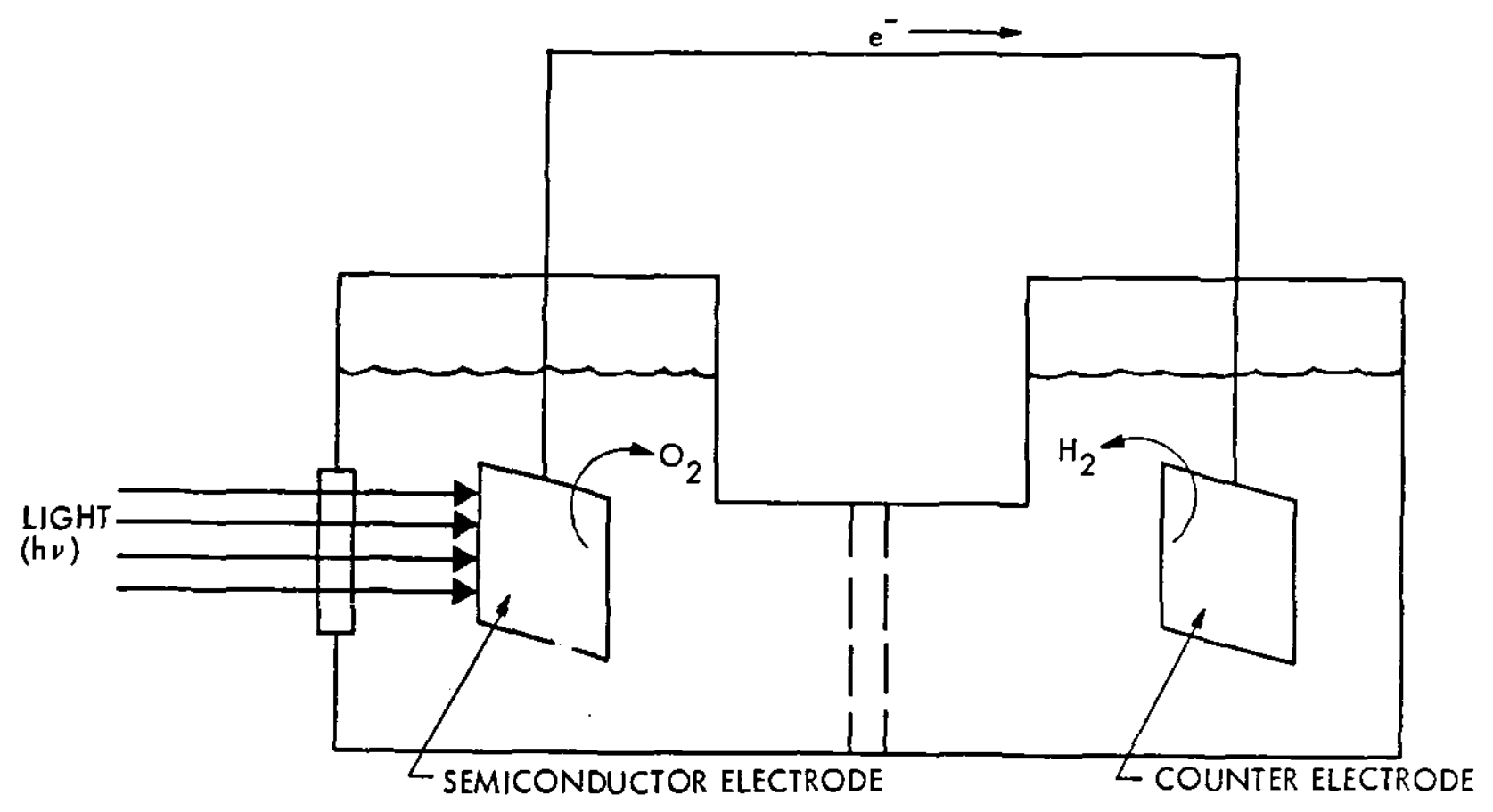

Figure 2-2. Photoelectrolysis Cell with a Single Semfconductor Electrode

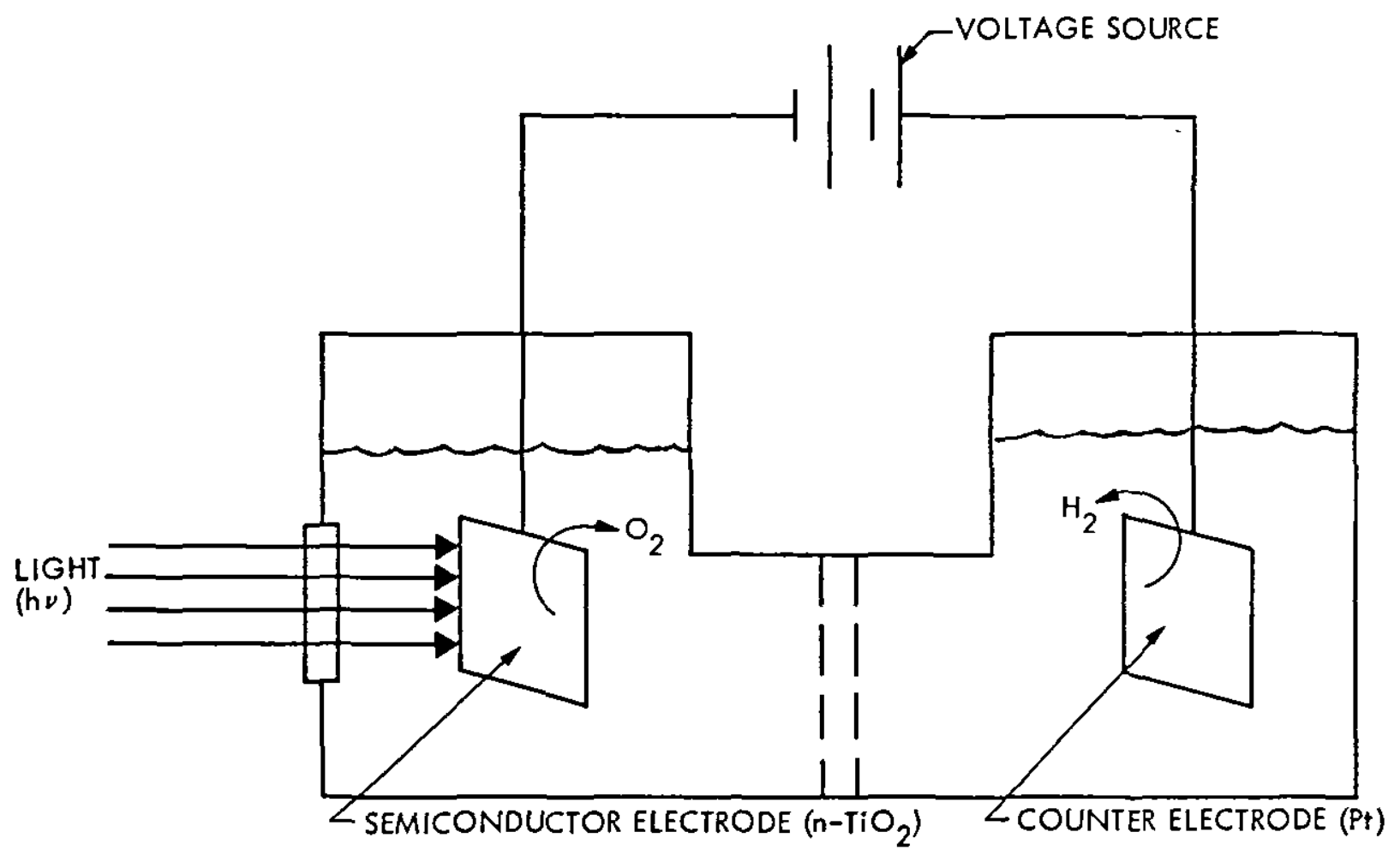

F1gure 2-3. IItage-Assisted Photoelectrolysis 


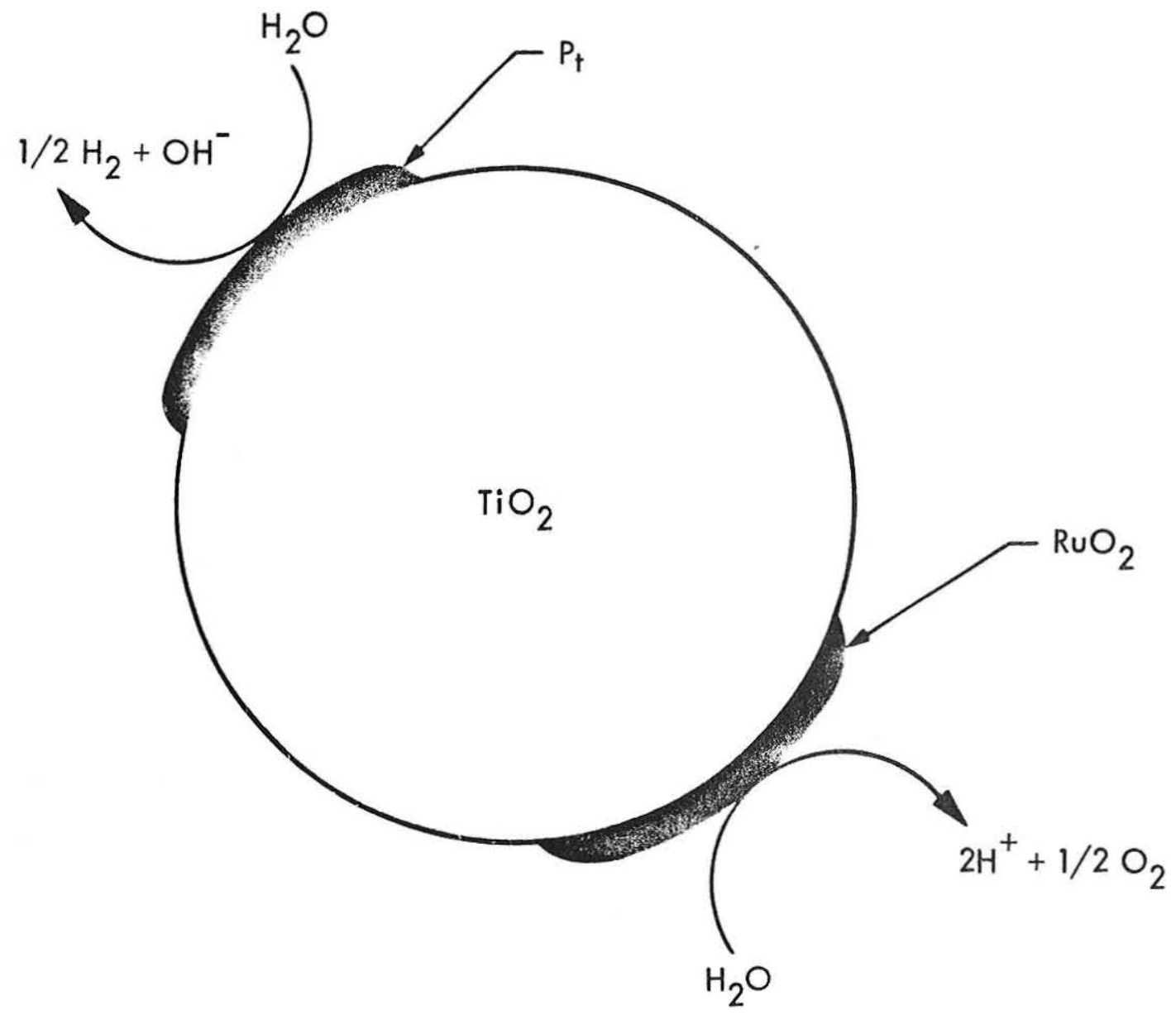

Figure 2-4. Colloidal Systems $\left(\mathrm{n}-\mathrm{TiO}_{2}\right.$ Loaded with $\mathrm{P}_{\mathrm{t}}$ and $\mathrm{RuO}_{2}$ ) 


\section{EFFICIENCY}

\section{Limiting Themodynamic Efficiency}

Both thermodynamic and kinetic factors 11mit the efficiency with which solar energy can be converted directly to work and/or storable chemical energy. The limiting thermodynamic efficiency of such devices, usually classified as quantum converters, has been examined by several investigators (References 1 through 10).

A schematic diagram of a solar quantum converter is shown in Figure 2-5. It is a threshold device because the energy conversion process is initiated by electronic excitation of an absorber, a quantized event. The minimumengy, $E_{g}$, required for such excitation is called the threshold or band-gap energy, and only photons with energies equal to or greater than $E_{g}$ can initiate the energy conversion process.

The thermodynamic analysis usually involves a number of assumptions, among which are the following:

(1) The converter is a perfect absorber; all photons with energy equal or greater than $E_{g}$ are completely absorbed and induce electronic excitation of the absorber with unit quantum yield.7

(2) All photons with $E \geq E_{g}$ are converted to the same amount of chemical energy; high energy photons generate no more chemical energy than low energy photons. 8

The fraction of the incldent photon energy that is available to initiate photochemistry, $\eta_{\mathrm{E}}$, is given by:

$$
\eta_{E}=\frac{J_{s} \quad E_{g}}{s}
$$

where $J_{s}=\int_{0}^{\lambda g} I_{s}(\lambda) d \lambda$ and $S=\int_{0}^{\infty} I_{s}(\lambda)(h c / \lambda) d \lambda$. $I_{s}(\lambda)$ is the incident photon flux in the wavelength interval $\lambda$ to $\lambda+d \lambda$, and $\lambda_{g}$ is the threshold wavelength.

${ }^{6}$ Complete absorption is assumed because this analysis is intended to yleld the maximum thermodynamic efficiency.

7 The quantum yield, $\phi$, is the number of molecules of product (in this case, molecules of electronically excited absorber) divided by the muber of photons absorbed.

${ }^{8}$ This is equivalent to assuming rapid internal conversion of higher electronic states to the lowest excited state, which is assumed to be thermally equilibrated at the temperature of the photoconverter. There is considerable evidence to support such an assumption. 


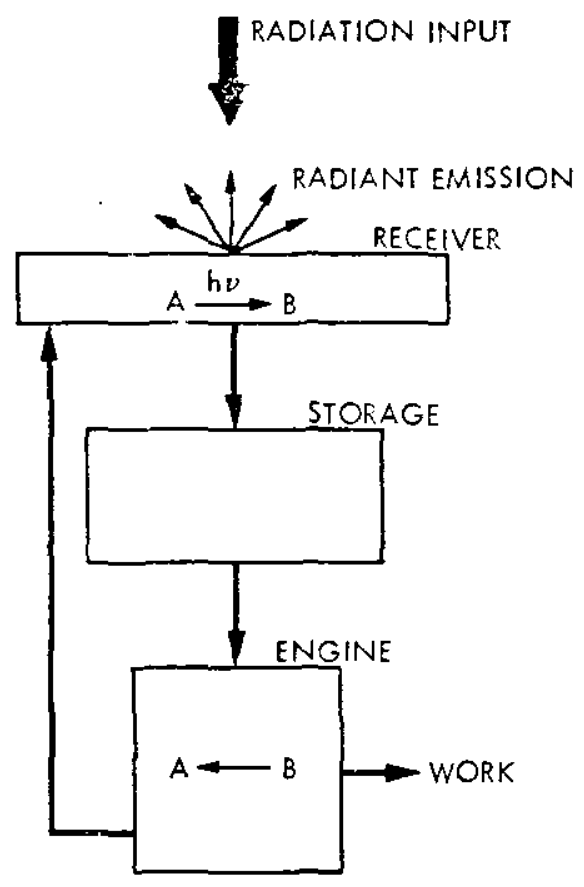

Figure 2-5. A Generalized Ouantum Converter

Calculations of $\eta_{E}$ reveal that, even for a perfect absorber with an optimum $\lambda_{g}$, less then half of the incident solar-photon energy is converted to excitation energy, and not all of this is avallable as work or chemical energy. E takes into account only the first 1 aw of thermodynamics and the quantized nature of the absorption process. Consideration of the second law leads to the conclusion that some of the excitation energy is necessarily degraded to heat. Thus, the liniting thermodynamic efficiency, $\eta_{\mathrm{QT}}$, is significantly less than $\eta_{\mathrm{E}}$.

Several approaches have been used to calculate 7 or; one of the most general is due to Haught (Reference 9). Haught's analysis is based on Planck's and Kirkoff's laws, the thermodynamic requicement that the entropy of an interactings system is a maximum at equilibrium, and the principle of detailed balance. These arguments will not be reproduced here, but Bolton, et al (Reference 10), have given an excellent review of the subject, including a number of different approaches to the derivation of $\eta_{\mathrm{OT}}$. There is general agreement that the limiting thermodynamic efficiency for quantum converters, using a single photosystem with unfocused sunlight, is about $31 \%$ for AM $0^{9}$ and $300 \mathrm{~K}$.

${ }^{9} \mathrm{AM}$ signjfies air mass., AM 0 corresponds to the insclation just outside Earth's atmosphere (i.e., air mass zero). AM I corresponds to the solar radiation at the Earth's surface with the sun at its zenith on a clear day. 
Figure 2-6 shows the variation in $\eta_{\mathrm{QT}}$ with $\lambda g$, the band-gap wavelength. The relatively low values for the limiting thermodynamic efficiency are inherent in the quantum nature of the conversion process and the consequences of the second law and, as such, are independent of the mechanistic detalls of the process. As Bolton, et al (Reference 10) have polnted out, "This limitation is thermodynamic and $f$ undamental: 1 t cannot be overcome by the choice of a different photosystem, use of catalysts, or any other stratagem."

Figure 2-6 applies to quantum converters using a single photosystem operated at $300 \mathrm{~K}$ with unfocused sunlight. Haught (Reference 9) and Bilchak, et al (Reference 11), have examined the influence of both temperature and solar concentration on the limiting efficiency. The variations in $\eta_{Q T}$ with solar concentration for a single photosystem operated at AM 1.2 , and various temperatures from 300 to $500 \mathrm{~K}$, are listed in Table 2-1. The efficiency, $\eta_{\mathrm{OT}}$, Increases by about two percentage points for each tenfold increase in intensity, and decreases by that same amount for each $50 \mathrm{~K}$ increase in temperature. Hence, the gain in efficiency resulting from a tenfold increase in intensity, will be offset by a $50 \mathrm{~K}$ increase in temperature. Thus, if solar concentration is to be employed for the purpose of increasing efficiency, it will probably be necessary to cool the reactor. On the other hand, solar concentration may have other advantages that would make it cost effective even without a significant increase in efficiency, e.g., reduction in the cost of the reactor.

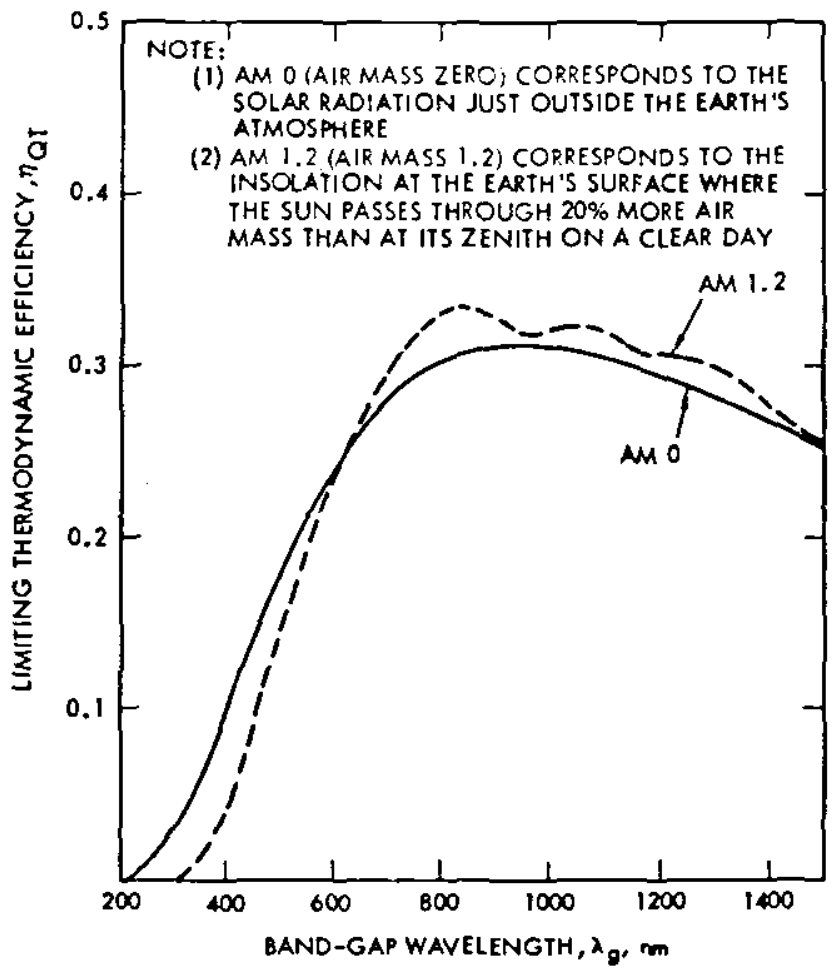

Figure 2-6. Limiting Thermodynamic Efficiency for an Ideal Quantum Converter as a Function of Band-Gap Wavelength 
Table 2-1. Limiting Thermodynamic Efficiencies for AM 1.2 Solar Radiation at Various Intensities and Absorber Temperatures (Reference 11) $\left(\lambda_{\mathrm{g}}=840 \mathrm{~nm}\right)$

\begin{tabular}{cccccc}
\hline & \multicolumn{5}{c}{ Absorber Temperature, $\mathrm{K}$} \\
\cline { 2 - 6 } $\begin{array}{c}\text { Intensity } \\
\text { suns }\end{array}$ & 300 & 350 & 400 & 450 & 500 \\
\hline 1 & 32.3 & 30.2 & 28.1 & 26.1 & 24.0 \\
10 & 34.1 & 32.3 & 30.5 & 28.7 & 26.9 \\
$10^{2}$ & 35.9 & 34.4 & 32.8 & 31.3 & 29.8 \\
$10^{3}$ & 37.7 & 36.5 & 35.2 & 34.0 & 32.7 \\
$10^{4}$ & 39.5 & 38.5 & 37.6 & 36.7 & 33.7 \\
\hline
\end{tabular}

The efficiency, $\eta_{\mathrm{QT}}$, can also be increased by using two or more separate photosystems involving different absorbers with different band-gap or threshold energies. Figure 2-7 shows contours of $\eta_{Q r}$ (as a percentage) as a function of $\lambda_{1}$ and $\lambda_{2}$ for a system with two absorbers subjected to AM 1.2 solar energy (Reference 6). One absorber absorbs all 11ght with $\lambda \leq \lambda_{1}$; the other absorbs al1 light with $\lambda_{1}<\lambda \leq \lambda_{2}$. A maximum $\eta_{\mathrm{QT}}$ of $4 \%$ is predicted for $\lambda_{1}=830 \mathrm{~nm}$ and $\lambda_{2}=1320 \mathrm{~nm}$. Figure $2-2$ is a schematic diagram for a photochemical system to split water using two photosystems that has been proposed by Bolton (Reference 7). In such a system, two photons are absorbed for every electron transferred in the overall reaction. In Figure $2-8, D$ and $A$ are the photosensitizers (i.e., absorbers) that drive the water-splitting reaction and iN and $M$, the catalysts that permit oxidation of water molecules to dioxygen and reduction of protons to dihydrogen in concerted reactions. In this case, the two photosystems are separated by a semipermeable membrane, permitting transport of electrons and protons between photosystems. A real device of this type has not yet been developed. 


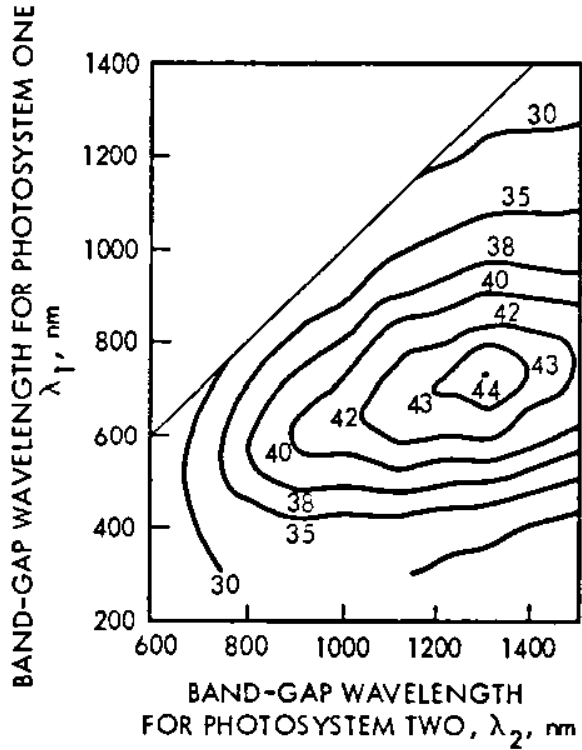

NOTE:

AM 1.2 (AIR MASS 1.2) CORRESPONDS TO THE INSOLATION AT THE EARTH'S SURFACE WHERE THE SUN PASSES THROUGH 20\% MORE AIR MASS THAN AT ITS ZENITH ON A CLEAR DAY

Figure 2-7. Efficiency Contours for a Quantum Converter Using Two Photosystems and Unfocused AM 1.2 Solar Energy

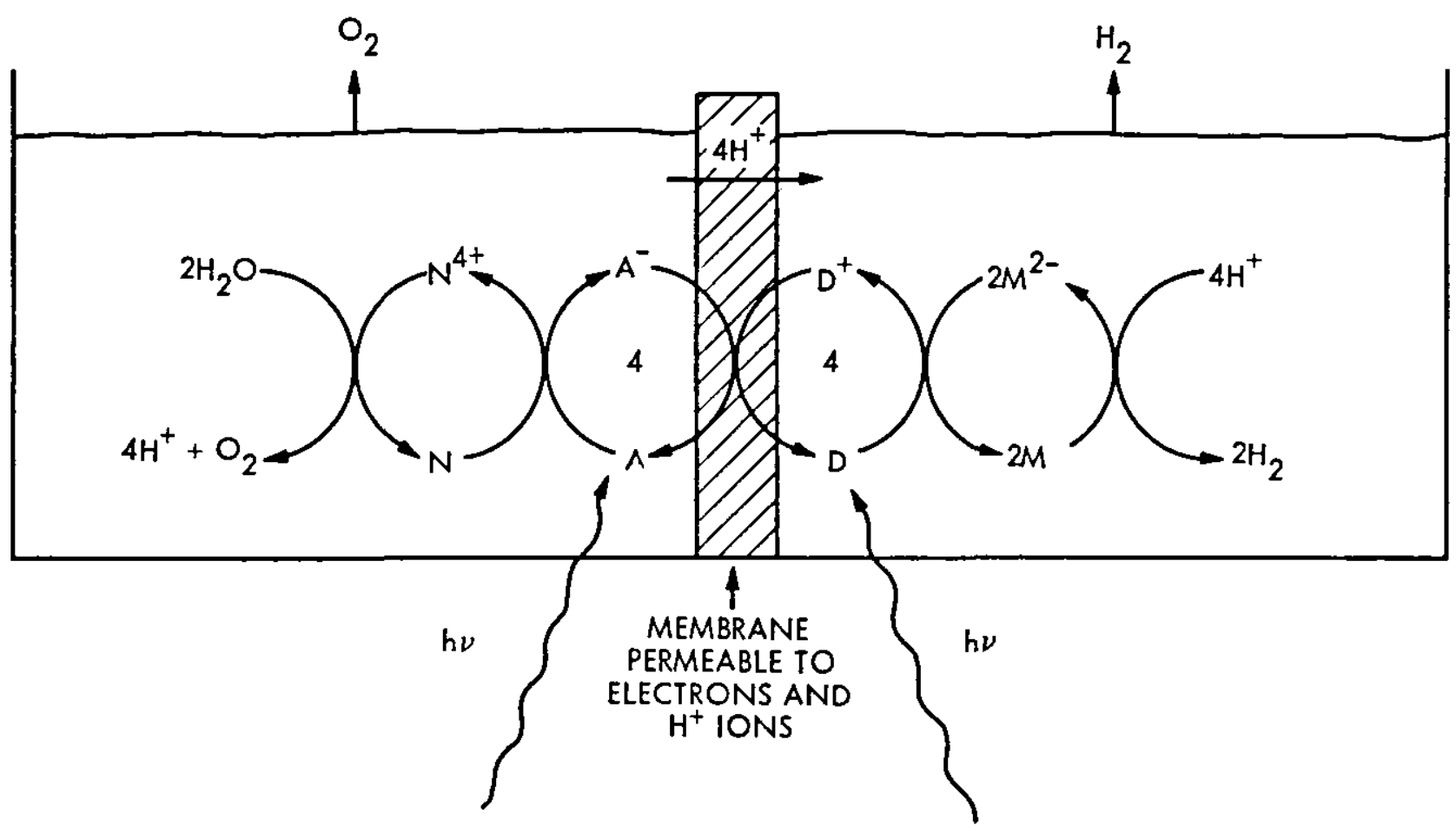

Figure 2-8. A Photochemical Scheme for Splitting Water Using Two Photosystems 


\section{Efficiencies of Real Systems}

The efficiencies discussed in the previous paragraphs are limiting or ideal thermodynamic efficiencies. Real systems, producing chemically stored energy, will have significantly lower efficiences. For example, the limiting values, discussed earlier, assume the absorber is ideal, i.e., all photons with $\lambda \leq \lambda_{g}$ are absorbed. In real photochemical systems, the absorption characteristics of the photosensitizer are such that not more than 70 to $80 \%$ of these photons is likely to be absorbed. Also, not all of the photochemical products will be collected from the system. Collection efficiency is unlikely to be greater than $90 \%$, especially when a gas is generated in a liquid system. There are also kinetic limitations that reduce the efficiency of processes that store energy chemically. If the product is to be kinetically stable, there must be an energy barrier to prevent its back reaction. This energy barrier is provided at the expense of the excitation energy, $\mathrm{E}_{\mathrm{g}}$. Bolton has estimater that this effect will reduce the limiting efficiency for a quantum converter using a single photosystem from about $31 \%$ to about $21 \%$ (Reference 6 ). On the basis of these considerations, it seems unlikely that the overall ef ficiency of a real quantum converter of this type will exceed 12 to $15 \%$. 
SECTION III

ENGINEERING ASSESSMENT OF SOLAR PHOTOCHEMICAL DIHYDROGEN PRODUCTION

\section{A. APPROACH AND METHODOLOGY}

The purpose of this phase of the study is to identify engineering requirements associated with solar-photochemical systems and scope the costs of a prototype system for producing fuels on a commercial scale. The photochemical process is specified only to the extent that it is assumed to produce dihydrogen from water. The nominal plant size chosen was $25,000 \mathrm{scmd}(850,000 \mathrm{scfd})$ with the product gas, dihydrogen, at a pressure of 50 atm. The results of this phase of the study are intended to provide a reasonably clear indication of the engineering design limitations on the development of solar-photochemical systems for large-scale productions of fuels.

Major factors influencing performance and costs include reaction efficlency, solar concentration ratio, and the operating temperature and pressure. Parametric studies of these factors were made to permit an estimate of the range of operating conditions (temperature and pressure) that can be used and the quality of solar concentrators needed, if any. Two baseline collector/ reactor designs were chosen for this study. The first design was a flat-plate, non-concentrating collector/reactor. The other design was a linear parabolic trough with a concentration ratio of 43 . Both baseline systems were analyzed to Include realistic performance projections and a broad scopling of costs including: collector/reactor, fluid piping, peripheral equipment, temperature control of the reactor (if necessary), and balance of plant. A design constraint used throughout this engineering feasibility study was that the system components should be based on currently available technology and equipment whenever possible.

\section{B. NON-CONCENTRATING SYSTEM}

The first system studied was a non-concentrating, flat-plate collector/ reactor. The mafor deslgn parameters for the selected baseline system are summarized in Table 3-1.

This baseline system is composed of a fleld of flat-plate collectors. The photochemically reactive solution is pumped to the collector/reactors where sunlight initiates the reaction, generating dihydrogen and dioxygen gas. This reaction occurs at essentlally atmospheric pressure. The dihydrogen gas, at approximately $54^{\circ} \mathrm{C}\left(130^{\circ} \mathrm{F}\right)$, is separated and transported by another plping network to a gas cleamp and compression unit where the pressure is raised from 1 atm to a normal gas pipeline pressure of 50 atm. For the baseline plant size of $25,000 \mathrm{scmd}$, the collector fleld area reguired is $120,000 \mathrm{~m}^{2}$, assuming an overall plant efficiency of approximately $10 \% .10$ A detailed baseline system design description will be presented along with system

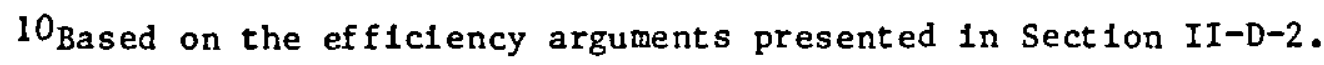


Table 3-1. Characteristics of the Baseline Non-Concentrating System

Characteristics

Feedstock

Product

Operating Pressure

Operating Temperature

Nominal Plant Size

Overall System Efficiency

Nominal Collector Area

Annual Solar Flux
Selected Conditions

Water

Dihydrogen Gas

1 atm

$54^{\circ} \mathrm{C}\left(130^{\circ} \mathrm{F}\right)$

$25,000 \mathrm{scmd}$

$10.3 \%$

$120,000 \mathrm{~m}^{2}$

$2430 \mathrm{kWh} / \mathrm{m}^{2} / \mathrm{yr}$

performance and cost projections. Finally, energy costs will be given and cost sensitivity with collector/reactor engineering design will be discussed.

The initial step in the conceptual design of the baseline system was the specification of a collector/reactor configuration. This component was to serve a dual purpose; as collector of solar photons needed to drive the process and as the photochemical reactor. Several guidelines which were considered in the design are given below:

(1) Solar energy absorbing surfaces and insulation were not desirable. Because photochemical reactions have higher limiting efficiencies at lower temperatures, the capture and retention of solar thermal energy is generally detrimental.

(2) The volume of the reactor was to be as small as possible in order to keep costs of photochemical reagents as low as possible. Thus, flat-plate collector/reactors were designed for a thin photochemical layer. Typical absorption characteristics of photosensitizers suggested a minimum layer thickness of about $1 \mathrm{~cm}$ for essentially complete absorption of the useful wavelengths of the solar energy by the sensitizers.

(3) Collection of the generated gas and the resupply of the photochemical reagents were to be incorporated in the reactor design.

(4) Wherever possible, conventional materials and fabrication techniques were to be used. 
With the above guidelines, the final conceptual design chosen was essentially two glass sheets, $2.54 \mathrm{~cm}$ ( $1 \mathrm{in.)}$ ) apart, surrounded by an extruded aluminum frame (see Figure 3-1). Glass was chosen as a glazing rather than plastics because of its strength, inertness and cost advantages. The fabrication of such a unit is similar to currently used methods in the double-glazed sliding glass door industry. The collector/reactor unit size was chosen to be $1.22 \times 3.66 \mathrm{~m}$ ( $4 \times 12 \mathrm{ft})$. This size was thought to be a compromise, which allows for reasonable handling by field crews and ease of factory fabrication.

The factory-fabricated collector/reactor unit would be fleld-assembled by construction crews at the plant site. The construction detail is shown in Figure 3-2. The water distribution header for the units would be located slightly above grade. As the dihydrogen gas evolved in the reactor, it would rise and be separated from the oxygen gas and collected in the gas collection header at the top of the unit. These headers would remain at about $2.13 \mathrm{~m}$ ( $7 \mathrm{ft}$ ) above grade sufficient for vehicle and working access. The angle fron posts would be mechanically driven into the ground by pile-drivers and these posts would serve as support for both the collector/reactor and the headers. The support frames for the collector/reactor units would give the units a 35-deg tilt from the horizontal (south-facing) to allow for the optimum annual collection of solar energy for site latitudes of about 35 deg.

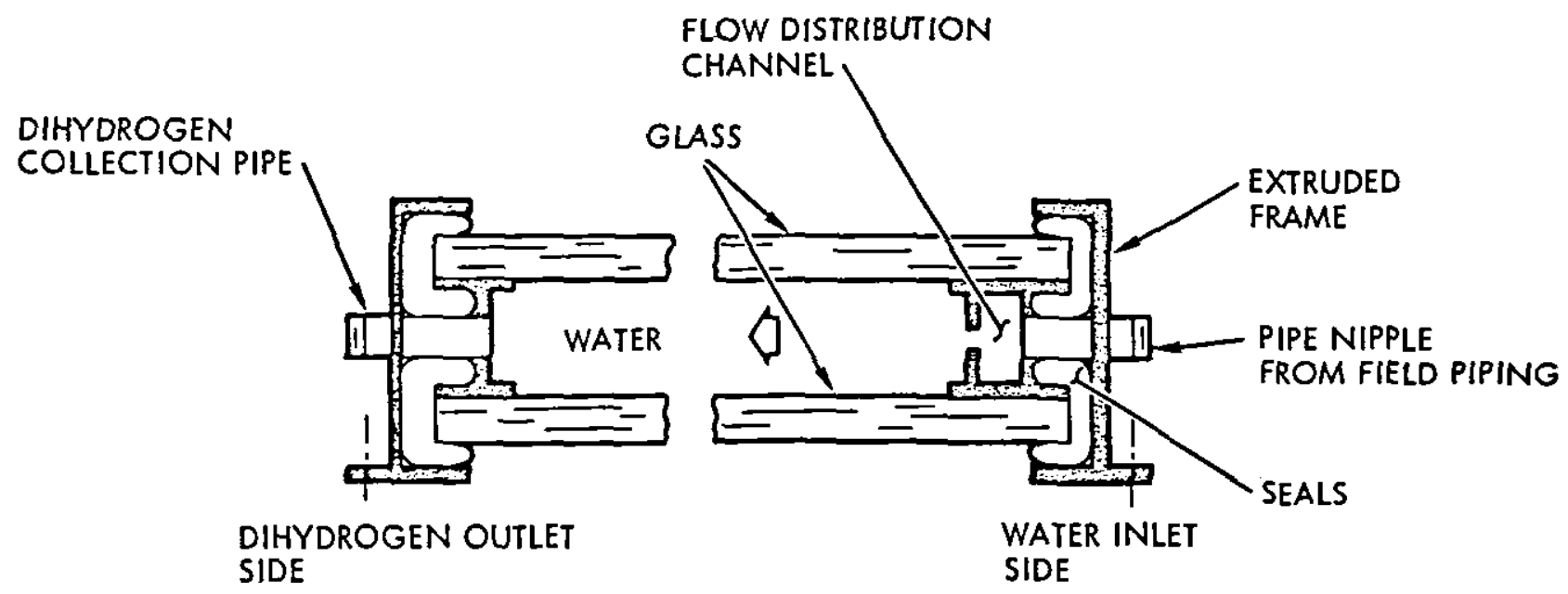

Figure 3-1. Baseline Flat-Plate Collector/Reactor Configuration 


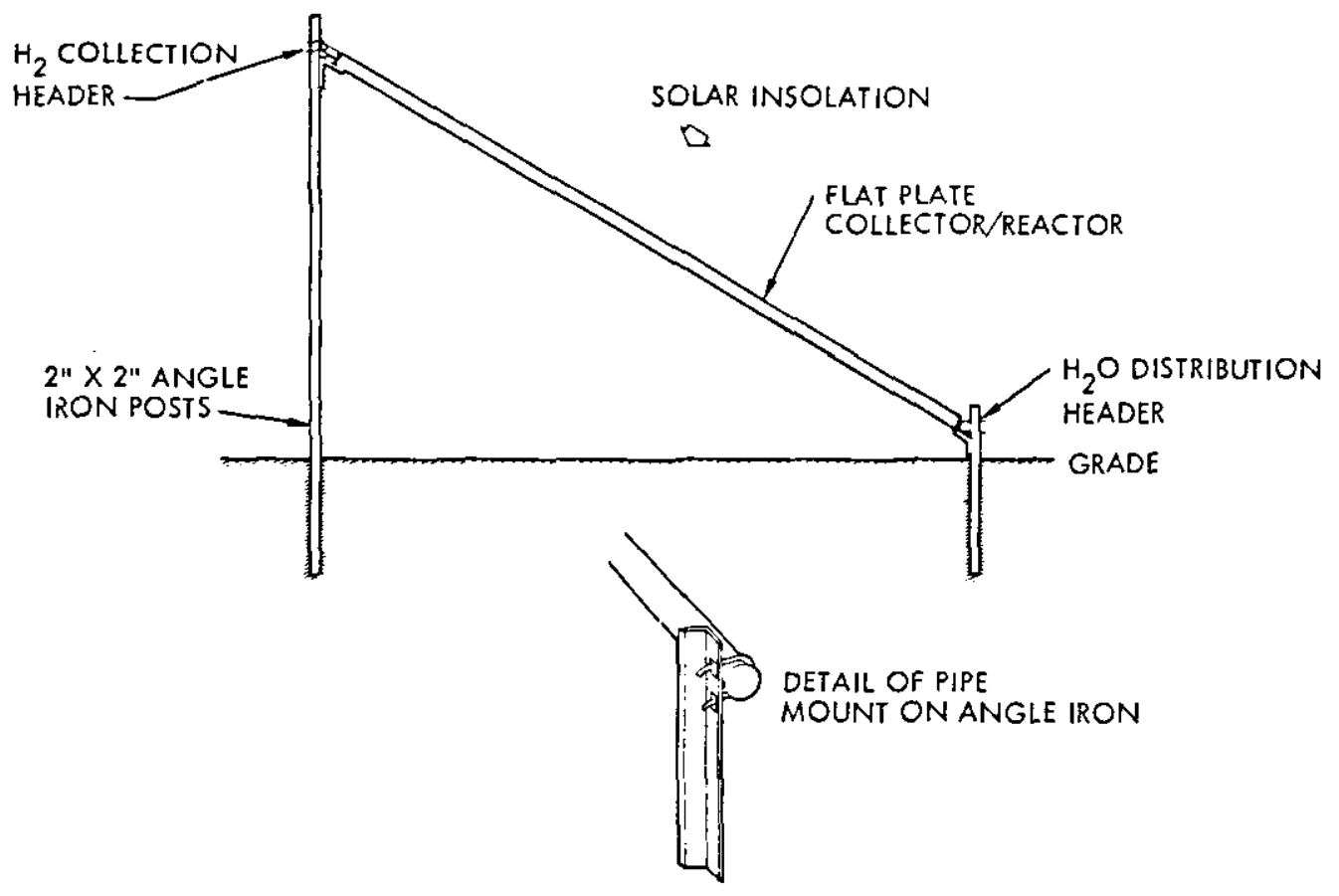

Figure 3-2. Side View of Collector/Reactor Assembly

The collector/reactor units would then be combined together in gangs of 12, giving a module size of $14.63 \mathrm{~m} \times 3.66 \mathrm{~m}(48 \times 12 \mathrm{ft})$. The size of this module was rather arbitrary, but it was thought to be a reasonable size for field fabrication. Field piping connections are shown in Figure 3-3. Both gas and liquid piping would be uninsulated and there would be no need for expansion joints or loops. Figure 3-4 shows the field layout and piping connections for $1 / 8$ of the field. The total field is shown in Figure 3-5. Water for the reactor is pumped from the central site and dihydrogen gas is returned to the central site for distribution. The transport piping used for the fleld is schedule 40 carbon steel piping. Labor-saving pipe construction techniques are assumed to be used whenever possible. These techniques include: (1) automated field welding, (2) factory assembly of piping components, and (3) piping supports integrated into collector/reactor supports (Reference 12). Fluid velocities in the water pipes were limited to $4.57 \mathrm{~m} / \mathrm{s}(15 \mathrm{ft} / \mathrm{s})$. Those in the dihydrogen pipes were limited to $30.5 \mathrm{~m} / \mathrm{s}(100 \mathrm{ft} / \mathrm{s})$. Field piping sizes ranged from nominal values of 0.95 to $7.62 \mathrm{~cm}(3 / 8$ to 3 in.) with $88 \%$ of the plping being $0.95 \mathrm{~cm}(3 / 8 \mathrm{in}$.) size. The central location for the collection of the dihydrogen gas from the field includes a compressor station to compress the gas from approximately 1 to $50 \mathrm{~atm}$, which is the typical pressure for plpleline gas transmission. The total fleld area for the 25,000 scmd plant is about $3.08 \times 1 \mathrm{~m}^{2}$ (83 acres). This includes collector/reactor area, maintenance corridor area, and field perimeter area. 


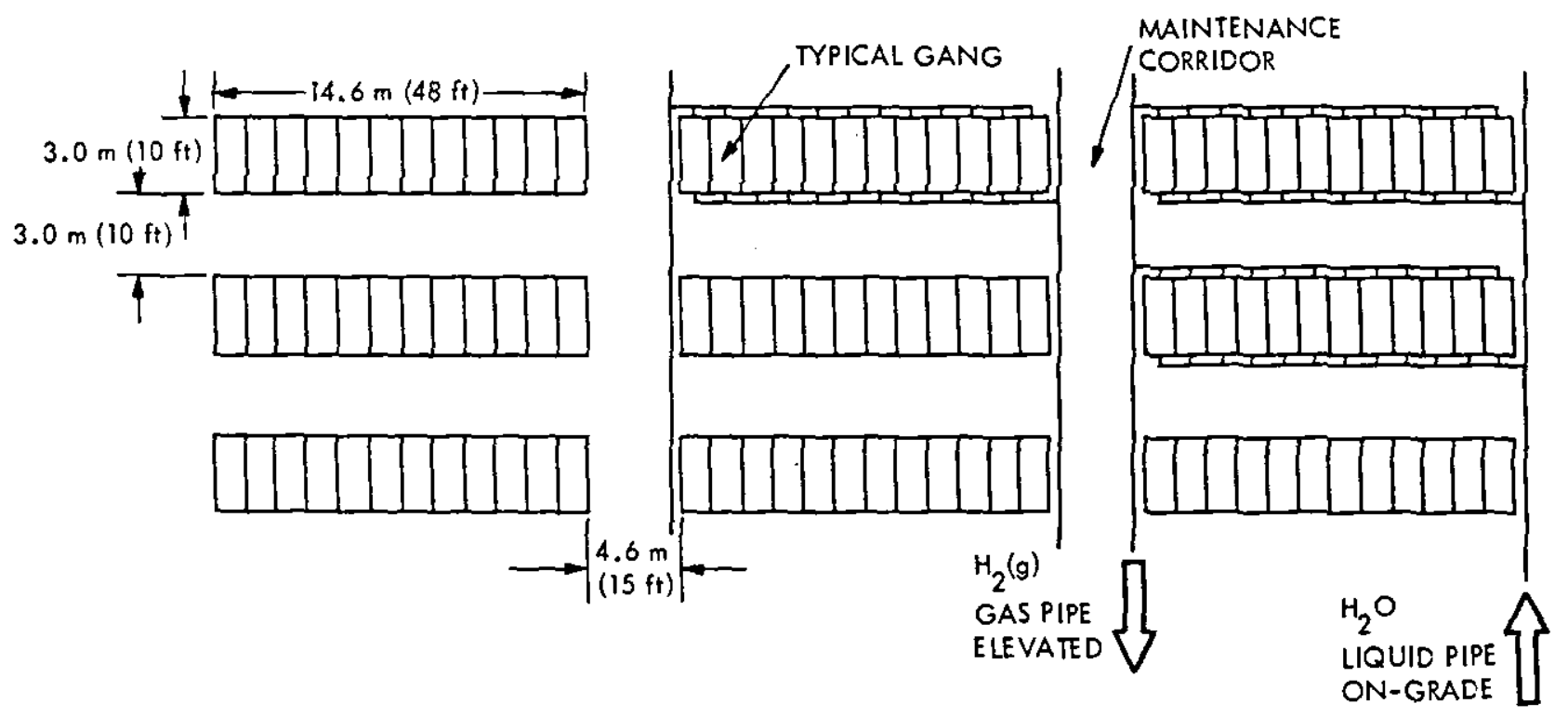

Figure 3-3. Detail of Flat-Plate System Layout

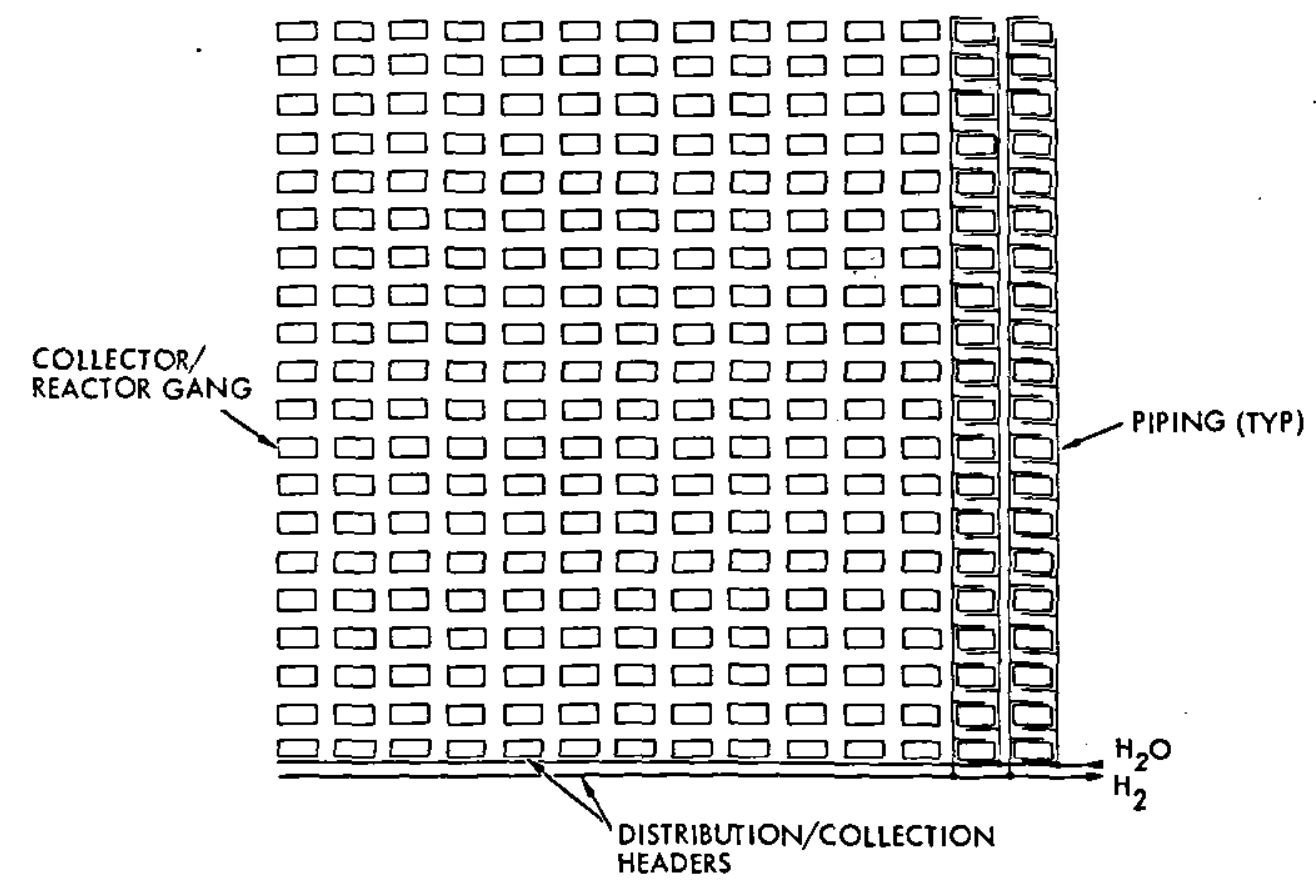

Figure 3-4. Flat-Plate Field Layout Showing Piping Connections 


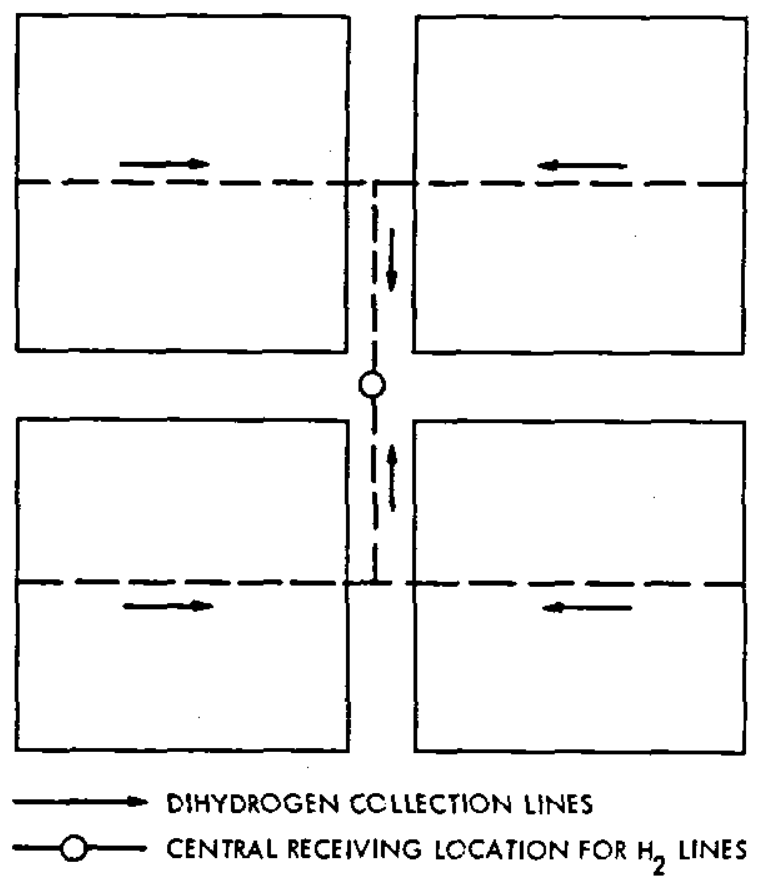

Figure 3-5. Plant Layout for Baseline Flat-Plate System

Subsystem capital costs for the $25,000 \mathrm{scmd}$ plant are given in Figure $3-6$ and Table 3-2 and 1nclude: (1) collector/reactor, (2) plping and collector support, (3) field pip1ng, (4) gas compression, and (5) balance of plant (BOP). The total is $\$ 19,454,000$, with the collector/reactor and BOP being the major cost subsystems, and support, fleld piping, and gas compression being relatively minor cost subsystems. All costs have been based on 1983 dollars.

A breakdown of the BOP costs is given in Table 3-3. Site preparation includes items such as land, surveying and grading. Construction includes items such as architects and engineers (A\&E) fees, construction management fees, and contingencies. Plant faclities include bulldings, roads, parking lots and fencing. Plant equipment includes vehicles, collector washing equipment, and spares. Obviously, any attempt to reduce plant capital costs should focus on the collector/reactor subsysten. A reduction in this subsystem cost will also be reflected in lower BOP costs.

These capital costs were translated into energy costs using an economics model widely used in solar energy studles (Reference 13). Fixed charge rates of 0.20 and 0.30 were used, and operating and maintenance was assumed to be $2 \%$ of the plant capital cost. The fixed charge rate of 0.20 is typlcal of utility Industry economics, and 0.30 typical of chemical industry economics. A photochemical fuel-producing plant will use a fixed charge rate in this ange. These energy costs were then plotted as a function of the overall system efficiency 


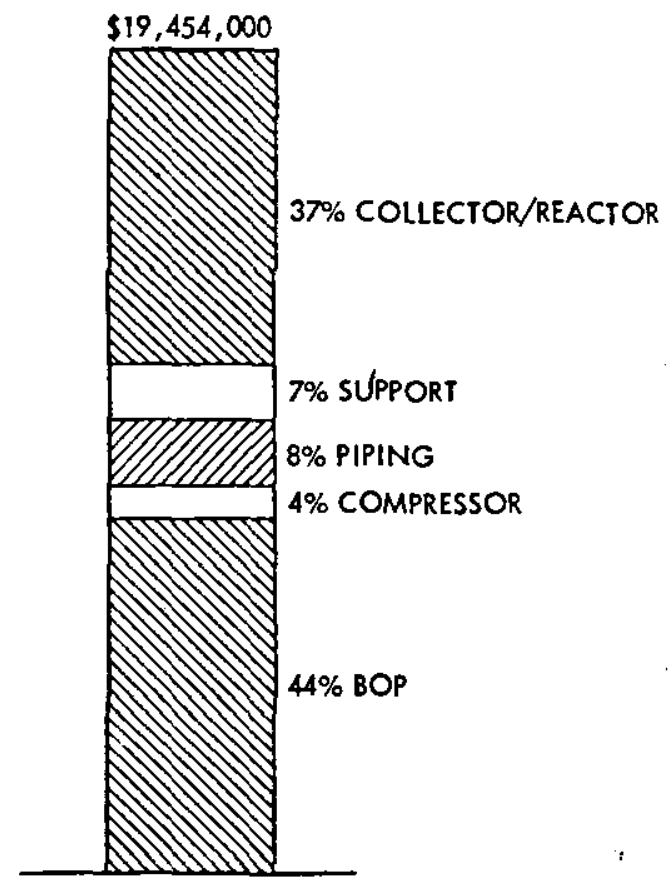

Figure 3-6. Capital Cost Breakdown for Baseline Flat-Plate System

Table 3-2. Capital Cost Breakdown for Basellne Flat-Plate System

\begin{tabular}{lc} 
Subsystem & Cost, $\$ \times 10^{3}$ \\
\hline Collector/React or & 7,096 \\
Piping and Collector Support & 1,305 \\
Field Piping & 1,483 \\
Gas Compression & 1,160 \\
Balance of Plant & 8,410 \\
Total & 19,454 \\
\hline
\end{tabular}


Table 3-3. Balance-of-Plant Cost Summary for Flat-Plate System

\begin{tabular}{cc}
\hline \multicolumn{1}{c}{ Item } & Cost, $\$ \times 10^{3}$ \\
\hline Site Preparation & 3,289 \\
Construction & 4,399 \\
Plant Facilities & 181 \\
Plant Equipment & $\frac{542}{8,411}$ \\
Total
\end{tabular}

as shown in Figure 3-7. For the baseline case of $10.3 \%$, overall efficiency, the energy cost ranges from $\$ 34$ to $\$ 56 / 10^{6} \mathrm{~kJ}$ ( $\$ 36$ to $\$ 59 / 10^{6} \mathrm{Btu}$ ) for fixed charge rates from 0.20 to $0.30 \%$, respectively. It can be seen that economic viabil1ty of these flat-plate systems would require a substantial improvement in photocherical conversion efficiencles over the baseline efficiency used in this study. The overall plant efflclency, based on a limiting thermodynamic efficiency of $31 \%$ for a single photon process (see Section II-D-1), is Jimited to about $25 \%$. At this efficiency, energy costs are reduced to $\$ 15$ to $\$ 23 / 10^{6} \mathrm{~kJ}$ ( $\$ 16$ to $\$ 24 / 106 \mathrm{Btu}$ ) for fixed charge rates of from 20 to $30 \%$, respectively. Cosis can also be reduced by finding a lower cost substitute for the collector/ roictor design. One possibility is the use of an inexpensive plastic glazing in place of the glass used in the baseline collector/reactor. If a plastic glazing can be obtained for $\$ 4.00 / \mathrm{m}^{2}$, energy costs for the baseline system would be reduced to $\$ 51 / 106 \mathrm{~kJ}\left(\$ 54 / 10^{6} \mathrm{Btu}\right)$, at a fixed charge rate of $20 \%$, about a $10 \%$ reduction in overall energy costs. Another possibility is to make the baseline system modules in a larger size. Rather than having 12 units, $1.22 \mathrm{~m} \times 3.66 \mathrm{~m}(4 \times 12 \mathrm{ft})$, in a module, it would be less costly to build the tnodule in a $14.63 \times 3.66 \mathrm{~m}(48 \times 12 \mathrm{ft})$ size which would still be highway transportable. Also, it may be worthwhile to determine the engineering feasibilfty of a plastic-lined shallow pond as a low-cost collector/reactor. 


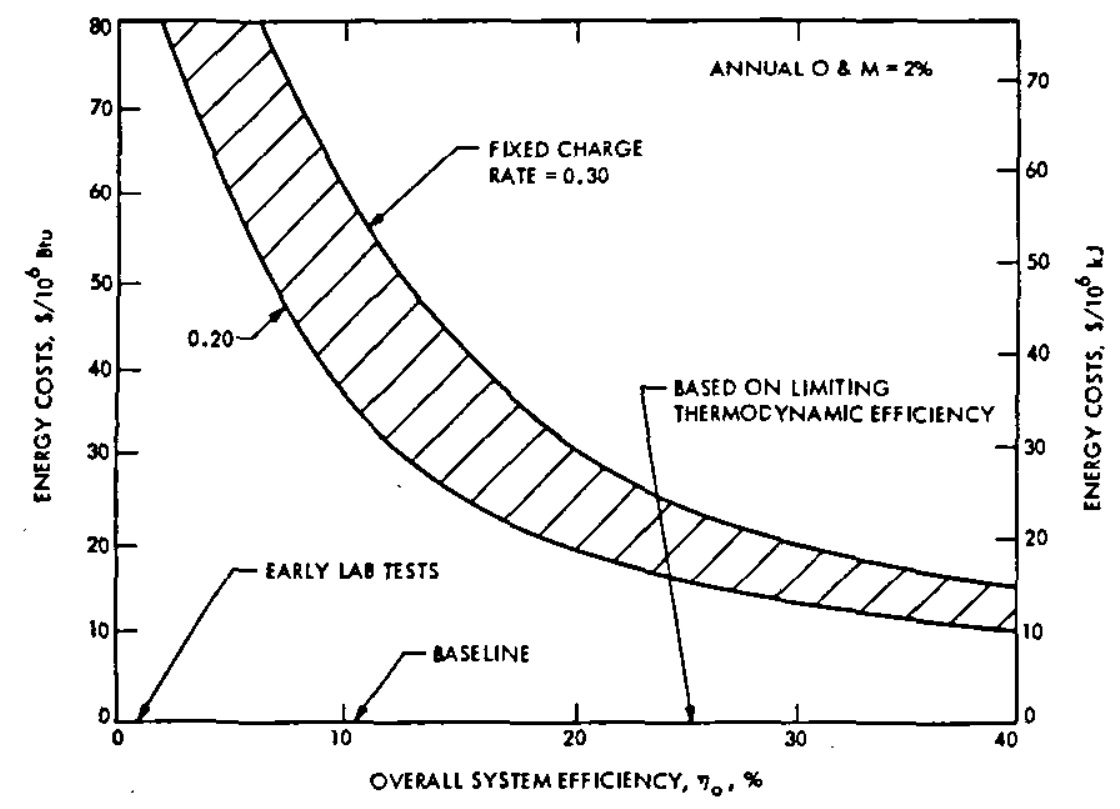

Figure 3-7. Cost of Dihydrogen from the Baseline Flat-Plate System

\section{CONCENTRATING SYSTEM}

Because of the relatively low efficiency of $10 \%$ assumed for the baseline flat-plate system, energy costs are quite high. The low efflclency results in the distribution of collector/reactors over a large area with associated increases In liquid and gas transport piping and BOP items. One method of reducing costs is the use of concentrated solar radiation focused on the reactor. Increasing the concentration while holding the reaction temperature constant increases the limiting thermodynamic efficlency of the quantum conversion process. This promises to reduce the field size and associated piping and BOP costs.

Although the concentration increases the limiting thermodynamic effictency of quantum conversion processes, the higher operating temperatures that could result will decrease the photochemical process efficiency (Figure 3-8). In this study, the reaction temperature resulted from optimizing the overall system efficiency. This optimized temperature was about $30^{\circ} \mathrm{C}$, which requires removing heat by cooling the reactor. The costs of cooling will be reflected in the overall energy costs for this system.

Several concentrating collector types were inftlally identified for the baseline concentrating system. A parabolic trough collector was selected for the baseline case because it has a moderate concentration range and is commercially available. Such a system represents the next major step-up in concentration over the flat-plate system. The major design parameters for the baseline concentrating system are given in Table 3-4 and are contrasted to 


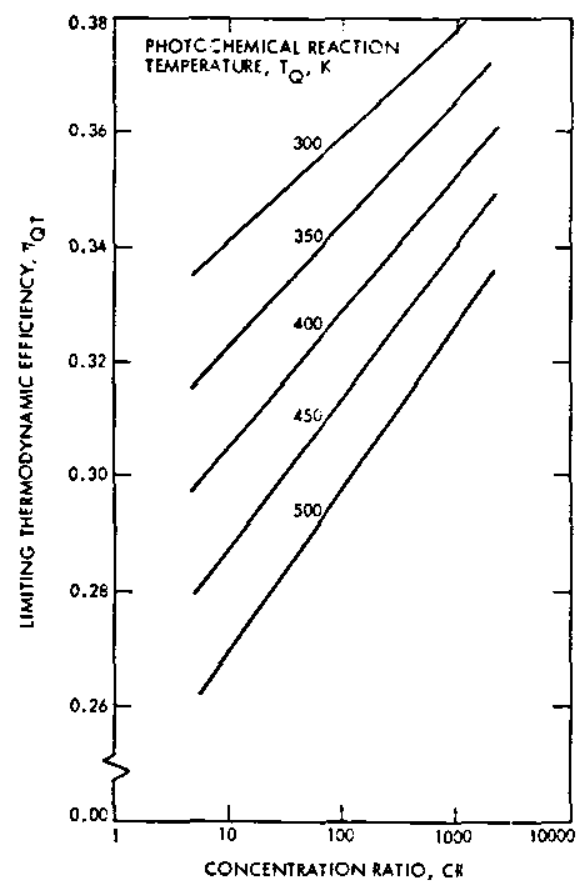

Figure 3-8. Concentration Effect on Limiting Thermodynamic Efficiency

Table 3-4. Comparison of the Baseline Non-Concentrating and Concentrating Systems

\begin{tabular}{|c|c|c|}
\hline Chaiacteristics & Non-Concentrating & Concentrating \\
\hline Feedstock & Water & Water \\
\hline Product Gas & Dihydrogen & Dihydrogen \\
\hline Operating Pressure & 1 atm & 1 atm \\
\hline Operating Temperature & $54^{\circ} \mathrm{C}$ & $29^{\circ} \mathrm{C}$ \\
\hline Nominal Plant S1ze & $25,000 \mathrm{scmd}$ & 25,000 scmd \\
\hline Photochemical Efficiency & $12.9 \%$ & $14.6 \%$ \\
\hline Overall System Efficiency & $10.3 \%$ & $11.6 \%$ \\
\hline Nominal Collector Area & $120,000 \mathrm{~m}^{2}$ & $125,000 \mathrm{~m}^{2}$ \\
\hline Annual Solar Flux & $2430 \mathrm{kWh} / \mathrm{m}^{2} / \mathrm{yr}$ & $2150 \mathrm{kWh} / \mathrm{m}^{2} / \mathrm{yr}$ \\
\hline Concentration Rat1o & 1 & 43 \\
\hline
\end{tabular}


the baseline flat-plate values. The plant output remains at 25,000 scfd of dihydrogen at 50 atm. The parabolic trough collectors had a baseline concentration ratio (CR) of 43 . The overall system efficiency is $11.6 \%$, a $12.6 \%$ increase over the non-concentrating system.

The parabolic trough collector used for a baseline in this study is similar to the one shown in Figure 3-9. The sketch is derived from a commercially available collector (Acurex Solar Model 3011 Concentrating Solar Collector), typical of many available trough-type collectors. The major modification to it would be a redesign of the recelver tube to serve as a photochemical reactor. The glass receiver tube, located at the focal line of the concentrator, contains the photochemical reagents. Concentrated solar energy would drive the photochemistry to produce dihydrogen and dioxygen gas, and the dihydrogen gas would be separated and collected by a fleld piping network. The baseline concentrating trough collector chosen was $6.1 \mathrm{~m}(20 \mathrm{ft}$ ) long with an aperture of $2.1 \mathrm{~m}$ ( $7 \mathrm{ft}$ ) and a rim angle of $9 \mathrm{C}$ deg. As previously mentioned, the concentration of solar energy on the receiver tube will cause the photochemical solution temperature to rise. It has been calculated that, if left uncooled, the photochernical reactor could, theoretically, reach temperatures in excess of $250^{\circ} \mathrm{C}\left(482^{\circ} \mathrm{F}\right)$. For this case of a bare glass recelver, the incident solar energy distribution is shown in Figure 3-10 (for a 1-in. photochemical layer). Of the incident solar flux, $10.4 \%$ is converted to chemical energy as dihydrogen, $30.5 \%$ is transmitted through the solution, and $59.1 \%$ is converted to thermal energy, which heats the water.

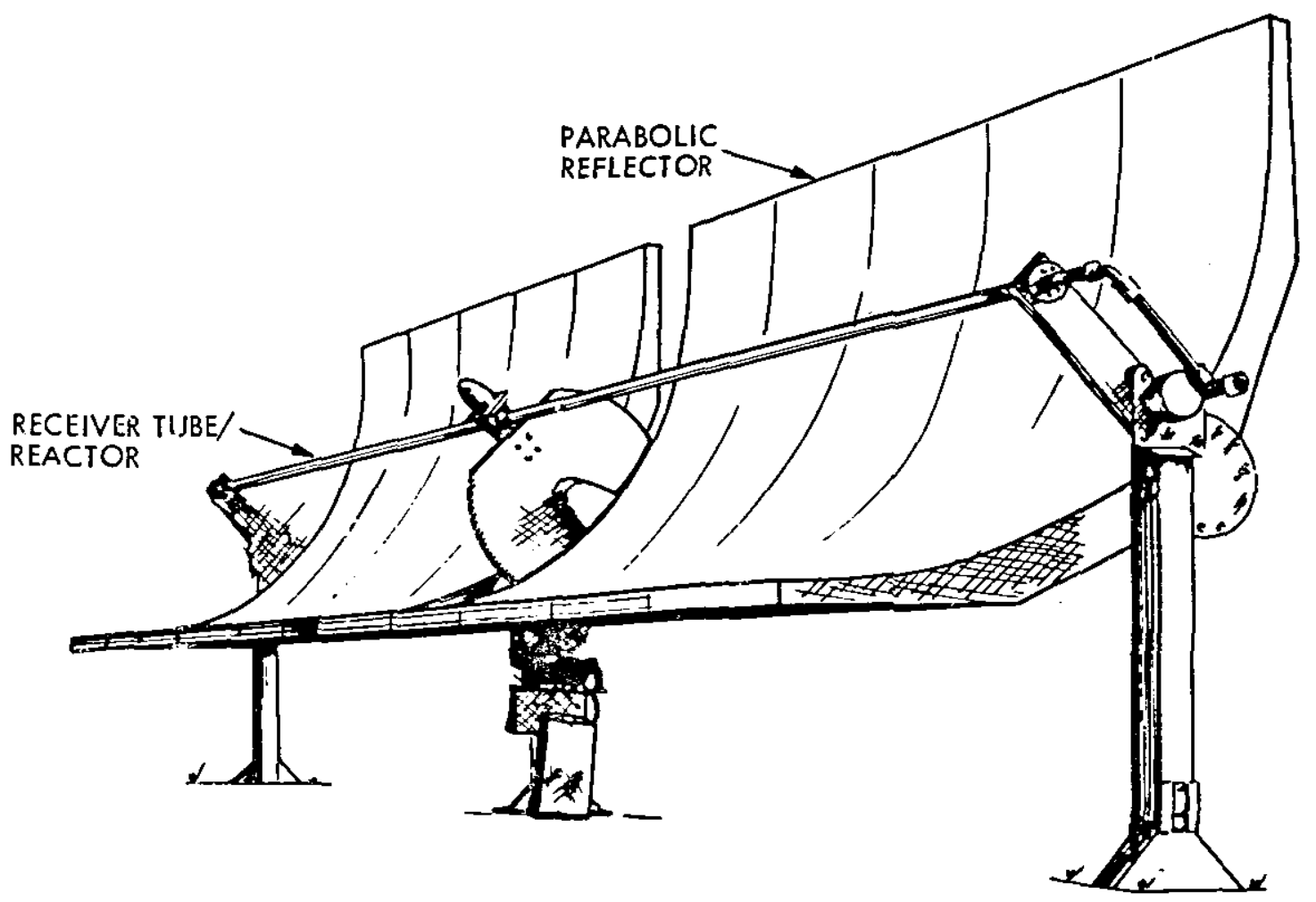

Figure 3-9. Parabolic Trough Collector/Reactor 


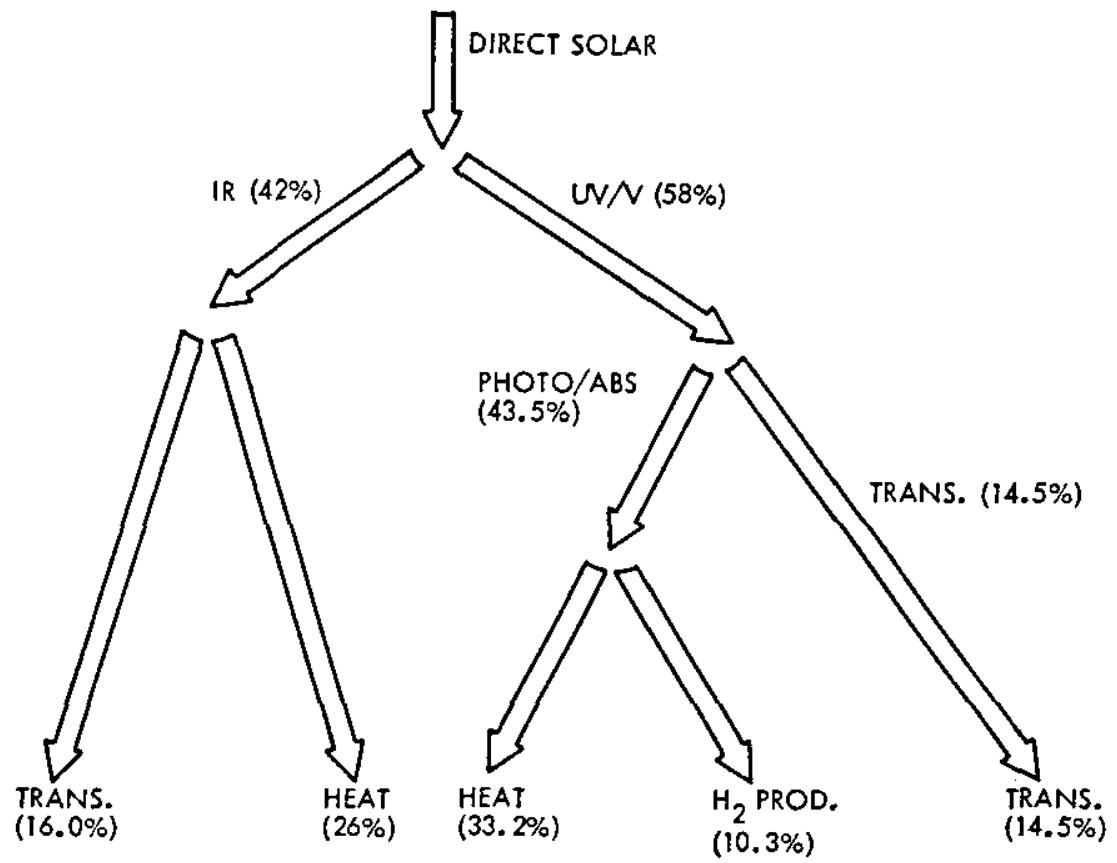

Figure 3-10. Bare Glass Receiver Solar Energy Distribution

Two methods of cooling the photochemical layer were considered. First, as noted in Figure $3-10,42 \%$ of the incident solar flux is in the infrared (IR) region. This radiation is not used in the photochemical process but does add considerably to the heat load. The use of exterior filters (or reflective coatings) on the glass receiver tube could reduce the IR load on the recelver and possibly eliminate or substantially reduce the need for act ive cooling. A commercially avallable IR reflective coating was found which exhibits relatively high transmission (78\%) in the vistble and high reflectivity in the IR region ( $90 \%$ reflectance for wavelengths greater than $2 \mu \mathrm{m}$ ). It is manufactured by Liberty Mirror and is expected to cost two to three times as much as uncoated glass. The solar energy distribution for this case is shown in Figure 3-11. About one half of the Incident flux is reflected and the thermal load is decreased by about $50 \%$, but the dihydrogen produced is also decreased by $38 \%$. This reduction in dihydrogen output, coupled with greater costs, makes the use of this IR reflective coating economically unattractive.

The second type of system studied for temperature reduction of the photochemlcal layer was an active cooling method using water as the coolant. A cylindrical recelver geometry of two concentric tubes has been assumed for the parabolic trough collector. Two different arrangements are possible. The first possibility is to place the photochemical solution in the inner tube surrounded by the coolant fluid in the annular region. This will be called front-side cooling. It has been determined that a thin layer, $1.27 \mathrm{~cm}(1 / 2 \mathrm{in.})$ or less, of water will provide conslderable filtration (about $50 \%$ ) of the IR radiation in the solar spectrum and also carry of $f$ heat from the thermal $10 \%$ ! on the 


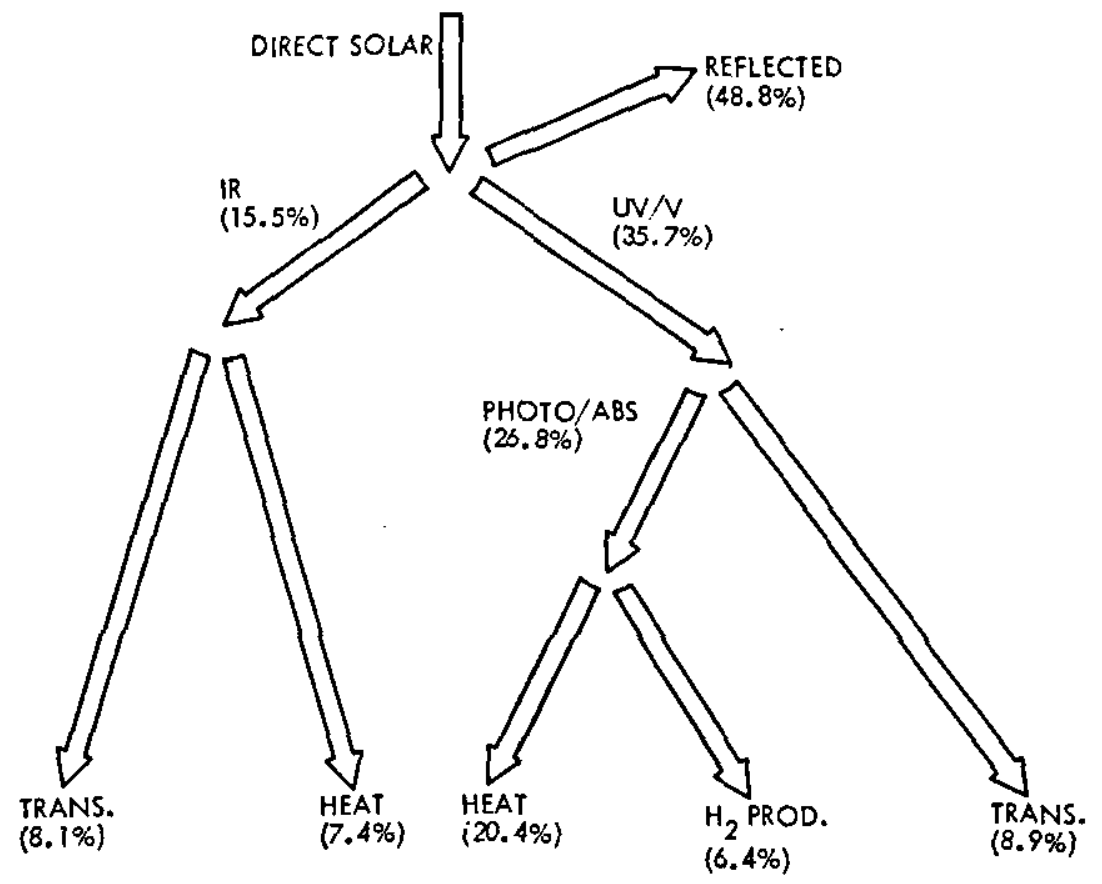

Figure 3-11. Gold Filter Receiver Solar Energy Distribution

photochemical solution. Figure 3-12 shows the energy distribution with frontside cooling. The water filter layer now directly removes part of the thermal load but the overall thermal load on the recelver is not substantially different. Therefore, the main function of the water filter layer is to actively remove heat from the system and thereby provide temperature control.

The second possibility for active cooling is to place the water coolant in the inner tube, or core region, whlle the photochemical layer is located in the annular region. This will be called core cooling. Figure 3-13 shows the energy distribution with a core-cooled reactor. Thermal loads are essentially identical for core and front-side cooling because the total water coolant and photochemical solution thicknesses remain the same. However, thermal loads in the two zones are different. From the analyses of thermal loads to be removed, there would seem to be no major differences between the front-side cooling and core cooling. The deciding factors may be product gas separation design considerations and/or second order photochemical effects. These factors were not considered in this study. The results of these energy distribution studies served as input to the following work involving optimization of overall system efficiency.

The two types of receiver designs (front cooled and core cooled) were then analyzed to determine the sensitivity of the overall system efficiency to concentration ratio. Overall efficiency includes photochemical efficiency as well as coolant pumping penalty. As the photochemical reaction temperature is reduced by cooling, the photochemical efficiency is increased. However, the 


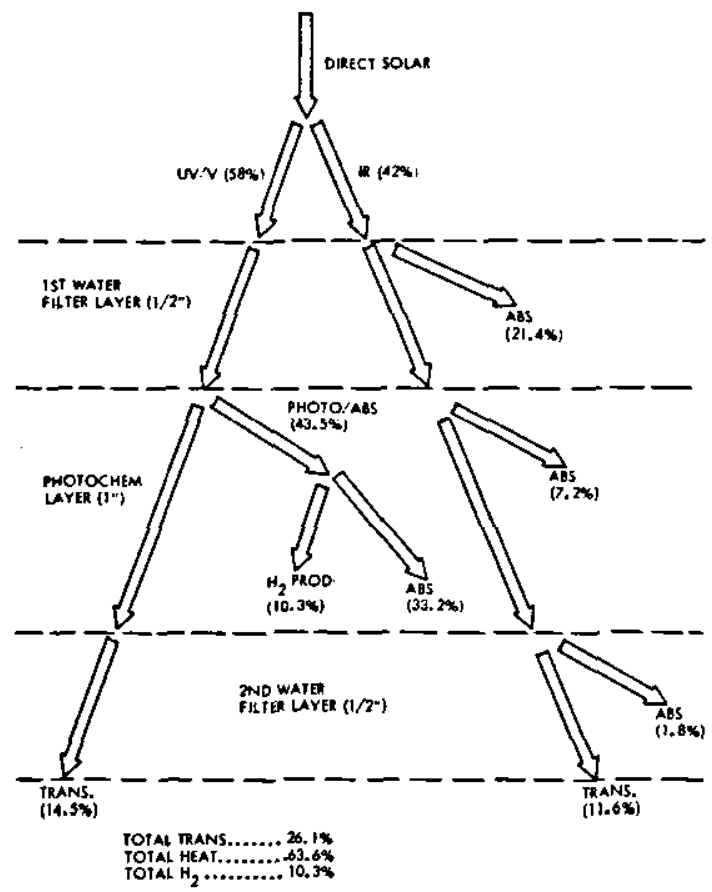

Figure 3-12. Front Side Cooled Recelver Solar Energy Distribution

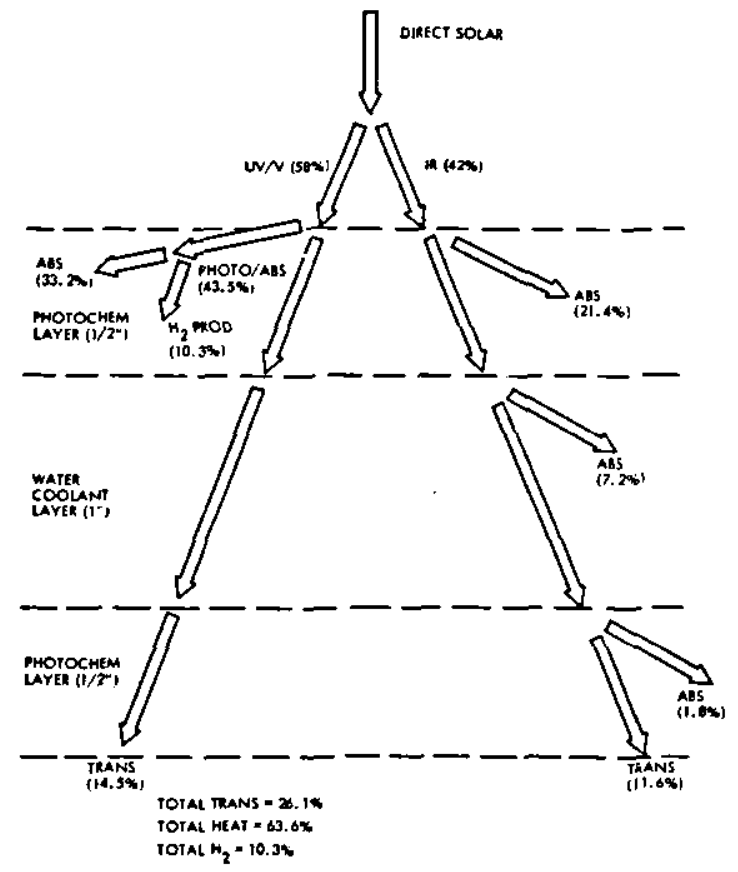

Figure 3-13. Core Cooled Recelver Solar Energy Distribution 
active cooling requires pumping power, which reduces the overall system eff1ciency. For this study, the overall system efficiency is defined as the product of the actual photochemical $\left(\eta_{Q}\right)$ compression $\left(\eta_{c}\right)$, pumping $\left(\eta_{\mathrm{pu}}\right)$, collector $\left(\eta_{\mathrm{co}}\right)$, and separation efficiencies $\left(\eta_{s}\right)$ :

$$
\eta_{\mathrm{o}}=\eta_{\mathrm{Q}} \quad \eta_{\mathrm{c}} \eta_{\mathrm{pu}} \eta_{\mathrm{s}} \eta_{\mathrm{co}}
$$

For the $25,000 \mathrm{scmd}$ baseline plant, the product $\eta_{\mathrm{c}} \eta_{\mathrm{s}}$ has been calculated to be 0.80 . The interaction between coolant pumping requirements and photochemical operating temperature indicated the possibility of an optimum coolant flow rate to maximize the overall efflclency. This effect was studied for several recelver/concentrator geometrles.

Table 3-5 shows the geometries studied. Case 1 geometries are front-side cooled with an outside glass tube dfameter of $5.1 \mathrm{~cm}(2 \mathrm{1n.})$ and an $1 \mathrm{nside}$ glass tube diameter of $3.2 \mathrm{~cm}(1-1 / 4 \mathrm{ln}$.$) . All glass tubing 1 \mathrm{~s}$ assumed to be $0.24 \mathrm{~cm}(3 / 32 \mathrm{in.})$ thj.ck. The aperture is then varied from 2.1 to $3.4 \mathrm{~m}$ ( 7 to $11 \mathrm{ft}$ ) to produce concentration ratios ranging from 42.8 to 67.2 . Case 2 geometries are core-side cooled with an aperture held at $2.1 \mathrm{~m}(7 \mathrm{ft})$. The concentric recelver tube geometries were then varied to produce concentration ratios from 40.0 to 77.5 .

\begin{tabular}{|c|c|c|c|c|c|c|c|}
\hline \multicolumn{8}{|c|}{$\begin{array}{l}\text { FRONI SIOE COOLED GEOMETRIES } \\
\text { (APERTURE VARIATIONS) }\end{array}$} \\
\hline \multirow{2}{*}{$\begin{array}{l}\text { CASE } \\
\text { NO. }\end{array}$} & \multicolumn{2}{|c|}{0} & \multicolumn{2}{|c|}{$\bar{b}$} & \multicolumn{2}{|c|}{ c } & \multirow{2}{*}{$C_{R}$} \\
\hline & con. & $\overrightarrow{\text { ir. }}$ & $\infty$ & in. & $m$ & 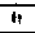 & \\
\hline 1,0$)$ & 5.06 & 2 & 3.18 & $|11 / 4|$ & 2.13 & 7 & 42.8 \\
\hline $1(b)$ & 5.08 & 2 & 3.18 & $11 / 4$ & 2.74 & 9 & 55.0 \\
\hline$\{(t\}$ & 5.08 & 2 & 3. 18 & $11 / 4$ & 3.35 & 11 & 67.2 \\
\hline
\end{tabular}

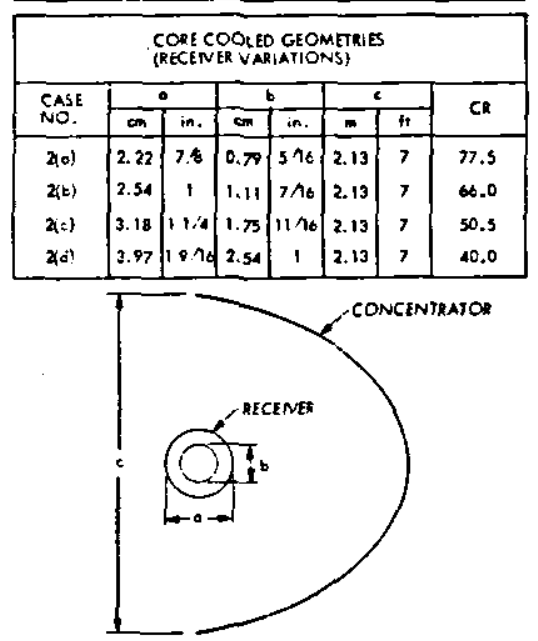

Figure 3-14. Concentrator/Receiver Ceometries 
For Case $2(c)$, the ef fect of varying coolant mass flow $r$ ate on the reaction temperature and efficiency is shown in Figure 3-14. These are typical of the results for all other geometrles studied. The peak efficiency, considering both the photochemical and pumping efficiency, is identified with a specific photochemical operating temperature and an average coolant flow velocity. The pumping power required was based on a $10.4 \%$ overall plant efficiency. It is interesting to note that, for all cases studied, the photochemical operating temperature for maximum overall efficiency was between 29 and $35^{\circ} \mathrm{C}$, slightly above ambient, requiring relatively high coolant mass flow rates. For real systems, it seems possible that operating temperatures of about $60^{\circ} \mathrm{C}$ may lead to higher effictencles (see Section V-B). This baseline concentrating system 1ncludes a coolant return loop located in back of the concentrating collector. The return loop has a heat exchange device for dissipating the thermal energy removed from the photochemical reactor. The optimized overall efficiencies are shown as a function of concentration ratio for Case 1 and Case 2 geometries in Figures 3-15 and 3-16, respectively. Three curves are shown on each graph. The upper curve is based on the limiting thermodynamic efficiency for solar quantum converters, and the baseline curve on the assumed baseline efficiency of $14.6 \%$ at a CR of 40 . The lowest curve is extrapolated from non-concentrating efficlencies observed in bench-scale experiments with photochemical water splitting. All three curves are quite flat, indicating a very weak dependence of efficlency on concentration ratio. Theory indicates the possibility of a maximum efficiency at a specific concentration ratio. This is due to the combined effects of temperature and concentration upon the limiting thermodynamic efficiency of quantum conversion

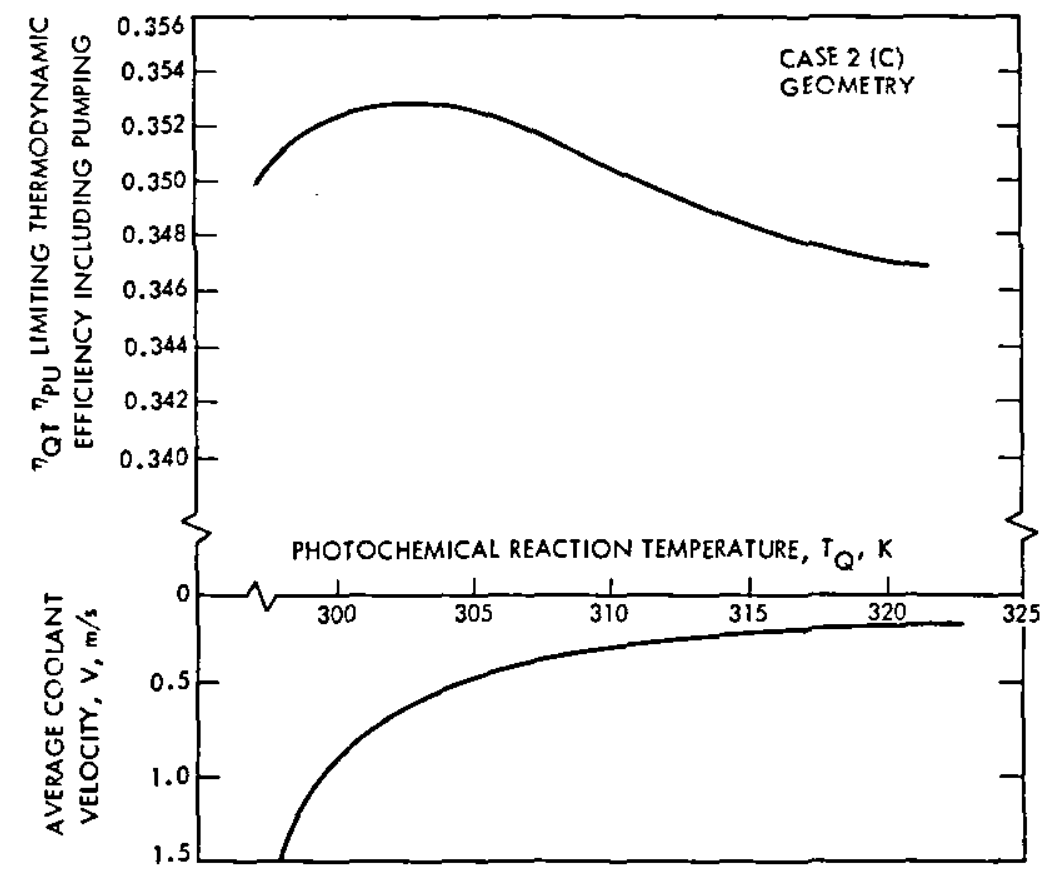

Figure 3-15. Effect of Coolant Flow Rate on Efficlency 


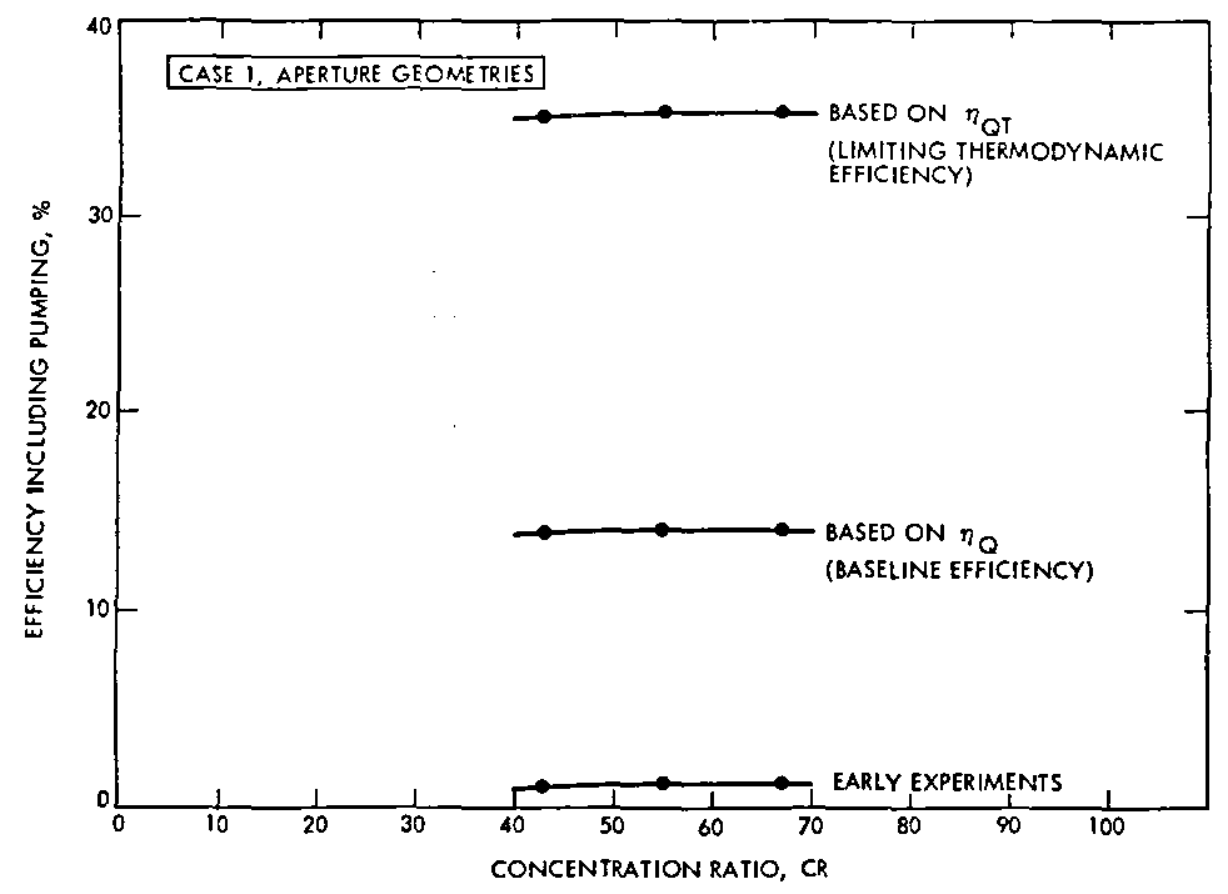

Figure 3-16. Effect of Concentration on Efficiency (Case 1)

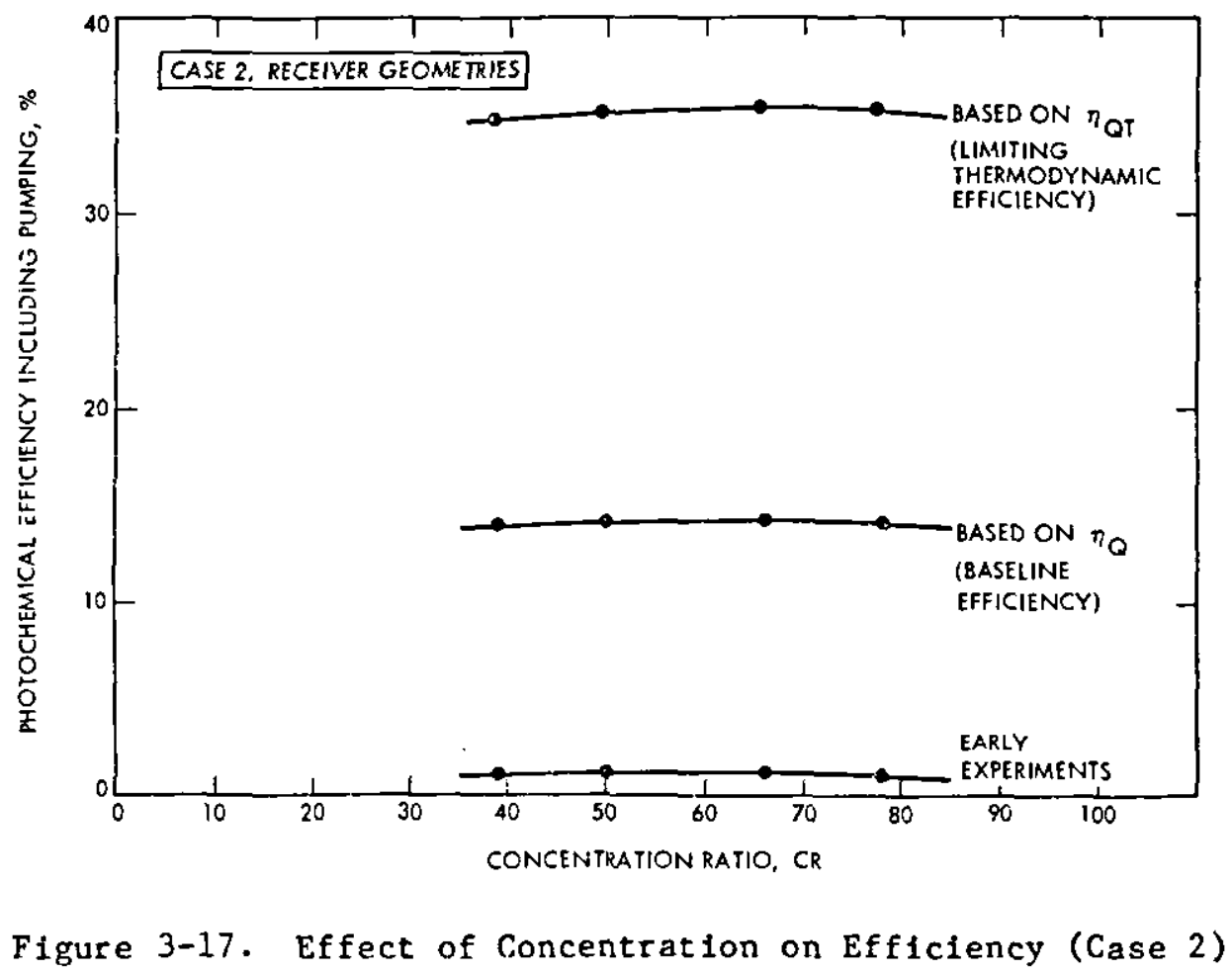


processes and the energy penalty associated with active cooling. As the concentration ratio increases, the photochemical efficlency increases; the operating temperature also increases, reducing the limiting photochemical efficiency. Active cooling reduces operating temperature, thereby increasing the photochemical and overall efficlency for a small pumping penalty. As the concentration ratio increases, the pumping penalty increases considerably causing a decrease in the overall system efficiency. Although not pronounced, a very small maximum is observed in Figures $3-15$ and 3-16. The major conclusion remains that overall system efficiency is not significantly dependent on the concentration ratio over the range of CRs studied.

Based upon these observations, the baseline collector/recelver geometry chosen was Case $1(a)$. This was a $5.1-\mathrm{cm}\left(2-1 \mathrm{n}_{\cdot}\right)$ glass tube concentric with a 2.5-cm (1-in.) tube with front-side cooling and a 2.1-m (7-ft) aperture, giving a concentration ratio of 42.8 . The concentration ratio (CR) is defined as:

$$
C R=\frac{\text { receiver illuminated area }}{\text { aperture area }}
$$

This geometry is quite similar to the commercially avallable parabolic trough collectors (see Figure 3-9) which have a concentration ratio of 43 . Modificarions include: (1) the design of the recelver tube which now must serve as the photochemlcal reactor and coolant channel, and (2) the addition of a heat rejection loop on the back side of the trough. The estimated costs for the collector/ reactor subsystem are shown in Table 3-6.

These costs reflect large volume purchases of equipment. The coolant loop costs include flex hose attachments at the ends of the recelver tube, return plping on the back of the trough and a forced alr/water heat exchanger for heat rejection. These costs have been determined assuming that four $6.1-\mathrm{m}(20-\mathrm{ft})-$ long collector units are coupled in series forming a $24.4 \mathrm{~mm}$ ( $80-\mathrm{ft}$ )-long module or string. The parabolic trough strings were laid out in an east-west field orientation, as shown in Figure 3-17. Dimensions for maintenance corridors were chosen to be simflar to those of the flat-plate (non-concentrating) fleld. Figure 3-18 shows a typical $1 / 8$ fleld layout for troughs and piping. The piping includes water supply for the photochemical reactor and dihydrogen gas return to a central site for compression and preparation for pipeline transport. All plping is uninsulated and on grade. The pipe specifled is carbon steel, schedule 40. Labor-saving pipe construction techniques are used whenever possible. The field piping for transport is between $0.95 \mathrm{~cm}$ and $10.2 \mathrm{~cm}(3 / 81 \mathrm{n}$. and $4 \mathrm{in.})$, with $64 \%$ being $0.95 \mathrm{~cm}(3 / 8 \mathrm{in.})$. 
A. Concentrating Collector/Reactor

\begin{tabular}{c|c|c}
\multicolumn{2}{c|}{ Description } & \multicolumn{2}{|c}{ Costs } \\
\cline { 2 - 3 } & $\$ / \mathrm{m}^{2}$ & $\$ / \mathrm{ft}^{2}$ \\
\hline $\begin{array}{l}\text { Uninstalled } \\
\text { Installation on Concrete Pad } \\
\text { Total Installed Cost Without } \\
\text { Receiver }\end{array}$ & 161.00 & 15.00 \\
Receiver Tube & 215.00 & 5.00 \\
Total Installed Cost With Receiver & 24.00 \\
\hline
\end{tabular}

B. Coolant Loop Costs

\begin{tabular}{|c|c|c|c|c|c|}
\hline \multirow{2}{*}{ Description } & \multicolumn{2}{|c|}{ Unit Cost } & \multicolumn{2}{|c|}{ Length } & \multirow[b]{2}{*}{ S/module } \\
\hline & $\$ / \mathrm{m}$ & $\$ / f t$ & m & ft & \\
\hline Flex Hose ( $1 / 2$ in.) & 82.00 & 25.00 & 4.9 & 16 & 400.00 \\
\hline Return Pipe (1/2 in.) & 15.00 & 4.50 & 24.4 & 80 & 360.00 \\
\hline Coolant Heat Exchanger & - & - & - & - & 140.00 \\
\hline Total Cost & & & & & 900.00 \\
\hline
\end{tabular}




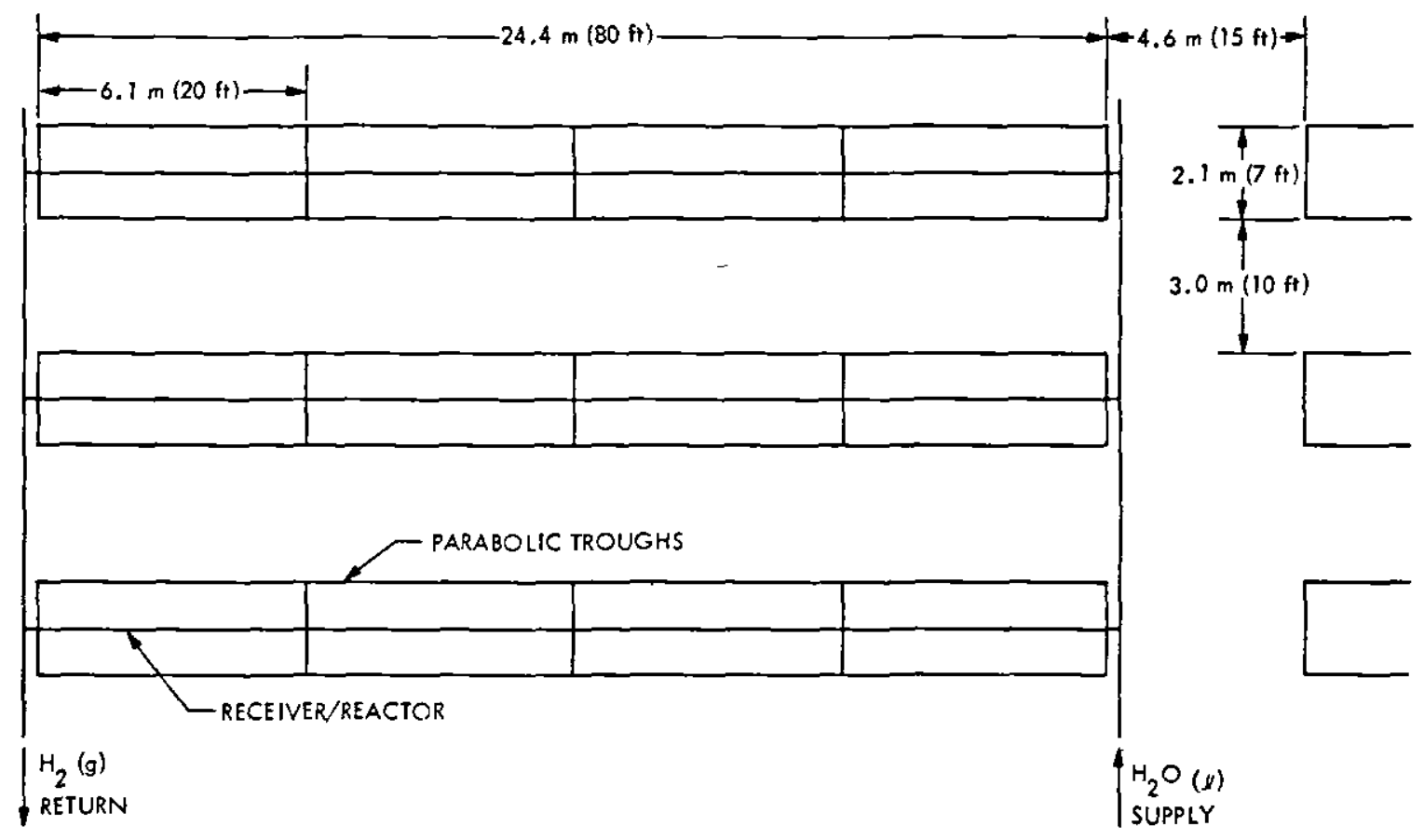

F1gure 3-18. Detail of Concentrating System Layout

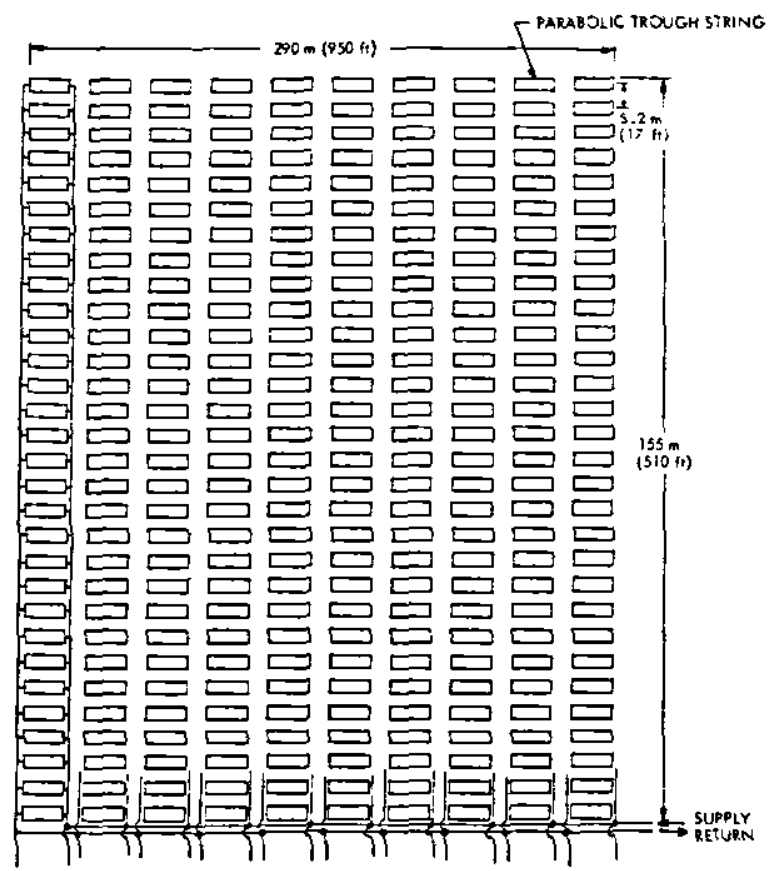

Figure 3-19. Concentrating Field Layout Showing Piping Connections 
A breakdown of BOP items is shown in Table 3-7, including site preparation, construction, plant facilities, and plant equipment. Total system capital costs are $\$ 48,187,000$, as shown in Table 3-8 and Figure 3-19. The dominant cost item for the concentrating system is the collector/reactor costs which account for $64 \%$ of the overall cost. Balance of plant amounts to $28 \%$; coolant equipment, fleld piping and compressors amount to minor percentages. Energy costs (using the same economles model used for the baseline non-concentrating system discussed previously) are given in Figure 3-20 as a function of overall system efficiency.

Table 3-6. Balance-of-Plant Cost Summary for Concentrating System

\begin{tabular}{lc} 
Item & Cost, $\$ \times 10^{3}$ \\
\hline Site Preparation & 3,543 \\
Construction & 9,376 \\
Plant Facilities & 185 \\
Plant Equipment & 542 \\
Total & 13,646 \\
\hline
\end{tabular}

Table 3-7. Cap1tal Cost Breakdown for Concentrating System

\begin{tabular}{lc} 
Subsystem & Cost, $\$ \times 10^{3}$ \\
\hline Collector/React or & 30,658 \\
Coolant Equipment & 2,170 \\
Field Piping & 553 \\
Gas Compressors & 1,160 \\
Balance of Plant & 13,646 \\
Total & 48,187 \\
\hline
\end{tabular}




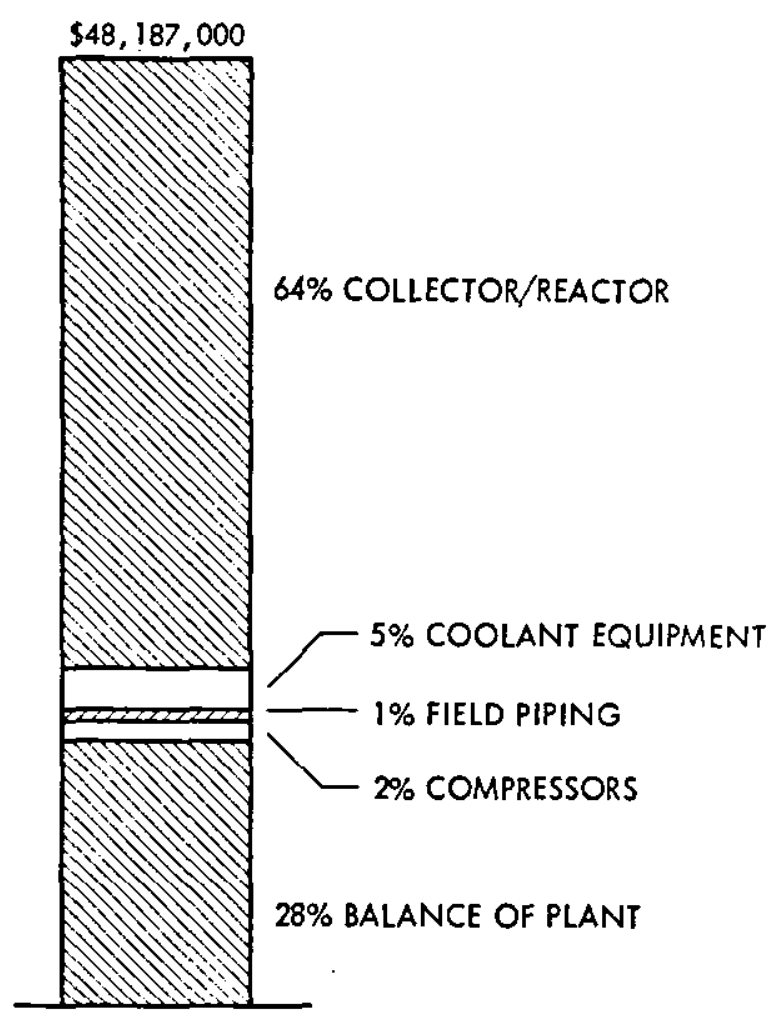

Figure 3-20. Capital Cost Breakdown for Concentrating System

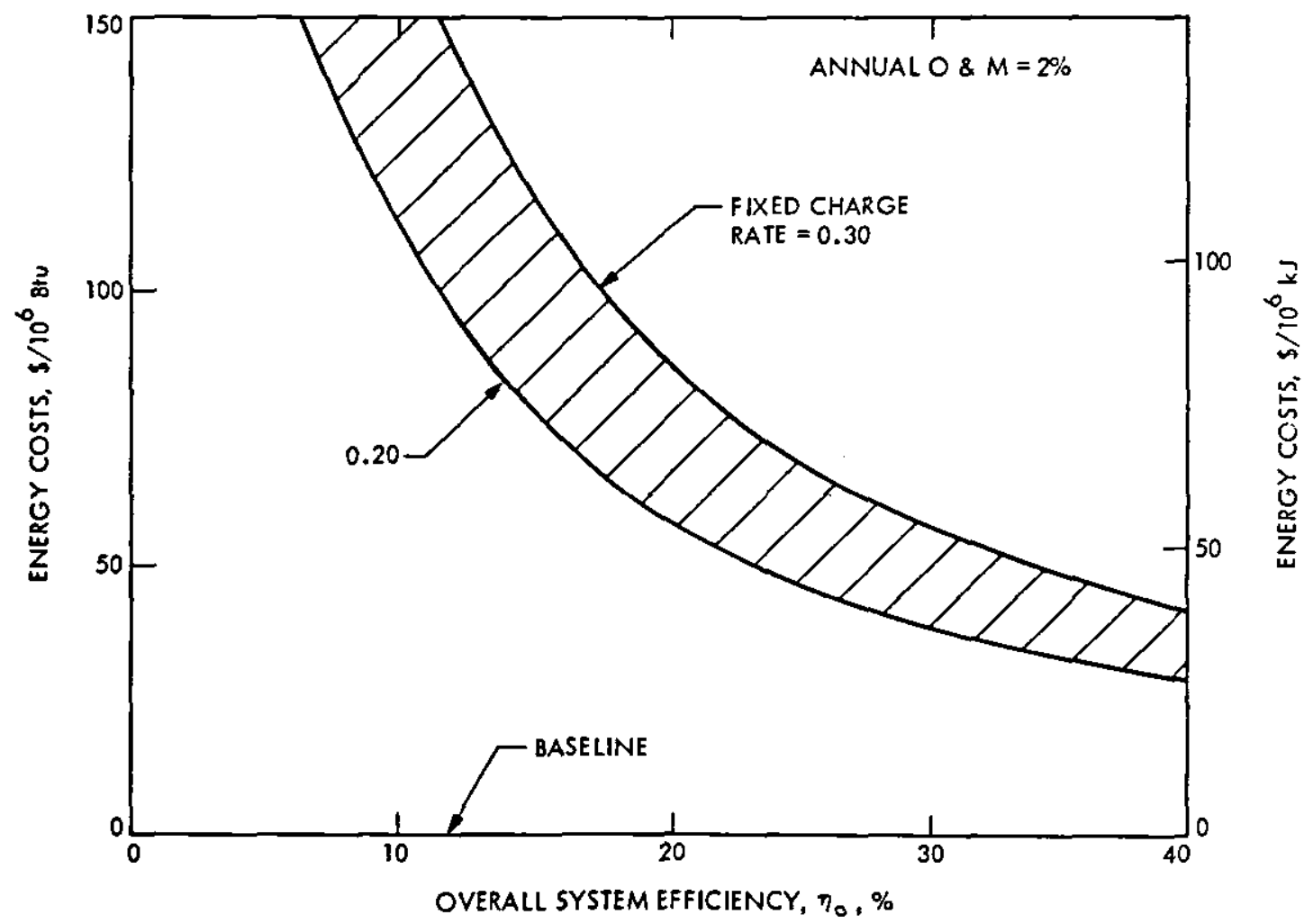

Figure 3-21. Cost of Dihydrogen from the Baseline Concentrating System 
Comparison with the flat-plate system (see Figure 3-7) shows that, for the baseline concentrating system chosen, energy costs are two to three times those for the non-concentrating system, depending on the fixed charge rate used. For the baseline system overall efficiency of $11.6 \%$, the energy cost would be from $\$ 94$ to $\$ 141 / 10^{6} \mathrm{~kJ}$ ( $\$ 99$ to $\$ 149 / 10^{6} \mathrm{Btu}$ ). This dramatic difference in energy costs can almost completely be attributed to the higher cost for the collection system (the tracking parabolic trough collectors). Any small advantage gained in the photochemical efficiency due to increased concentration is lost because of much higher costs for collection and lower annual energy collection because concentrating systems do not use the diffuse component of the insolation.

The basic problem is that the baseline commercially avallable parabolic trough chosen is a sophisticated device designed to produce high temperatures. However, in photochemical applications, the refined optics and sophistication to produce such high temperatures are counterproductive. It may prove better to employ a less optically sophisticated design using less costly materials. However, lowering the costs of the collector/receiver to a level competitive with non-concentrating systems may prove to be very difficult.

\section{SYSTEMS COMPARISONS}

System comparisons are discussed below:

(1) The baseline collector/reactor designs used, which are based on conventional equipment and technologies, are costly and alternate designs should be investigated. It should be noted that the energy cost projections presented are optimistic since no incremental reactor costs have been included for photochemical reagents or separation of product gases. Also, $\mathrm{H}_{2}$ reactor gas seal problems have been assumed to be solvable without major redesign and a freeze protection system for the photochemical solution in the reactor and distribution pipes was not addressed.

(2) For the baseline system, the overall effect of concentration was detrimental to lowering the energy cost. Two factors played a pivotal role in this. First, the annual solar flux on the concentrating collector is lower berause of its inability to collect diffuse radiation. This effect dominated the slight increase in photochemical efficiency due to increased concentration. Therefore, greater collector area is required for the concentrating system for the same plant output. The second factor is the additional cost of sophisticated tracking collectors with precise optics. These collectors are designed to produce high outlet temperatures. In this study, high concentrations are tesirable but high temperatures are detrimental. If a promising photochemical process is identified which operates more efficiently at higher temperatices, the use of solar concentrators would be more attractive.

(3) Alternative non-concentrating collector/reactor designs should be investigated. As his study showed that the baseline concentrating system was more costly than the flat-plate system, the approach of a very simply constructed non-concentrating system may be economically 
more attractive. Possibilities include a lined shallow pond reactor, and/or the use of a low-cost substitute for glass ( $32 \%$ of baseline collector/reactor cost), or the use of larger collector/reactor module sizes. The pond reactor may also provide a solution for the freeze protection problem of the reactor and fleld piping.

(4) Alternative concentrating collector/reactor designs should be investigated to better match the photochemical process requirements to the collector/reactor design. For instance, precise optics, which give high operating temperatures, may not be appropriate. The advantages of concentration may be attained with less critical optics, leading to lower collector/reactor subsystem costs. Also, the possibility of concentration without focusing may prove even more cost competitive since both direct and diffuse solar radiation could be used.

(5) For the baseline concentrating system chosen, cooling was necessary to maintain the photochemical reaction temperature such that the overall system efficiency was optimized. The coolant equipment incremental costs were minor, contributing $5 \%$ to the overall energy costs.

(6) Field plping for water and dihydrogen gas does not seem to be a critical cost item in this analysis. Therefore, refined optimization methods applied to this subsystem will not result in substantial improvements in the economics. Also, operating the gas side field piping at higher pressures to reduce the pipe sizes does not seem to be economically attractive because of additional compression costs and incremental costs for reactor redesign for higher pressure containment.

(7) Balance-of-plant 1tems, which are often neglected in solar photochemical process studies, amount to a substantial fraction of the overall system costs (28 to $44 \%$ ). All economlc studies for solar-derived fuels should be based on an accepted BOP methodology.

(8) Alternative photochemical processes, which give a better match with highly concentrating collector features, should continue to be pursued. The use of more costly highly concentrating collectors may be justified if a solar photochemical process that is more efficient at higher solar concentrations and operating temperatures can be found.

(9) The concept of an infrared (IR) reflective coating to reduce the thermal load on the reactor appears promising. However, currently available coatings reflect too much of the useful photochemical spectrum (22\%) and are too costly. Further research for coatings with better optical properties seems warranted.

(10) The baseline concentrating system collector/reactor costs are based, to a large extent, on commerclally avallable equipment giving a high confidence level to the final energy costs. This is not true to the same extent for the baseline flat-plate system costs. These costs were based on available technologies, but extrapolated to the chosen specific photochemical collector/reactor design. 


\section{SECTION IV}

STATE OF THE ART

\section{A. INTRODUCTION}

The current status of fuel-producing photochemical and photoelectrochemical processes is briefly reviewed to provide background and perspective for the study of engineering feasibility that is the focus of this report.

As of this date, research has concentrated almost exclusively on splitting water to produce dihydrogen.

\section{B. HOMOGENEOUS PHOTOCHEMICAL WATER SPLITTING}

\section{Cyclic Photoredox Processes}

These are photochemical processes of the type described in Section II-B. They are cyclic in the sense that all spectes are regenerated, except water and its decomposition products, $\mathrm{H}_{2}$ and $\mathrm{O}_{2}$. Because only a very small fraction $(<<1 \%)$ of solar radiation is at wavelengths short enough to initiate direct photodecomposition of water, a sensitizer is required. The sensitizer is electronically excited by the absorption of solar photons of appropriate energy $\left(E \geq E_{g}\right)$. This excitation energy drives a sequence of reactions that result in the decomposition of water to $\mathrm{H}_{2}$ and $\mathrm{O}_{2}$ via a process that can be described by the following set of reactions:

$$
\begin{aligned}
& 2 \mathrm{~S}+\mathrm{h} \nu \longrightarrow 2 \mathrm{~S} * \quad \text { (excitation) } \\
& 2 S^{*}+20-2 S^{+}+2 Q^{-} \quad \text { (electron transfer) } \\
& 2 \mathrm{~S}^{+}+\mathrm{H}_{2} \mathrm{O} \stackrel{\text { cat. }}{\longrightarrow} 2 \mathrm{~S}+1 / 2 \mathrm{O}_{2}+2 \mathrm{H}^{+} \\
& 2 \mathrm{O}^{-}+2 \mathrm{H}_{2} \mathrm{O} \stackrel{\text { cat. }}{\longrightarrow} 2 \mathrm{O}^{\prime}+\mathrm{H}_{2}+2 \mathrm{H}^{-} \\
& \mathrm{H}_{2} \mathrm{O} \longrightarrow \mathrm{H}_{2}+1 / 2 \mathrm{O}_{2} \text { (net reaction) }
\end{aligned}
$$


Electron transfer may be elther to or from $S^{*}$, depending upon the nature of sensitizer and quencher. These systems are referred to as homogeneous despite the fact that the best catalysts for reactions (4-3) and (4-4) are colloidal dispersions of ruthenium oxide $\left(\mathrm{RuO}_{2}\right)$ and platinum, respectively. They might be more accurately described as homogeneous photoredox reactions coupled to microheterogeneous catalysts.

Complexes of transition metals with appropriate organic ligands, such as the polypyridines, are among the more widely used sensitizers (References 14 through 23). These complexes absorb strongly in the visible to produce electronically excited states which posses favorable lifetimes and redox properties. The most frequently employed sensitizer of this type is tris $\left(2,2^{\prime}\right.$-bipyridine) ruthenium(II) cation, hereafter written as $\mathrm{Ru}$ (bpy) $\frac{2}{3}+$.

Metalloporphyrins (References 24 through 31) and porphyrin derivatives, such as proflavin (References 32 and 33 ) have also been used to photosensitize water splitting, and Gray (References 34 and 35) has employed dinuclear, metal-to-metal bonded bridge compounds.

The viologens, especially methyl viologen, 11 are the most widely used quenchers (References 15 through 23 and 25 through 27).

Cyclic processes of this general type exhibit very low conversion efficiencies. Kalyanasundaram and Grätzel (Reference 15) splft water to $\mathrm{H}_{2}$ and $\mathrm{O}_{2}$ by irradiation of aqueous solution with $\mathrm{Ru}(\mathrm{bpy}) \mathrm{H}_{3}^{2+}$ as sensitizer and methylviologen as quencher. However, the quantum efficiency for production of $\mathrm{H}_{2}$ is only about $0.1 \%$, 2 and production of $\mathrm{H}_{2}$ stops after a few hours irradiation. Buildup of $\mathrm{O}_{2}$ in the system leads to reoxidation of the reduced form of methylviologen, thereby lowering the yield of $\mathrm{H}_{2}$. At sufficiently high concentrations of $\mathrm{O}_{2}$, dihydrogen is no longer produced.

The major reason for the low quantum efficiencies observed in such systems seems to be the very rapid non-productive back reaction between the charge pairs produced in reaction $(4-2)$.

\section{Sacrificial Reagents}

Significantly higher yields of $\mathrm{H}_{2}$ can be obtained by introducing a sacrificlal reagent, however, such systems are no longer cyclic. The sacrificial reagent may inhibit charge recombination by scavenging either $\mathrm{S}^{+}$or $\mathrm{Q}^{-}$via an Irreversible redox reaction in which the sacrificial reagent is consumed.

11 Methylviologen is $N, N^{\prime}-d i m e$ thy $1-4-4^{\prime}-$ bipyridium dication.

12 The quantum efficlency is based on molecules decomposed per photon absorbed. The conversion efficiency for a solar-powered device would be less than half of the quantum efficiency because fewer than half of the solar photons are absorbed by the sensitizer. 
The unscavenged ion is then able to produce $\mathrm{H}_{2}$ or $\mathrm{O}_{2}$ by either reaction (4-4) or (4-3). Some sacrificial reagents act by quenching $S^{*}$ to form efther $S^{+}$or $\mathrm{S}^{-}$and a co-product that undergoes a rapid irreversible process allowing elther $\mathrm{S}^{+}$to oxidize water or $\mathrm{S}^{-}$to reduce $1 \mathrm{t} . \mathrm{H}_{2}$ or $\mathrm{O}_{2}$, but not both, may be produced when a sacrificial reagent is employed.

Mild reducing agents such as ethylenediaminetetraacetic acid (EDTA) and triethanolamine (TEOA) are effective sacrifical reagents if dihydrogen is the desired product. For example, the guantum efficiency for production of $\mathrm{H}_{2}$ from aqueous systems containing Ru(bpy) $3_{3}^{2+}$ as sensitizer and $\mathrm{MV}^{2+}$ as quencher, increases from about $0.1 \%$ to about $13 \%$ in the presence of EDTA (Reference 19). A st1ll higher quantum efficlency, $30 \%$, has been reported for a system in which a zinc porphyrin is sensitizer, $\mathrm{MN}^{2+}$ is quencher, and EDTA is the sacrificial reagent (Reference 26 ).

Systems requiring a sacrificial reagent might be practical for commercial sale production of $\mathrm{H}_{2}$ if an inexpensive reagent were available. 13 At the present stage of development, studies with sacrificial reagents are used primarily to obtain kinetic data and to evaluate various components of the photoredox process. For example, this technique has been very useful in assessing potential catalysts for the $\mathrm{H}_{2}$ and $\mathrm{O}_{2}$ producing steps.

\section{Organized Assemblies}

Another strategy for inhibiting non-productive charge recombination in photochemical processes involves the use of organized assemblies of molecules such as micelles and vesicles. This approach will not be discussed here, however, the use of organized assemblies is treated in a companion report, "Review of Solar Fuel-Producing Quantum Conversion Processes." The use of organized assemblies is at a relatively early stage of development, and only modest improvements in efficlency have been achieved as of this time.

\section{PHOTOELECTROCHEMICAL WATER SPLITTING}

The basic principles underlying photoelectrochemistry have been presented in a number of review articles (Reference 38 through 43 ). Characteristically, the fuel-producing reactions in photoelectrochemical devices occur at the surfaces of electrodes, one or both of which is an 1lluminated semiconductor. Illumination of the semiconductor excites electron from the valence to the conduction band. The electron-hole pairs generated tend to separate in the electric field that arises spontaneously at the semiconductor-elect rolyte interface. Holes and electrons migrate to the electrode surfaces where they drive redox reactions to produce the desired products.

${ }^{13}$ Lehn has suggested the possibility of obtaining such reagents from organic wastes or biomass (Reference 36), and Sakata and Kawa1 (Reference 37) report that urine and cockroaches can be used as sacrificlal electron donors in related semiconduct or systems. 


\section{Voltage-Assisted Photoelectrolysis}

Although the origins of photoelectrochemistry can be traced back to the work of Becquerel in 1839, interest in the possibility of splitting water photoelectrochemtcally is a relatively recent development. In 1972, Honda and Fufishima (Reference 44) reported that water could be decomposed to $\mathrm{H}_{2}$ and $\mathrm{O}_{2}$ at voltages well below the theoretical decomposition potential in a cell with a $n-\mathrm{THO}_{2}$ photoanode and a platinum cathode. A schematic diagram of such a cell is shown in Figure 2-4.

Since then, a number of semlconductors have been used in voltage-assisted photoelectrolysis (References 45 through 47) but, in general, conversion efficiencies ${ }^{14}$ with solar radiation have been relatively low, a few percent or less. Heller and Vadulnsky (Reference 47) have reported a conversion eff1ciency of $12 \%$ for photoelectrolys is of aqueous $1 \mathrm{M} \mathrm{HCl}-2 \mathrm{M} \mathrm{KCl}$ to produce $\mathrm{H}_{2}$ and $\mathrm{Cl}_{2}$. The cell employed a platinized $\mathrm{p}$-In photocathode and a platinum anode. This efficiency is based upon the electric power saved by the use of the photocathode relative to what would have been required with a platinum cathode. It is not calculated on the basis of the relationship given in footnote 14. Th1s is the highest efficiency that has been reported for any fuel-producing solar quantum converter.

\section{Unbiased Cells with a Single Photoelectrode}

In these devices, one electrode is an flluminated semiconductor and the counter electrode is an inert conductor, such as platinum or carbon (see Figure 2-3). Light absorbed at the photoelectrode is the only energy input. Sustained photoelectrolysis of water without application of an external voltage was first achfeved using a UV-1lluminated, n-SrTiO 3 photoanode, and a platinum cathode (References 48 through 50). However, the band-gap energy in this case is so large $(3.2 \mathrm{eV})$ that the efficiency would be unacceptably low with solar radiation.

Spectral response can be improved by sensitization of the semiconductor electrode with dyes or molecular substrates attached to the surface. A number of semiconductor-sensitizer combinations have been investigated, but efficiencies remain low (References 38 and 51 through 56). Thin layers of sensitizer are required in order to have efficient charge transfer between $S^{*}$ and the semiconductor, however, thin layers result in incomplete absorption and low effictency.

A rather simflar approach is to surface-dope large band-gap semiconductors with transition metal ions (References 57 through 61). Although response is extended into the visible, efficiencies are still only about $1 \%$. More work 1 s needed to refine techniques for extending spectral response.

\footnotetext{
${ }^{14}$ Effictency $=(100)$ [(Chemical energy of $\mathrm{H}_{2}$ produced) - (electrical energy supplied)/1ncident solar energy].
} 


\section{Unblased Cells with Two Photoelectrodes}

In this case, two photons are absorbed (one at each photoelectrode) to generate one net electron-hole pair for the fuel-producing reaction. Such devices may be able to use lower band-gap semiconductors that better ut1lize the solar spect rum. An especially interesting configuration is that in which a p-type semiconductor is joined via an ohmic contact to an n-type semiconductor so that no external wires are required (Figure 4-1). Celis of this type have been referred to as photochemical diodes (Reference 38 ).

A variety of such cells have been investigated but, thus far, efficiencles have been less than $1 \%$ (References 62 through 65 ).

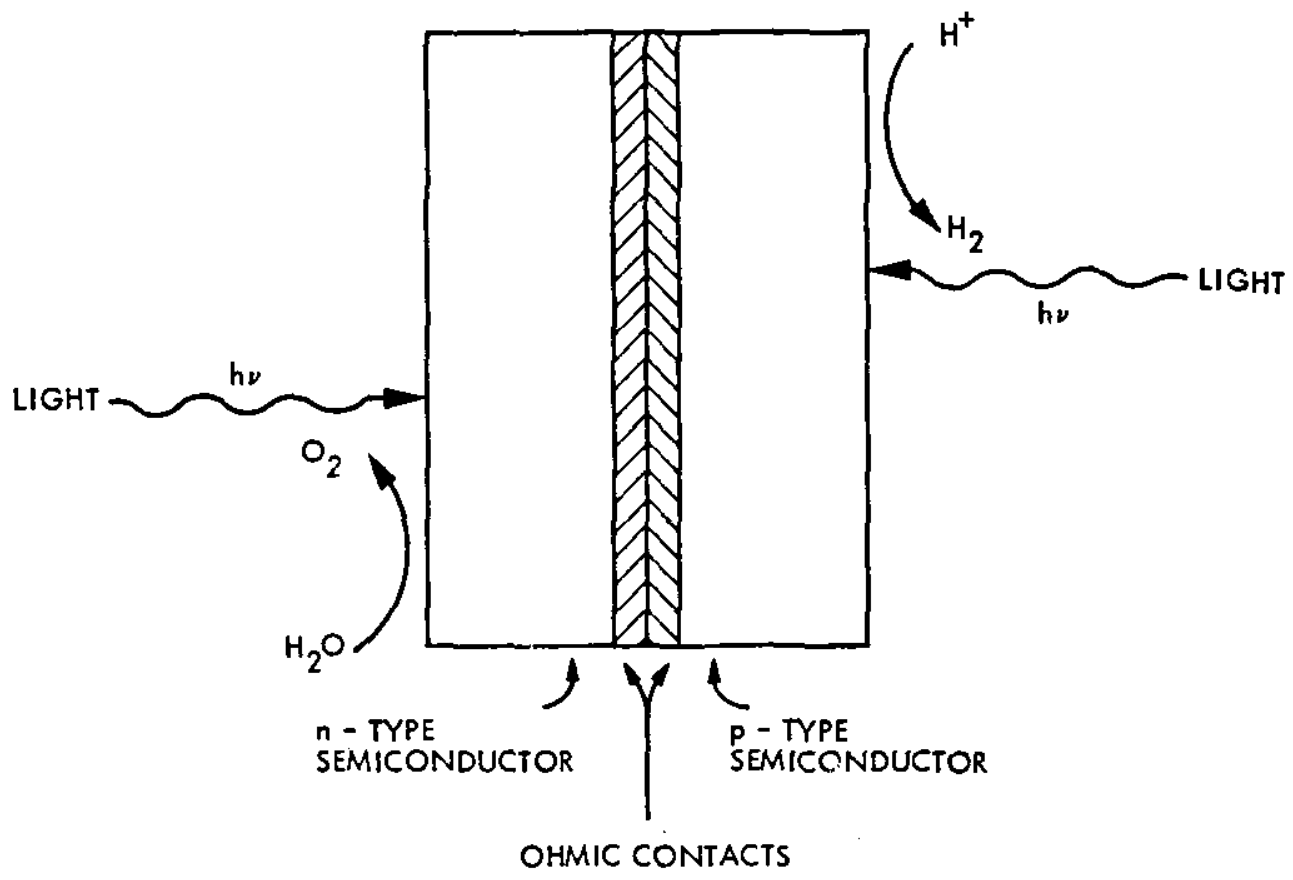

Figure 4-1. Photochemical Diode

\section{Colloidal Semiconductor Systems}

Grätzel and his colleagues have developed systems in which collolial $n-\mathrm{THO}_{2}$ particles loaded with ultrafine deposits of $\mathrm{RuO}_{2}$ and platimum act as wireless cells with an $n-\mathrm{T}_{10} \mathrm{O}_{2}$ photoanode short-circuited to a platinum cathode (References 66 through 69). Figure 2-4 is a schemattc representation of such a particle system. 
Water can be split with relatively high quantum efficiency by direct excitation of the semiconductor. However, the efficiency is extremely low with solar radiation because of the large band-gap energy of $\mathrm{TiO}_{2}$. Grätzel and his co-workers are attempting to extend the spectral response into the visible by surface-doping the colloidal Ti02 particles with transition metals. Sustained water cleavage with visible light has been observed with aqueous suspensions of $\mathrm{T}_{2} \mathrm{O}_{2}$ particles doped with $\mathrm{Cr}^{3+}$ (Reference 58). The observed quantum efficiency for production of $\mathrm{H}_{2}$ is approximately $1 \%$ with visible light.

Particle systems are attractive because their relative simplicity could result in lower construction and malntenance costs. However, unlike cells with well separated electrodes, particle systems produce a mixture of gases which must be separated.

\section{Problem Areas}

There are two major problems associated with solar-driven photoelectrochemical processes. One is that the relatively large band gap required for fuel production results in poor use of the solar spectrum (see Table 4-1). Theoretically, water splitting should require $1.23 \mathrm{eV}$ per electron transferred (1.e., $2.46 \mathrm{eV}$ per molecule of $\mathrm{H}_{2}$ ). However, because of the over-voltages associated with evolution of $\mathrm{H}_{2}$ and $\mathrm{O}_{2}$ and the unavoidable losses associated with entropy production, about $2.2 \mathrm{eV}$ is probably required in practice (References 40,43 and 57). Moreover, the band edges of the semiconductor must be properly situated with respect to the electrical potentials for oxidation and reduction of water. At tempts to increase the spectral response of large band-gap semiconductors by bonding a photosensitizing substrate to the surface of the photoelectrode or surface-doping with transition metal ions have not been very successful thus far.

The other major problem area is photoelectrochemical corrosion of the semiconductor electrode. Photogenerated holes and electrons may undergo redox reactions with the semiconductor itself leading to its irreversible dissolution or surface corrosion (References 70 and 71). Several techniques for inhibiting corrosion have been 1nvestigated. Although these methods have led to some improvements in stability, photoelectrochemical corrosion continues to be a major problem (Reference 43). 
Table 4-1. Fractions of Solar Energy as a Function of the Band-Gap Energy of the Semiconductor Electrode

\begin{tabular}{ccc}
$\begin{array}{c}\text { Band-Gap Energy, } E_{g} \\
\text { eV }\end{array}$ & $\lambda, \mathrm{nm}$ & Solar Energy, \% \\
1.4 & 882 & 39.4 \\
1.6 & 772 & 31.9 \\
2.0 & 686 & 24.4 \\
2.2 & 617 & 18.2 \\
2.4 & 561 & 13.6 \\
2.6 & 514 & 9.8 \\
2.8 & 475 & 6.5 \\
3.0 & 441 & 4.1 \\
3.2 & 412 & 2.4 \\
\hline
\end{tabular}

\section{CONCLUSIONS}

Thus far, research related to development of fue1-producing solar quantum converters has focused almost exclusively upon processes that split water to produce dihydrogen. Cyclic homogeneous photochemical processes have very low quantum officiencies $(<0.1 \%)$. The major reason for low efficiency is the rapid non-productive recombination of charge pairs that are intermediates in the photoredox cycle. Yields of $\mathrm{H}_{2}$ from homogeneous systems can be significantly increased by addition of sacrificial reagents which supress charge recombination. The highest quantum efficiency reported for systems using sacrificial reagents is about $30 \%$, which corresponds to a solar conversion efficiency of about $12 \%$. Because such systems are no longer cyclic, they will require an inexpensive sacrifictal reagent if they are to be practical for large-scale production of fuels.

Currently, the conversion efficiencies observed for solar photoelectrochemical water splitting are higher than those for cyclic homogenous photochemical processes; however, they are still low. The highest conversion efficiency yet reported for any fue1-producing solar quantum converter is $12 \%$. Th1s yield was observed in the voltage-assisted photoelectrolysis of IMKCI-2MHC1 to produce $\mathrm{H}_{2}$ and $\mathrm{Cl}_{2}$. 



\author{
SECT ION $V$ \\ SYSTEMS AND OPERATING OPTIONS
}

\title{
A. INTRODUCTION
}

The basic solar photochemical and photoelectrochemical processes for producing fuels and chemicals are described in Section II, and their current research and development status is reviewed in Section IV. In this chapter, systems and operating options are considered.

The posslbility of operating at elevated temperatures is one such option. The others are hybrid and coupled systems.

As the term is used here, a hybrid system is a solar thermochemicalphotochemfcal hybrid that produces a fuel in a cyclic process in which an appropriate feedstock (e.g., water) and solar energy are the only net inputs. other substances are required, but they are regenerated in the cycle. Such hybrids are essentially thermochemical cycles in which at least one step is photochemical. The various steps in such cycles are generally carried out at different temperatures.

Coupled systems, on the other hand, combine a photochemical process (quantum converter) with a thermal converter operating at a common temperature. The specific processes associated with the two converters is specified only to the extent that one (the quantum converter) is a threshold device, 15 the other (the thermal converter) is not. The final systems concept considered is one in which the photochemical process is operated at or near ambient temperature, and the thermal converter is operated at high temperatures.

\section{B. PHOTOCHEMISTRY AT ELEVATED TEMPERATURES}

If solar photons are used to drive photochemical processes, operating temperatures will be significantly above ambient unless some type of cooling strategy is employed. This will be especially important if concentrated sunlight 1 s used. Thus, it would be of interest to determine whether there are photochemical processes for producing fuels or chemicals that would benefit from operation at elevated temperatures. Elevated temperatures, in this case, means about 350 to $370 \mathrm{~K}$ for non-concentrating system and perhaps 500 to $600 \mathrm{~K}$ (or higher) in concentrating systems. 16

${ }^{15}$ Threshold devices require photons with energies equal to or in excess of a threshold or band-gap energy, $E_{g}$.

${ }^{16}$ In both concentrating and non-concentrating systems, the temperature of the photosystem will depend upon a number of variables. 
Photochemical excitation 1s highly specific. Absorber molecules, of ten at low concentration, are selectively excited resulting either in their dissociation or their conversion to an electronically excited state. If the latter is sufficlently long-lived, it may react with suitable substrates to produce chemfcal changes. When a system is heated, excitation is essentially nonspecific. There is an increase in the average energies of all molecules present in the system and no electronic excitation occurs. Because of the significant difference in the specificity of the excitation, and the fact that electronically excited molecules may react quite differently than ground-state molecules, the reaction products may differ when the same system is excited photochemically rather than thermally. Because increased temperature will reduce the specificity, there is usually no incentive to operate photochemical systems at elevated temperatures.

There are other factors that may mitigate against using high temperatures. For example, absorbers well matched to the solar spectrum are usually rather complex molecules that may be expected to undergo increased degradation when the temperature is increased. In most fuel-producing photochemical systems, the absorber functions as a photosensitizer which must survive repeated cycling if the process is to be cost effective.

Another factor that must be considered is the decrease in the limiting thermodynamic efficiency of all quantum converters with increasing temperature. The 1imiting efficiency decreases approximately two percentage points per $50 \mathrm{~K}$ increase in temperature (see Section II-D). If, however, a photochemical system is operating at efficiencies below the limiting thermodynamic value, increasing temperatures may lead to an increase in efficiency because of favorable kinetic consequences.

Thus, Gratzel, et al (Reference 68), reported a 50-fold increase in the yield of $\mathrm{H}_{2}$ from photochemical cleavage of water when the temperature is Increased from 298 to $348 \mathrm{~K}$. This system is relatively complex and the increased yields of $\mathrm{H}_{2}$ are rationalized in terms of favorable effects of increased temperature upon a number of kinetic factors. Richoux (Reference 72), in a much simpler system, has shown that increasing temperatures increase the efficiency of photo-induced charge separation in aqueous solutions in which a zinc porphyrin is sensitizer and methyl viologen is quencher. This is espectally interesting because nonproductive charge recombination reactions contribute significantly to the low efficiencies of homogeneous, photochemical watersplitting processes. Richoux reports that the relative quantum yield of separated fons $\left(\mathrm{S}^{+}\right.$and $\mathrm{Q}^{-}$) more than doubles when temperatures are increased from 293 to $353 \mathrm{~K}$. These results may seem to contradict the argument that the limiting thermodynamic efficiency of quantum converters decreases with an increase in temperature. However, in both cases, the photochemical system is operating far below the limiting thermodynamic efficiency.

Because real systems will almost certainly operate below the limiting efficlency, there may be kinetic advantages to operating water-splitting systems at temperatures of the order of $350 \mathrm{~K}$. Sensitizers are likely to be sufficiently stable in this temperature range and cooling requirements can be reduced with some saving in system costs. 
A search of the scientific literature was conducted to determine the extent of photochemical work at elevated temperatures to identify photochemical processes that might benefit from operation at elevated temperature. A computerbased search of chemical abstracts for the period 1967-1982 was conducted using the Dialog Information Retrieval Service. The computer was instructed to retrieve abstracts which contained a combination of either the words "high temperature" or "elevated temperature" with "photochemistry" or "photolysis." None of the abstracts retrieved contained information that would suggest a possible photochemical process for producing fuels or 1mportant chemical products at elevated temperatures. However, it should be emphasized that this was only a cursory search of the literature.

In concluding this discussion of photochemistry at elevated temperatures, it should be noted that Haught (Reference 9) has shown that it will generally be more efficient to use solar thermal converters at temperatures in excess of about $500 \mathrm{~K}$. At these temperatures, thermal systems have higher limiting efficiencies than quantum converters, and this superiority increases with further increases in temperature.

\section{THERMOCHEMICAL-PHOTOCHEMICAL HYBRIDS}

Pure solar thermochemical processes for water splitting recelve the necessary driving energy as heat. Such processes are expected to have greater efficiencies because they use the solar spectrum more efficiently and are not subject to sone of the losses inherent in quantum conversion (e.g., Internal conversion).

In principle, the simplest example of a pure thermochemical process would be direct thermolysis of water into dihydrogen and dioxygen. However, temperatures of $2500 \mathrm{~K}$, or higher, are required to achieve significant decomposition and, hence, materials and separation problems are severe. As a result, direct thermochemical splitting of water has received relatively little attention. Funk and Reinstron (Keference 73) were the first to suggest that thermochemical decomposttion of water could be carried out indirectly at significantly lower temperatures by a series of chemical reactions that: constitute a closed cycle with respect to all species except water and its decomposition products, dihydrogen and dioxygen. Hundreds of cycles have been proposed, but fewer than a dozen have been studied in sufficient detall to confirm that they are workable on a laboratory scale. Preliminary analyses indicate that some of the cycles have efficiencies as high as 40 to $45 \%$ (Reference 74 ).

In some cases, at least one step is driven primarily by the input of electrical work. These so-called thermochemical-electrochemical hybrids are designed to eliminate a difficult processing step(s) or to close a cycle that includes a step that is thermally unworkable. Examples are the Westinghouse (References 74 and 75 ) and EURATOM-Mark 11 sulfuric acid cycles (References 74 and 76).

By analogy, it might be suggested that hybrid cycles could be devised which incorporate a photochemical step. However, no such hybrid has been reported in the literature probably because of the low efficiency of solar photochemical processes. As shown in Section II-D, such processes have a 
limiting efficiency of about $30 \%$ and for real systems, the efficiency is not 1ikely to exceed 15\%. Thus, inclusion of a photochemical step would considerably reduce overall cycle efficiency.

Also, it would be difficult to use proposed strategies for optimizing the plant capacity factor of solar thermochemical cycles if such hybrids were developed. Capacity factor will be an important consideration because thermochemical plants will be highly capital intensive. When a solar heat source is used, the high temperature step(s) of the cycle will have a low capacity factor, assuming high temperature-heat storage is not available. This can be mitigated to some degree by sizing these units so that the lower temperature steps in a cycle can be operated continuously. In general, the units operated continuously can be built at about one-fifth the maximum capacity of the high-temperature part of the plant. If, however, one of the low temperature steps is photochemical, the effectiveness of this sizing strategy would be significantiy compromised.

On the basis of these arguments, thermochemical-photochemical cycles do not seem to be an attractive option.

\section{COUPLED SYSTEMS}

Haught has examined the efficiency of a system consisting of a quantum converter coupled to a thermal converter (Reference 9). A schematic diagram of such a device is shown in Figure 5-1. Note that both converters operate at a common temperature, $T_{0}$. Figure 5-2 shows the efficiency of such a system as a function of temperature. The efficiency of the quantum converter decreases with increasing temperature while that of the thermal converter increases. It is clear from Figure 5-2 that there is 1ittle incentive to couple the two converters in this fashion unless the quantum converter is significantly cheaper than the thermal device. In that case, a coupled system might be useful up to about $600 \mathrm{~K}$.

As an alternative, the quantum converter could be operated at near ambient temperatures and the thermal converter at high temperatures. The shorter wavelengths of the solar spectrum would be used to drive a photochemical process in the quantum converter and the long wavelengths would be collected by the thermal converter. In this case, the quantum converter would produce chemically stored energy and the thermal converter would probably produce electricity. For example, the heliostats of a central recelver solar-thermal power plant might be made with a mirror coating that is highly reflective in the infrared, but highly transparent in the visible and near-ultraviolet. The quantum converter would be located beneath the mirrored surface.

This type of coupling could be an attractive strategy for using quantum conversion devices that produce chemically stored energy. The tracking heliostats would increase the average intensity for the quantum converter and the reflection of infrared radiation to the central receiver would permit the quantum converter to operate more efficiently because of the lower operating temperature. The increased cost of the more complex heliostats would have to be justified by the value of the fuel produced by the quantum converter. 


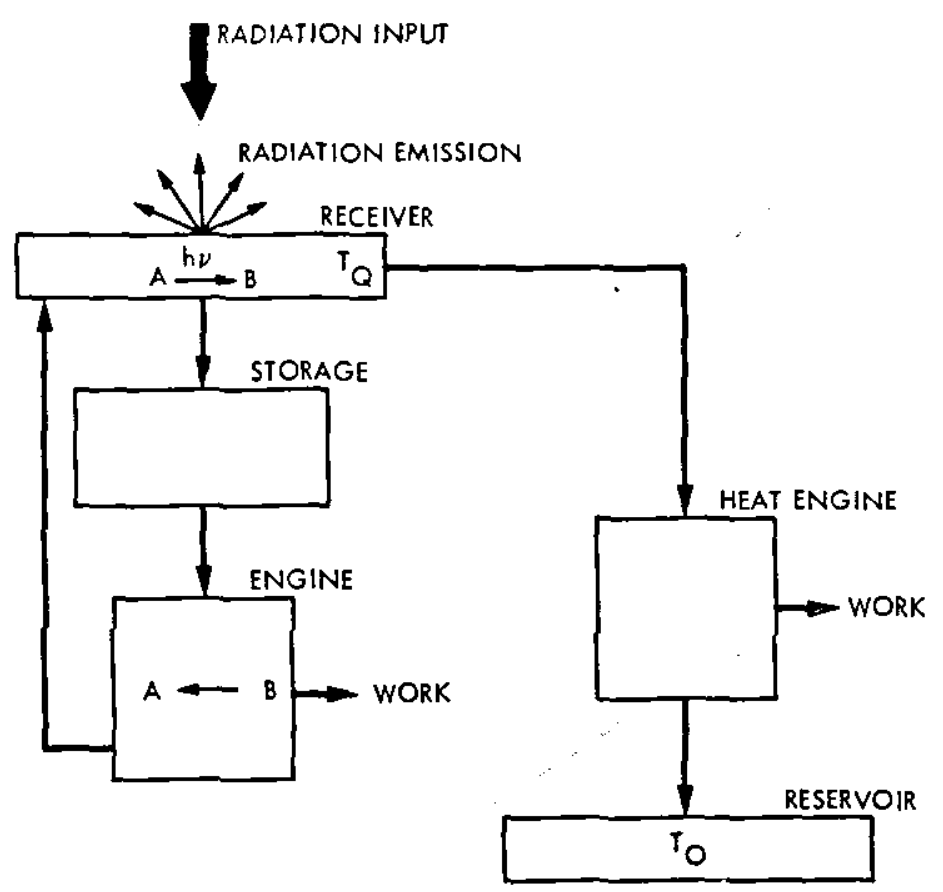

Figure 5-1. Coupled Duantum/Thermal Converter

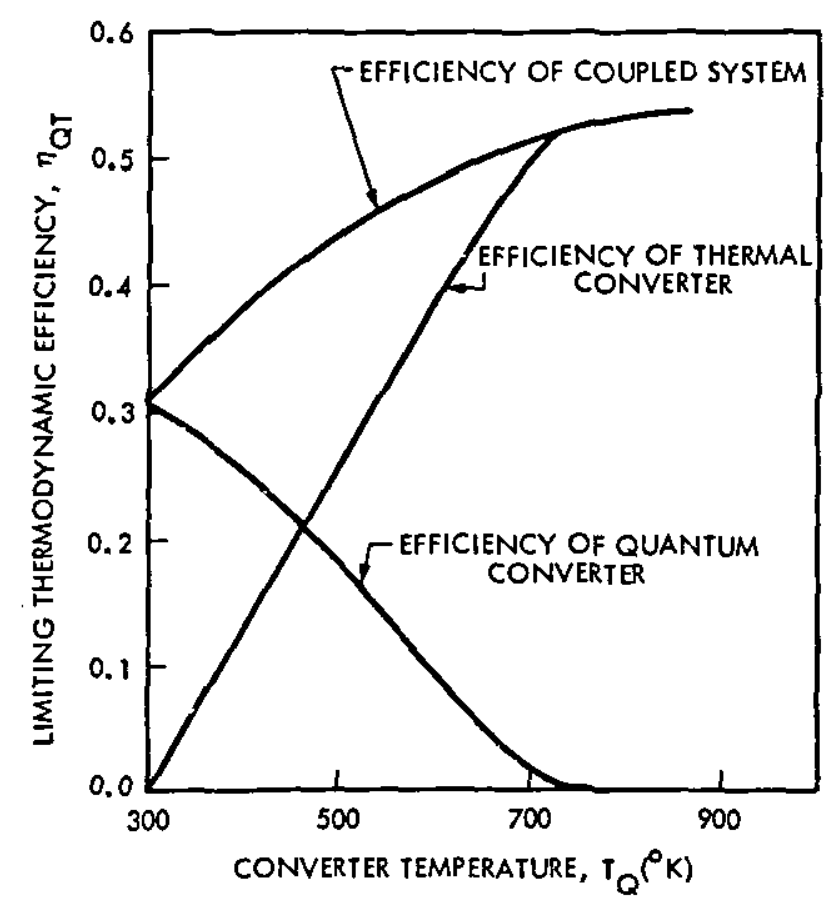

Figure 5-2. Conversion Efficiency Versus Temperature for a Single Collector Coupled Ouantum/Thermal System 
As an example, an infrared reflective coating, produced by Liberty Mirror, has the optical properties shown in Figure 5-3. This glass was considered as a possible construction material for a photochemical reactor that could be used with concentrated sunlight (Section III-C). In that case, the idea was to reduce the heating of the reactor by reflecting most of the infrared radiation. Incomplete transission in the vistble and ultravlolet, however, leads to a reduction in overall efficiency of $38 \%$ if the absorber is assumed to be ideal.

Nonetheless, mirrored surface may be developed which will have acceptable optical properties. If so, this might prove to be a desirable option for using quantum conversion devices. Johnson has recently carried out a thermodynamic analysis of systems of this general type, which he refers to as thermally decoupled systems (Reference 77 ). He finds a significant advantage for the thermally decoupled systems vis-à-vis those in which the thermal and quantum converter both operate at the same temperature.

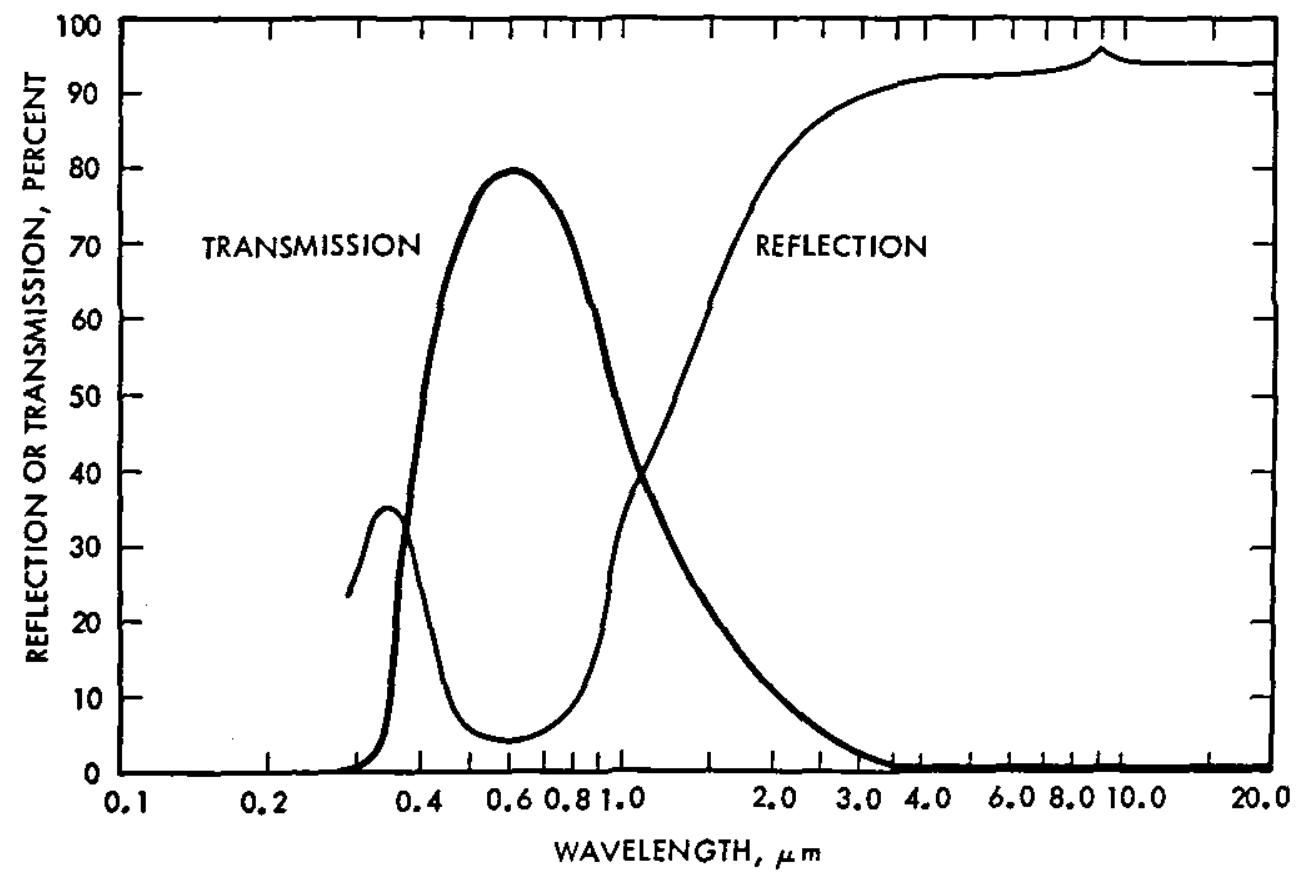

F1gure 5-3. IR-81-E Conductive Infrared Reflection Coating 
(1) The overall system efficiency is the single most important factor in determining the cost of fuel produced by a photochemical process. The overall system efficiency is dominated by the relatively low efficiency of the photochemical process.

(2) For the baseline flat-plate and concentrating systems with overa11 efficiencies of $10.3 \%$ and $12.6 \%$, respectively, energy costs can be reduced by more than a factor of two by a doubling of the photochemical efficiency. This would reduce energy costs for the flat-plate system to a range of from $\$ 19$ to $\$ 29 / 10^{6} \mathrm{~kJ}$ ( $\$ 20$ to $\$ 30 / 10^{6} \mathrm{Btu}$ ).

(3) Fuel-producing solar quantum converters employing a single photosystem are unlikely to have efficiencies greater than about $15 \%$. If multiple photosystems are used, higher efficiencies should be possible. For example, the limiting thermodynamic efficiency for a device with two photosystems could be as much as $50 \%$ greater than one with a single photosysten.

(4) In both the non-concentrating and concentrating baseline systems, the major cost component is the collector/reactor subsystem (from 37 to $64 \%$ of total energy costs). Also, BOP costs substantially increase energy costs (28\% to $44 \%$ of total energy costs) and should always be properly accounted for.

(5) The energy costs for both baseline systems studied are somewhat optimistic because of the simplicity of baseline design considerations. For example, product gas separation is not considered and any unique material problems are 1gnored. Although there is an awareness of these potential problem areas, research has not sufficlently advanced to allow specific design considerations to be developed.

(6) The energy costs derived from this study are not strongly dependent on the photochemical process because reactor detail was not included. Therefore, for the first-order analysis of this study, these energy costs may be interpreted to be for a generic single-photon photochemical process.

(7) For the baseline concentrating system reactor, cooling was required to keep the reaction temperature low enough to yield higher photochemical efficiencles. However, the performance and cost penalties for this were relatively small (about a $2 \%$ penalty in overall efficiency and $8 \%$ of the energy cost). 
(8) A number of factors have been identified that mitigate against operating solar photochenical systems at elevated temperatures. The most general, and probably the most important factor, is the decrease in limfting thermodynamic efficiency, $\eta_{Q T}$, with increased temperature. For systems operating below $\eta_{\mathrm{QT}}$, favorable kinetic consequences resulting from increased temperature may, in some cases, outweigh thermodynamic considerations.

(9) It is unlikely that solar thermochemical-photochemical hybrid cycles will be viable options for production of fuels or chemicals. The low efficiency of a photochenical step would result in a considerable reduction in overall cycle efficlency.

(10) The incorporating of solar fuel-producing quantum converters beneath the mirrored surface of hellostats of a central-recelver power station may prove attractive if a suitable mirror surface can be developed. Photons corresponding to $\lambda>\lambda_{\mathrm{g}}$ would be reflected to the central receiver; those with $\lambda \leq \lambda_{g}$ would be transmitted to the quantum converter. 
(1) Engineering studies should be made with emphasis on reducing energy costs by using low-cost materials and construction methods integrated into large-size collectors/reactors. One such concept would be a large, shallow solar pond.

(2) Research should focus on fuel-producing solar quantum conversion processes that promise high efficiencies. Greater emphasis should be given to processes that employ multiple photosystems.

(3) An engineering feasibility study should be made of incorporating fuel-producing quantum converters within IR-reflecting heliostats at central receiver power plants. 

SECTION VIII

REFERENCES

1. Shockley, W., and Queisser, H.J., "Detailed Balance Limit of Efficiency of $\mathrm{p}-\mathrm{n}$ Solar Cells," J.App1. Phys., Vo1. 32, p. 510, 1961.

2. Ross, R.T., "Thermodynamic Limitations on Conversion of Radiant Energy into Work," J. Chem. Phys., Vol. 45, pp. 1-7, 1966.

3. Ross, R.T., and Calvin, M., "Thermodynamics of Light Emission and Free Energy Storage in Photosynthesis," Biophys. J., Vol. 7, pp. 595-614, 1967.

4. Ross, R.T., and Hsiao, T.L., "Limits on the Yield of Photochemical Solar Energy Conversion," J.Appl. Phys., Vol. 48, pp. 4783-4785, 1977.

5. Almgren, M., "Thermodynamic and Kinetic Limitations on the Conversion of Solar Energy into Storable Chemical Free Energy," Photochem. Photobiol., vol. 27, pp. 603-9, 1978 .

6. Bolton, J.R., "Solar Fuels," Science, Vo1. 202, pp. 705-11, 1978.

7. Bolton, J.R., and Hal1, D.0., "Photochemical Conversion and Storage of Solar Energy," Ann. Rev. Energy, Vol. 4, pp. 353-401, 1979.

8. Ross, R.T., and Collins, J.M., "Efficiency of Quantum-Utilizing Solar Energy Converters in the Presence of Recombination Losses," J. Appl. Phys., Vol. 51, pp. 4504-7, 1980.

9. Haught, A.F., Physics Considerations of Solar Energy Conversion, United Technologies Report, UTRC 80-9, 1980.

10. Bolton, J.R., Haught, A.F., and Ross, R.T., "Phocochemical Energy Storage: An Analysis of limits," Photochemical Conversion and Storage of Solar Energy, Academic Press, 1981 .

11. Bilchak, R.V., Connolly, J.S., and Bolton, J.R., Effects of Temperature and Intensity on Thermodynamic limits for Efficiencies of Photochemical Conversion of Solar Energy, SERI/TP-623-643, June 1980 .

12. Biddle, J., Revere, W., and Fujita, T., "Low-Cost Thermal Transport Piping Networks for Solar Industrial Process Heat Applications," JPL paper presented at the 5 th Annual Solar IPH Conference in Houston, Texas, December $16-19,1980$.

13. A Standard Description and Costing Methodology for the Balance-of-plant Items of a Solar Therma 1 Electric Power Plant, Report of a MultiInstitutional Working Group, DOE/JPL-1060-59, JPL Publication 83-4, January 1983. 
14. Creutz, C., and Sutin, N., "Reaction of Tris (Bipyridine) Ruthenium (III) with Hydroxide and its Application in a Solar Energy Storage System," Proc. Nat. Acad. Sci. USA, Vol. 72, pp. 2858-2862, 1975.

15. Kalyanasundaram, K., and Grätzel, M., "Cyclic Cleavage of Water into $\mathrm{H}_{2}$ and $\mathrm{O}_{2}$ by Visible Light with Coupled Redox Catalysts," Angew., Vo1. 18, pp. 701-702, 1979 .

16. Brown, G.M., Chan, S.F., Creutz, C., Schwarz, H.A., and Sutin, N., "Mechanism of Formation of Dihydrogen from the Photoinduced Reactions of Ru(bpy) ${ }_{3}^{2+}$ with Rh(bpy) $3_{3}^{3+}, "$ JACS, Vol. 101, pp. 7638-7640, 1979.

17. Chan, S.F., Chou, M., Creutz, C., Matsabara, T., and Sutin, N., "Mechanism of Formation of Dihydrogen from the Photoinduced Reactions of $\mathrm{Ru}(\mathrm{bpy}) 3^{2+}$ and $\mathrm{RH}(\mathrm{bpy}) 3_{3}^{3+}$ Complexes," JACS, Vol. 103, pp. 369-379, 1981 .

18. Sutin, N., and Creutz, C., "Light-Induced Electron Transfer Reactions of Metal Complexes," Pure and Appl. Chem., Vol. 52, pp. 2717-38, 1980.

19. Kiwi, J., and Grätzel, M., "Protection, Size Factors, and Reaction Dynamics of Colloidal Redox Catalysts Mediating Light-Induced Hydrogen Evolution from Water," JACS, Vol. 101, pp. 7214-7217, 1979.

20. Lehn, J.M., and Sauvage, J.P., "Chemical Storage of Light Energy. Catalytic Generation of Hydrogen by Visible Light of Sunlight. Irradiation of Neutral Aqueous Solutions." Nouv. J. Chim., Vol. 1, pp. 449-451, 1977.

21. Delaivre, P.J., Sullivan, B.P., Meyer, T.J., and Whitten, D.G., "Applications of Light-Induced Electron Transfer Reactions," J. Chem Soc., Vol. 101, pp. 4007-4008, 1979.

22. Balzani, V., Bolletta, F., Gandolfi, M.T., and Maestri, M., "Bimolecular Electron Transfer Reactions of the Excited States of Transition Metal Complexes," Topics Curr. Chem. Vol. 75, pp. 1-64, 1978.

23. Sutin, N,, "Light-Induced Electron Transfer Reactions," J. Photochem., Vo1. 10, pp. 19-40, 1979.

24. Okura, I., and Kim-Thuan, N., "Hydrogen Generation by Visible Light with Ruthenium Carbonyl Tetraphenylporphyrin in Aqueous Micellar Solutions," J. Chem. Soc., Chem. Comm., pp. 84-85, 1980.

25. Kalyanasundaram, K., and Grätze1, M., "Light-Induced Redox Reactions of Water-Soluble Porphyrins," Helv. Chim. Acta, Vo1. 63, pp. 478-485, 1980.

26. Harriman, A., Porter, G., and Fichoux, M.C., "Photosensitized Reduction of Water to Hydrogen Using Water-Soluble Zinc Porphyrins," J. Chem. Soc., Faraday Trans. II, Vol. 77, pp. 833-844, 1981.

27. Harriman, A., Porter, G., and Richoux, M.C., "Colloidal Pt Catalysts for Reduction of Water to Hydrogen, Photosensitized by Reductive Quenching of Zinc Porphyrins," J. Chem. Soc., Faraday Trans., Vol. 77, pp. 1939-1948, 1981 . 
28. Richoux, M.C., "Metalloporphyrin Photosensitized Reduction of Water," Photogeneration of Hydrogen, Academic Press, New York, 1982.

29. Harriman, A., Porter, G., and Walters, P., "Attempted Photo-0xidation of Water to Oxygen Using Zinc (II) Porphyrins," J. Photochem., Vol. 19, pp. 183-87, 1982 .

30. Harriman, A., and Richoux, M., "Photoproduction of Hydrogen from Reductive Quenching of a Water-Soluble Zinc Porphyrins," J. Photochem., Vol. 15, pp. 335-39, 1981 .

31. Lever, A.B.P., Ramaswamy, B.S., and Licoccia, S., "Sensitized Photoreduction of $\mathrm{MV}^{2+}$ by Metalloporphyrins," J. Photochem., Vol. 19, PP. $173-182,1982$.

32. Kalyanasundaram, K., and Dung, D., "Role of Proflavin as a Photosensitizer for Light-Induced Hydrogen Evolution from Water," J. Phys. Chem,, Vol. 84, pp. 2551-2556, 1980.

33. Kalyanasundaram, K., and Grätzel, M., "Proflavin-Sensitized Photoproduction of $\mathrm{H}_{2}$ from Water" J. Chem. Soc., Chem. Comm., PP. 1137-1138, 1979.

34. Mann, K.R., Lewis, N.S., Miskowski, V.M., Erwin, D.K., Hamond, G.S., and Gray, H.B., "Solar Energy Storage: Production of $\mathrm{H}_{2}$ from Dinuclear Rhodium Complex in Acidic Aqueous Solution," JACS, Vol. 99, pp. 5525-5526, 1977.

35. Maverick, A.W., and Gray, H.B., "Solar Energy Storage Reactions Involving Metal Complexes," Pure and App1. Chem., Vol. S2, pp. 2339-48, 1980.

36. Lehn, J.M., "Photoinduced Generation of Hydrogen and-Oxygen," Photochemical Conversion and Storage of Solar Energy, Academic Press, New York, 1981.

37. Sakata, T., and Kawai, T., "Hydrogen Production from Biomass and Water by Photocatalytic Processes," Nouv. J. Chim., Vol. 5, pp. 279-282, 1981.

38. Nozik, A.J., "Photoelectrosynthesis at Semiconductor Electrodes," Photochemical Conversion and Storage of Solar Energy, Academic Press, New York, 1981 .

39. Bard, A.J., "Photoelectrochemistry," Science, Vol. 207, pp. 139-144, 1980.

40. Gerischer, H., "Heterogeneous Electrochemical Systems for Solar Energy Conversion," Pure \& App1. Chem., Vol. 52, PP. 2649-2667, 1980.

41. Tomkiewicz, M., and Fay, H., "Photoelectrolysis of Water with Semiconductors," Appl. Phys., Vol. 18, pp. 1-28, 1979.

42. Wrighton, M.S., "Photoelectrochemical Conversion of Optical Energy to Electricity and Fuels," Acc. Chem. Res., Vol. 12, pp. 303-310, 1979.

43. Bard, A.J., "Design of Photoelectrochemical Systems for Solar Energy Conversion," J. Phy. Chem., Vol. 86, pp. 172-177, 1982. 
44. Fujishima, A.K., and Honda, K., "Electrochemical Photolysis of Water at a Semiconductor Electrode," Nature, Vol. 238, pp. 37-40, 1972.

45. Wrighton, M.S., Ginley, D.S., Wolczanski, P.T., Ellis, A.B., Morse, A.M., and Lintz, A., "Photo-Assisted Electrolysis of Water in $\mathrm{TiO}_{2}$, "Proc. Nat1. Acad. Sci. USA, Vo1. 72, pp. 1518-1522, 1975.

46. Heller, A., "Conversion of Sunlight into Electric Power and Photoassisted Electrolysis of Water," Acc. Chem. Res., Vol. 14, pp. 154-162, 1981.

47. Heller, A., and Vadminsky, R.G., "Efficient Solar to Chemical Conversion: 12\% Photoassisted Electrolysis," Phys. Rev. Lett., Vol. 46, pp. 1153-1156, 1981 .

48. Marroides, J.G., Kafalas, J.A., and Kolesar, D.F., "Photoelectrolysis of $\mathrm{H}_{2} \mathrm{O}$ with $\mathrm{SrTiO}_{3}$ Anodes," App. Phys. Letters, Vol. 28, pp. 241-243, 1976.

49. Watanabe, T., Fujishima, A., and Honda, K., "Photoelectrochemical Reactions at $\mathrm{SrTiO}_{3}$ Electrodes," Bul1. Chem. Soc., Japan, Vo1. 49, Pp. $355-358,1976$.

50. Wrighton, M.S., Ellis, A.B., Wolczanski, P.T., Morse, D.L., Abrahamson, H.B., and Ginley, D.S. "SrTiO 3 Photoelectrodes," JACS, Vol. 98, pp. 2774-2779, 1976 .

51. Hamnett, A., Dare-Edwards, M.P., Wright, R.D., Seddon, K.R., and Goodenough, J.B., "Photosensitization of $\mathrm{TiO}_{2}$ with [Ru(bpy) $\left.{ }_{3}\right] \mathrm{Cl}_{2}$," J. Phys. Chem., Vol. 83, pp. 3280-3286, 1979 .

52. Tsubomura, H., Matsumura, M., Nomura, Y., and Amamiya, T., "Dye Sensitized Zinc Oxide: Aqueous Electrolyte: Platinum Photoce11," Nature, Vol. 261, pp. 402-403, 1976.

53. Gerischer, H., and Willig, F., "Reaction of Excited Dye Molecules at Electrodes," Topics. Curr. Chem., Vol. 61, PP. 61-84, 1976.

54. Spitler, M.T., and Calvin, M., "Electron Transfer at Sensitized $\mathrm{TiO}_{2}$ Electrodes," J. Chem. Phys., Vol. 66, pp. 4294-4305, 1977.

55. Fleischauer, P.D., and Allen, J.K., "Photochemical Hydrogen Formation by the Use of $\mathrm{TiO}_{2}$ Thin-Film Electrodes with Visible-Light Excitation," J. phys. Chem., Vol. 82, pp. 432-438, 1978.

56. Dare-Edwards, M.P., Hamnet, A., and Goodenough, J.B., "The Efficiency of Photogeneration of Hydrogen at P-Type III/V Semiconductor," J. Electroanal. Chem., Vol. 119, Pp. 109-114, 1981.

57. Bin-Daar, G., Dare-Edwards, M.P., Goodenough, J.B., and Hamnett, A., "New Anode Materials for Photoelectrolysis," J. Chem. Soc., Farad Trans. I, Vol. 79, Pp. 1199-1213, 1983.

58. Borgare11o, E., Kiwi, J., Grätzel, M., Pelizzetti, E., and Visca, M., "Visible Light-Induced Water Cleavage in Colloidal Solutions of Chromium-Doped Ti0 2 Particles," JACS, Vo1. 104, Pp. 2996-3002, 1982. 
59. Matsumura, M., Hiramota, M., and Tsubomura, H., "Photolysis of Water Under Visible Light with Doped $\mathrm{SrTiO}_{3}$ Electrodes," J. Electro. Soc., Vol. 130, pp. 326-330, 1983 .

60. Maruska, H.P., and Ghosh, A.K., "Transition-Metal Dopants for Extending the Response of Titanate Photoelectrolysis Anodes," Solar Energy Mater., Vol. 1, pp. 237-247, 1979.

61. Campet, G., Dare-Edwards, M.P., Hamnett, A., and Goodenough, J.B., "New Semiconducting Anodes for the Photoxidation of Water," Nouv. J. Chim, Vol. 4, PP. 501-507, 1980.

62. Guruswamy, V., and Bockris, J.0'M., "Hydrogen and Electricity from Water and Light," Solar Energy Mat., Vol. 1, pp. 441-449, 1979.

63. Nozik, A.J., "p-n Photoelectrolysis Cells," Appl. Phys. Lett., Vol. 29, pp. 150-153, 1979.

64. Ohashi, K., McCann, J., and Bockris, J.0'M., "Stable Photoelectrochemical Cells for Splitting Water," Nature, Vol. 266, pp. 610-611, 1977.

65. Leygraf, C., Hendewerk, M., and Somorjai, G.A., "Photodissociation of Water by $\mathrm{p}^{-}$and $\mathrm{n}$-type Polycrystalline Iron Oxides Using Visible Light ( $2.7 \mathrm{eV}), "$ Proc. Nat1. Acad. Sci.USA, Vol. 79, PP. 5739-5741, 1982.

66. Kiwi, J., Borgarello, E., Pelizzetti, E., Visca, M., and Grätzel, M., "Cyclic Water Cleavage by Visible Light: Drastic Improvement of Yields of $\mathrm{H}_{2}$ and $\mathrm{O}_{2}$ with Bifunctional Redox Catalysts," Angew. Chem. Intl. Ed., Vol. 19, pp. 646-648, 1980.

67. Grätzel, M., "Photoinduced Water Splitting," Photochemical Conversion and Storage of Solar Energy, Academic Press, New York, 1981.

68. Borgarello, E., Kiwi, J., Pelizzetti, E., Visca, M., and Grätzel, M., "Sustained Water Cleavage by Visible Light," JACS, Vol. 103, pp. 6324-6329, 1981 .

69. Borgare110, E., Kiwi, J., Pelizzetti, E., Visca, M., and Grätzel, M., "Photochemical Cleavage of Water by Photocatalysis," Nature, Vol. 289, pp. 158-160, 1981 .

70. Bard, A.J,, and Wrighten, M.S., "Thermodynamic Potential for the Anodic Dissolution of n-type Semiconductors," J. Electro. Soc., Vol. 124, Pp, 1706-1710, 1977.

71. Gerischer, H., "On the Stability of Semiconductor Electrodes Against Photodecomposition," J. Electroanal. Chem., Vol. 82, pp. 133-143, 1977.

72. Richoux, M.C., "The Temperature Dependence of the Efficiency of Photoinduced Charge Separation in Aqueous Solutions," J. Photochem, Vol. 22, pp. 1-6, 1983. 
73. Funk, J., and Reinstrum, R., "Energy Requirements in Production of Hydrogen from Water," Ind. Eng. Chem., Process and Design and Dev., vol. 5, pp. 336-342, $1 \overline{966 .}$

74. Carty, R.H., Mazumder, M.M., Schreiber, J.D., and Pangborn, J.B., Thermochemical Hydrogen Production, GRI Report GRI-80/0023, Chicago, June 1981 .

75. Farbman, G.H., "The Westinghouse Sulfur Cycle: Program Status," Int. J. Hydrogen Energy, Vol. 4, pp. 111-122, 1979.

76. Struck, B.D., et al, "Electrolytic Cell for Sulfuric Acid Hybrid Cycle," Proc. 4th WHEC, pp. 483-92, Pasadena, June 1982.

77. Johnson, D., Quantum and Thermal Conversion of Solar Energy to Useful Work, SERI/TP-252-2137, December 1983. 


